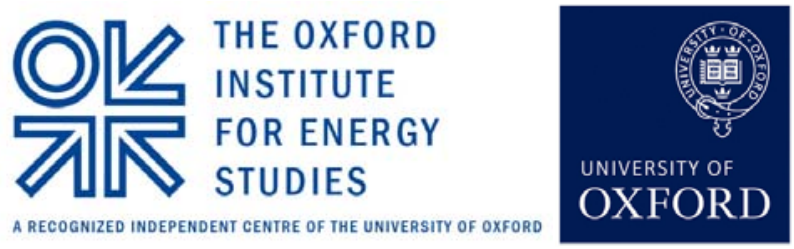

\title{
The Impact of Import Dependency and Wind Generation on UK Gas Demand and Security of Supply to 2025
}

Howard V Rogers

NG 54

August 2011 
The contents of this paper are the authors' sole responsibility. They do not necessarily represent the views of the Oxford Institute for Energy Studies or any of its members.

Copyright $(2011$

\section{Oxford Institute for Energy Studies}

(Registered Charity, No. 286084)

This publication may be reproduced in part for educational or non-profit purposes without special permission from the copyright holder, provided acknowledgment of the source is made. No use of this publication may be made for resale or for any other commercial purpose whatsoever without prior permission in writing from the Oxford Institute for Energy Studies.

ISBN

978-1-907555-31-2 


\section{Preface}

For most of the past decade the UK gas market has been the biggest in Europe, and gas has been the most important fuel in the country's energy balance. For these reasons alone, the future of UK gas supply and demand should be considered extremely important issues by a range of energy stakeholders. Most of the White Papers, roadmaps and scenarios published over the past decade, setting ever-more challenging targets for carbon reduction over the next several decades, suggest that UK gas demand will start to decline during the 2010s and fall away rapidly thereafter. Those concerned about security of gas supply, which is routinely equated with increasing exposure to regional and global markets and prices via increasing import dependence, have greeted such conclusions with approval. In this view, dependence on gas and particularly rising import dependence is seen as a major problem which will be remedied by the introduction of low carbon energy sources.

This paper is the first independent attempt, of which I am aware, to address both of these questions within a framework which takes empirical account of both regional and global gas markets, and the introduction of increasing intermittent wind generation in the UK power sector. The results of Howard Rogers' herculean empirical modelling effort challenge the assumption that, as a result of substantial increases in renewable generation capacity, the role of gas will decline rapidly over the next decade and beyond. The study suggests that the importance of gas for power generation will remain undiminished until 2025. Although its role may change, gas is likely to be particularly important in respect of ensuring security of supply in the context of increasing wind generation.

It is no part of the remit of the OIES gas research programme to promote natural gas, either in the UK or more generally. We are gas researchers not advocates or lobbyists. However, our research increasingly suggests that the likely future role of gas in energy balances has been, and continues to be, under-estimated in a range of countries including, somewhat surprisingly given its long gas history, the UK.

Jonathan Stern

Oxford, August 2011 


\section{Contents}

$\begin{array}{ll}\text { Introduction } & 1\end{array}$

Chapter 1 Historical UK Gas Supply, Demand and Flexibility 4

Chapter 2 The Changing Regional and Global Natural Gas

Environment since 2000 .

Chapter 3 Key Issues for the UK Market 15

Chapter 4 Analytical Framework and Scenario Derivation 21

4.1 Future Supply Mix and Seasonal Flexibility Requirements 21

4.2 Future UK Supply Scenario Rationale $\quad 23$

4.3 Future Global LNG Supply and European Pipeline Imports 25

4.4 Other Major Future Uncertainties $\quad 27$

4.5 Future UK Storage Capacity Levels $\quad 29$

4.6 Modelling Approach for UK and Continental Europe 29

Chapter 5 Results by Scenario for Different Storage Levels 31

5.1 UK and Continental Europe Annual Supply \& Demand -

‘LNG Rules the Waves’ Scenario. $\quad 31$

5.2 UK and Continental Europe Annual Supply \& Demand -

'Russia Fills the Gap’ Scenario.

5.3 Review of Scenario Results. $\quad 41$

5.4 Past UK Storage Policy Evolution $\quad 50$

Chapter 6 Wind Intermittency

6.1 Introduction and Context 53

6.2 Data Assembly 56

6.3 2009 Wind Generation History Match and Future

Wind Generation Modelling $\quad 61$

6.4 Future Year Generation Stack Interactions $\quad 64$

6.5 Discussion of Results 
Appendix A: Critical Assumptions made in the Analysis

Bibliography

Figures

Tables 


\section{Introduction}

Natural gas plays a key role in the UK's energy mix. As the UK's domestic gas production continues to decline and import dependence rises, and at the same time the country's energy (particularly power generation) balance moves significantly towards lower carbon energy sources, (particularly wind energy), the following questions arise:

- Where will the UK's future gas supplies come from and what will be the likely mix of pipeline gas imports and LNG?

- What impact will the future anticipated growth in UK wind generation have on gas consumption levels and dynamics in the power sector?

What are the risks which would threaten gas supply security in relation to increased imports, seasonal demand requirements and back-up for intermittent renewables? How can they be mitigated? For UK gas, the story of the past 40 years has been one of a rapid increase in consumption, reaching a plateau in the 2000s, the rise and subsequent decline of domestic production and (to date) a successful transition to net gas importer status. Since the ramp-up of LNG supplies from Qatar from October 2009 onwards, the UK has enjoyed the status of an LNG transit market for much of that period, with 'excess' supply flowing on to the European Continent via sub-sea pipeline. The rapid build-up of import infrastructure which took place in the 2000s was not however accompanied by significant additions to UK gas storage capacity, despite some significant supply security events in that decade, largely due to infrastructure technical problems. At the end of the 2000s, just as policymakers began to focus on the need to ensure an adequate level of storage provision, the advent of targets and commitments relating to $\mathrm{CO}_{2}$ reductions and renewable energy shifted the policy focus away from gas. Mitigating the UK's exposure to natural gas supply security events represents 'unfinished business'. This will become more, not less, crucial as wind generation capacity increases and the role of gas-fired generation (as the primary means by which variable wind power generation can be balanced) increases in importance.

As the UK's gas imports increase and the need for new sources of flexibility grows, the challenge is to understand how the UK market will fare in a very much more interconnected gas world than was the case in previous decades. In order to provide an analytical framework to investigate these issues, the Global Tradeflow Model, described in a previous paper ${ }^{1}$ has been extended to cover Europe at the national level on a monthly basis. Thus the UK and its interactions with the global LNG supply pool, pipeline supplies from Norway and Continental Europe can be quantified within an overarching assumption set - or scenario. This approach highlights the dilemma of whether the UK should 'trust to the market' and effectively continue to rely mainly on seasonal flows from Norway and via gas interconnections with the European Continent, or whether there should be a policy imperative to ensure a higher level of UK seasonal storage as an insurance against low probability but high impact gas supply security events.

${ }^{1}$ Described in Rogers 2010, pp. 40 - 59. 
It is sometimes stated that the UK's gas security would be considerably enhanced by the existence of long-term contracts for gas supply. However, long term contracts are no panacea. They do not necessarily ensure the adequacy of physical upstream supply, (as with LNG contracts between Indonesia and Japan in the $2000 \mathrm{~s}^{2}$ ), are often priced in relation to oil products which bear no relation to the underlying dynamics of the gas market and, increasingly in the case of LNG contracts, contain provisions for the diversion of supply to higher priced markets. As a gas market open and connected to global supply, the future dynamics of the UK market will be increasingly driven by developments in global gas market fundamentals.

This paper is written at a time of single-minded political commitment to achieve a dramatic shift in the UK's power generation base towards wind power. With other renewables (solar) limited in scope; and technologies (carbon capture and sequestration) facing post 2020 leadtimes to achieve widespread deployment and public acceptance and clear planning hurdles (nuclear); wind generation represents the only hope of achieving $2020 \mathrm{CO}_{2}$ and renewables commitments. The impact of rapidly increasing levels of wind generation on the UK power balance creates challenges due to the variability in wind speed. The analysis contained in this report provides a confirmation of the crucial role of gas in the UK power generation mix as wind capacity grows, while raising searching (and very germane) questions as to the practical, manageable limit to wind generation capacity within the current regulatory framework.

The case for ensuring a 'leave nothing to chance' approach to gas supply through adequate storage provision has failed to resonate with policymakers to date. The analysis in this paper, demonstrating the crucial role of gas in balancing variable wind generation, aims to go some way to rectify this situation.

The structure of the paper is as follows:

Chapter 1 examines the UK market in historical context.

Chapter 2 briefly describes developments in the international gas environment since 2000 .

Chapter 3 frames the key issues for the UK in terms of future supply sources, infrastructure and flexibility.

Chapter 4 describes the UK gas supply and demand analytical framework and derives two supply mix scenarios for the UK for further interrogation.

Chapter 5 examines the results of the scenarios and draws conclusions on the trade-off between additional UK seasonal storage versus increased reliance on interconnector flows. This chapter also examines the economics of building new storage facilities in the UK.

Chapter 6 develops a framework to model future wind power generation, its interaction with gas fired generation and issues related to the practical limits of wind capacity in the UK.

\footnotetext{
${ }^{2}$ Rogers 2010, pp. 31 - 32.
} 
Future levels of power sector gas consumption and the scale of power sector gas supply flexibility are also addressed.

Chapter 7 sets out the paper's key conclusions.

The Appendix sets out some of the critical assumptions used in the modelling work and the methodology for wind power generation modelling. 


\section{Chapter 1. Historical UK Gas Supply, Demand and Flexibility}

The discovery of commercially exploitable natural gas on the UK Continental Shelf in the 1960s presaged a radical shift in the country's energy mix. As Figure 1 shows, natural gas' share of primary energy has grown from zero in 1965 to some $40 \%$ in the late 2000 s. The growth in gas consumption initially displaced coal and oil in space heating and post 1990 displaced coal and oil in the power generation sector ${ }^{3}$. The increased use of gas has been a key driver in reducing the UK's $\mathrm{CO}_{2}$ emissions - also shown in Figure 1.

\section{Figure 1. UK Primary Energy Consumption by Fuel and $\mathrm{CO}_{2}$ Emissions.}

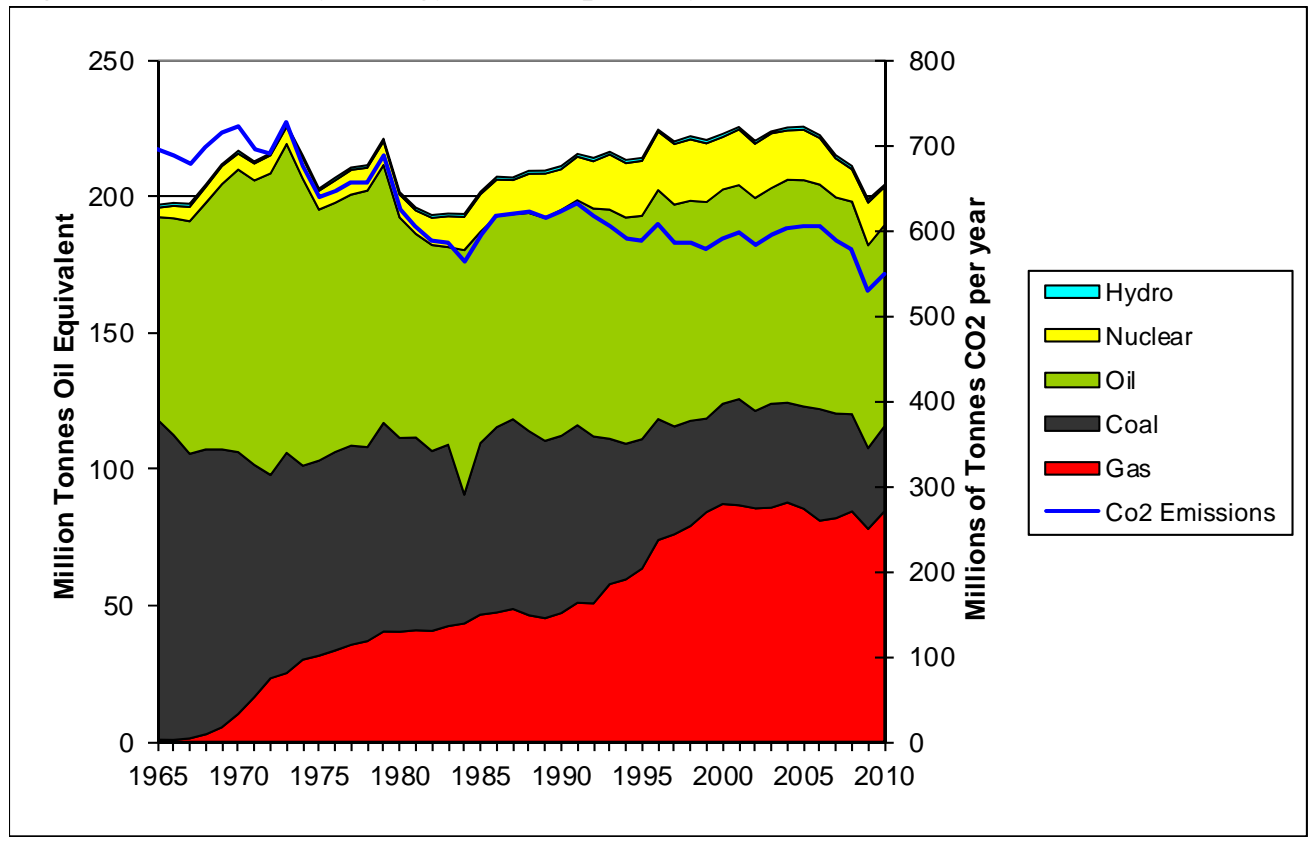

Source: BP Statistical Review of World Energy, 2011, hydro, nuclear, oil, coal, gas and $\mathrm{CO}_{2}$ emissions pages.

UK natural gas production peaked in 2000 and has since been in decline. In 2001-03, annual production decline was in the range 1-2\%. Between 2004-07 annual decline was more severe, ranging from 7-10\%. From 2007-08 the decline slowed to 3.3\%, between 2008-09 it accelerated to $15.3 \%$ but between $2009-10$ the decline was $3.4 \%$. Whilst such a fall-off in the UK's domestic production has heightened concerns over growing import dependency, it was eminently predictable (and predicted). Figure 2 compares a forecast of UK annual gas production from WoodMackenzie's North Sea Service in 2000 with the actual outcome, derived from IEA monthly statistics. While the forecast had lower production in the period 2008 to 2010, the broad trend has been borne out by the actual data.

\footnotetext{
${ }^{3}$ Note that natural gas also displaced town gas in cooking and space heating. In 1970 town gas consumption was 10.7 million tonnes oil equivalent (mtoe). By 1976 it was 0.5 mtoe and less that 0.1 mtoe by 1998 . DUKES Overall Data Tables, Table 1.5: Final energy consumption by fuel 1970 to 2009, http://www.decc.gov.uk/en/content/cms/statistics/publications/ecuk/ecuk.aspx
} 
Figure 2. UK Gas Production: WoodMackenzie’s 2000 forecast vs. Actual Data

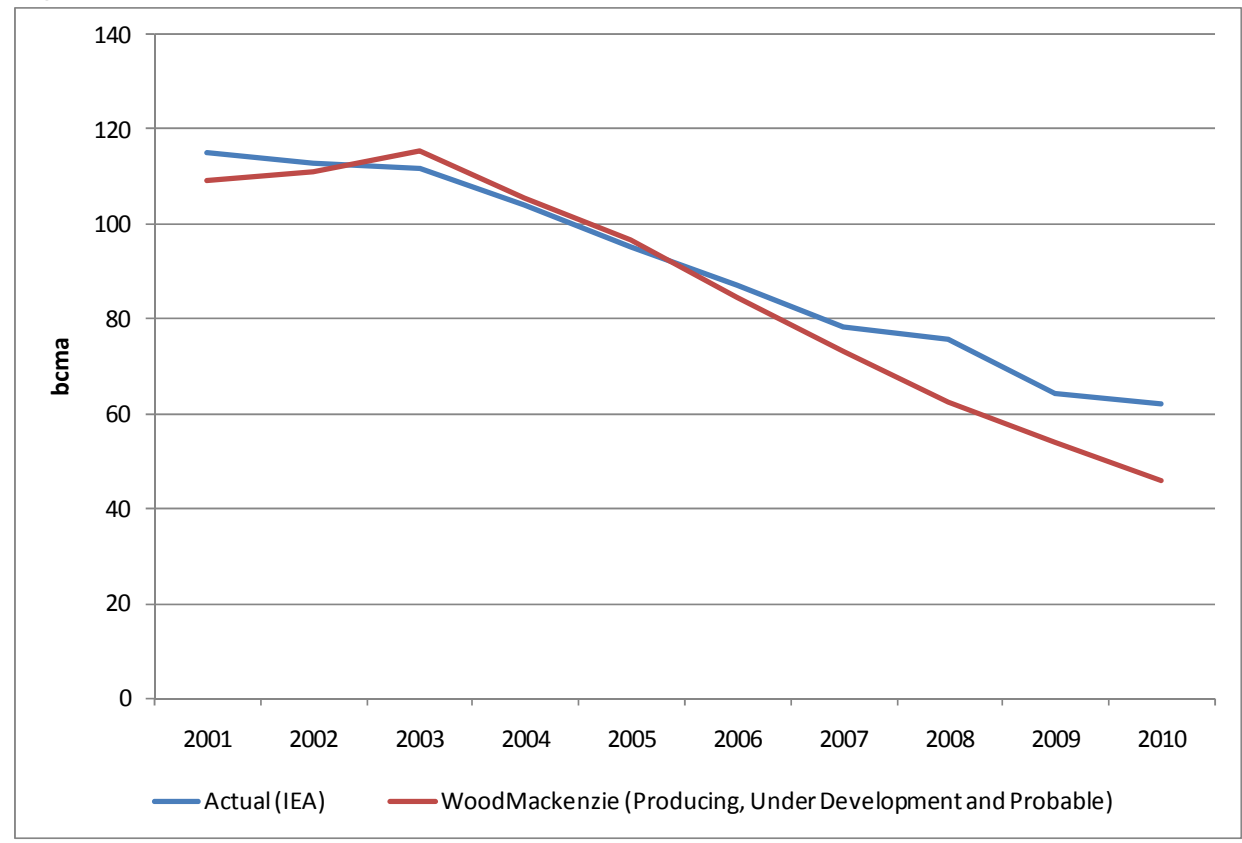

Sources: Wood Mackenzie North Sea Service 2000, IEA Monthly Data.

The perception that the UK existed as a 'natural gas island' prior to the opening of the Bacton - Zeebrugge Interconnector (IUK) in 1998 is not strictly accurate. In the 1980s and the early 1990s the UK imported Norwegian gas (12.8bcma in 1985) ${ }^{4}$ and small volumes of LNG in the 1970s (up to $0.9 \mathrm{bcma}$ ) ${ }^{5}$. While the initial function of the Interconnector may have been to allow the export of 'excess' summer gas production to the Continent, once UK production commenced its long term decline and the prospect of the UK as a net gas importer became inevitable, attention increasingly focussed on the development of pipeline and LNG regasification import infrastructure. By 2010 the UK imported 45\% of its total natural gas supply and $51 \%$ of its consumption requirements in the form of Norwegian and Dutch pipeline gas and LNG from a variety of sources ${ }^{6}$. As the UK's domestic production continues to decline the proportion of imported gas will inevitably rise.

The widespread use of gas in space heating in the residential and commercial sectors results in total gas demand being seasonal in nature. In the coldest month (typically January) demand is generally some 2.1 times higher than in August, on a monthly total basis. Prior to 1985, seasonal flexibility was provided almost wholly by the wide nomination ranges contained within gas contracts between the then state monopoly buyer, British Gas, and UKCS gas field owners. In 1985 British Gas’ Rough storage facility became operational and in 2010 it still

\footnotetext{
${ }^{4}$ Cedigaz \& BP

${ }^{5}$ Cedigaz 2004, pp. $4-9$.

${ }^{6}$ The European Waterborne LNG Report, $17^{\text {th }}$ March 2011, p. 29., IEA Monthly gas data aggregated to annual basis
} 
represented $75 \%$ of UK storage capacity ${ }^{7}$. (Rough was a partially depleted offshore gas field which was converted to a storage facility). With the liberalisation of the UK gas market in the 1990s, new UKCS fields were produced at full capacity on a year round basis without the constraints of a buyer-nominated contract ${ }^{8}$. This also became the norm for older fields, where the original field-specific 'depletion contracts' ${ }^{9}$ were renegotiated to become 'supply contracts' ${ }^{10}$ with no dedicated field. Through time, the seasonality of UK production has declined and is expected to continue to do so.

Figure 3. UK Storage Working Gas Volume (Existing and Under Construction) plus Potential Projects

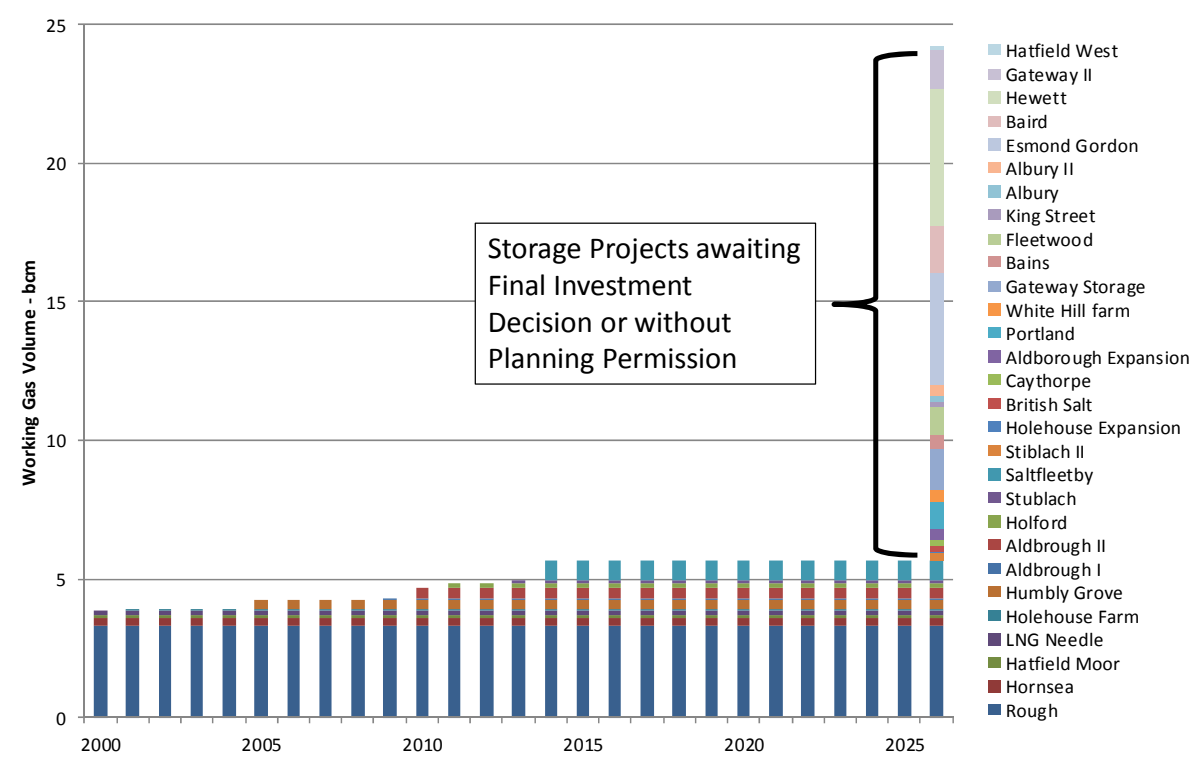

Source: National Grid 2009, Tables 4.7E, 4.7F and 4.7G, pp. 66-67.

This has prompted a debate over the need to construct new storage capacity. No storage facilities were built in the period between privatisation in 1986 and 2000 (see Stern 2010, Table 5.1 page 135). Since 2000 new storage build rate has been modest as shown in Figure 3. At the beginning of 2010 the UK's total storage working gas volume was some $4.3 \mathrm{bcm}$.

\footnotetext{
${ }^{7}$ GSE 2010

${ }^{8} \mathrm{~A}$ gas sale and purchase contract under which the buyer nominates the volumes to be supplied by the seller on a daily basis within agreed limits.

${ }^{9}$ A Depletion Contract is a gas sale and purchase agreement which relates to the supply of gas from a defined gas field or fields, usually for the producing life of the field(s).

${ }^{10}$ A Supply Contract is a sale and purchase agreement under which the seller is able to source the gas from a portfolio of fields or even the traded market.
} 
When Aldborough II, Holford, Stublach and the recently approved Saltfleetby ${ }^{11}$ come onstream, by 2014 the UK will have $5.7 \mathrm{bcm}$ of storage. In addition to these existing facilities and those under construction, there are a further $4.6 \mathrm{bcm}$ with planning permission but still awaiting Final Investment Decision (FID), and 14 bcm which is either still awaiting FID or has not yet applied for planning permission. (Storage projects in all categories are shown at the extreme right hand side of Figure 3).

The case for new storage build has been impeded by several factors which include the challenging nature of the planning and approval process, the difficulty in raising finance in the wake of the 2008 economic recession and the increase in energy sector project capital costs generally since 2004. Market signals have also been muted with no stable seasonal price differential evident over the past several years in the UK. ${ }^{12}$ In the meantime, pipeline imports from Norway and the Netherlands have developed a distinct winter bias, providing significant seasonal flexibility to the UK in lieu of new storage capacity. The 2009/10 winter was a particularly severe one for the UK and although storage inventories by end March 2010 were down to $10 \%$ of working gas capacity ${ }^{13}$, the UK market met demand through increased LNG imports and pipeline gas from Norway and the Netherlands with no enforced supply cuts to customers.

Figure 4. UK Gas Demand by Sector 2000 -2010 (Actual)

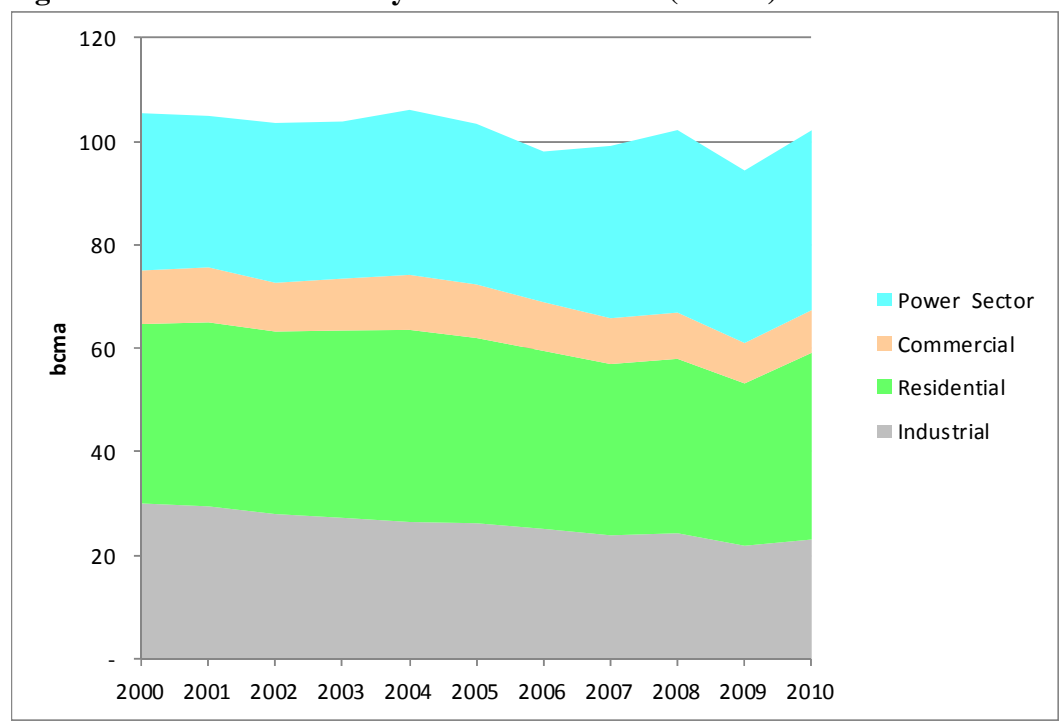

Source: DECC Quarterly Tables 'Energy Trends', Table ET 4.1 'Natural Gas Supply and Consumption',

\section{http://www.decc.gov.uk/en/content/cms/statistics/energy stats/source/gas/gas.aspx}

\footnotetext{
${ }^{11}$ Although this project was approved by HMG in October 2010 there have been no reports of subsequent construction activity.

${ }^{12}$ Remuneration of storage investment ultimately depends upon the difference between summer and winter gas prices. In the UK since the mid 2000 s this price differential has been variable and generally lower than that required to underpin storage investment.

${ }^{13}$ GSE 2009
} 
On demand, the UK has in the past been the subject of highly optimistic future demand forecasts. Projections made in 2000 quite commonly assumed that UK gas consumption by 2015 would reach $120 \mathrm{bcma}$. Gas demand grew strongly in the UK during the 1990s; on average at a rate of $6.5 \%$ per year, reaching $105 \mathrm{bcm}$ in year 2000. Since 2000, UK gas demand has stagnated; varying between 98-105 bcma up until the impact of the economic recession took 2009 demand down to $93 \mathrm{bcm}$. Figure 4 shows UK gas demand by sector from 2000 to 2010 (before temperature correction). The decline in industrial demand from 2000 to 2007 was partly offset by growth in gas demand in the power generation sector.In 2010 demand appeared to have recovered significantly from the recession-impacted 2009 level, however this was in large part due to colder than average ambient temperatures in early and late 2010.

The two major issues influencing views of future UK gas demand (as viewed from 2011) are: the impact of domestic dwelling insulation and more efficient boilers in the residential sector, and gas' role in a changing power generation mix. The de-commissioning of coal fired generation due to the implementation of the Large Combustion Plant Directive might be expected to increase the future demand for gas, while the policy commitment to rapidly increase the capacity of wind generation to meet 2020 emissions and renewable targets introduces much uncertainty. The latter is addressed directly in Chapter 6 .

Whatever the outcome for gas demand by 2025, natural gas will still play a significant part in the UK's energy mix. Understanding the issues of supply and flexibility within a changing domestic, and increasingly interconnected international setting is fundamental to the design of policies to ensure the reliability of this key energy source on which much of the UK's space heating and power generation will continue to rely. 


\section{Chapter 2. The Changing Regional and Global Natural Gas Environment since 2000.}

A previous paper ${ }^{14}$ discussed the development of the world's regional gas markets and the key supply and demand dynamics of the past decade. Given the increasing interconnectedness between regional markets facilitated by flexible LNG supplies, any attempt to understand the future UK market in isolation is at best futile and at worst delusional. The following is a brief description of the key trends post 2000 and the state of play in early 2011.

In North America (the US, Canada and Mexico) the onset of decline in US domestic production after 2001 raised the prospect of the US becoming a significant importer of LNG, which resulted in the construction of some 125 bcma of $U_{S}^{15}$ regasification capacity and upstream liquefaction projects in Qatar and elsewhere to meet this anticipated need. In the event, the successful exploitation of US shale gas reversed the aggregate production decline to the extent that US domestic production grew steadily post 2005. At the end of 2010 the US was importing minimal volumes of LNG. Gas prices in this liberalised market, formerly linked periodically with oil products through fuel competition in the power sector, have been below fuel oil equivalent levels for the majority of the 2006 - 2010 period. Natural gas demand growth during this time has been moderate; for North America in total it averaged $1.4 \%$ per year for 2001 to $2010^{16}$. In the US, the post 1998 erosion of industrial demand stabilised in the middle of the 2000s whilst gas demand growth in the power generation sector has offset this reduction. North American demand in 2010 was 853 bcma $^{17}$.

In Asia, the majority of gas is consumed within the country in which it is produced, often at low, regulated prices. Pipeline trade from Indonesia to Singapore and Malaysia, Malaysia to Singapore, and Myanmar to Thailand amounted to $20.2 \mathrm{bcm}$ in $2010^{18}$. Of note however is the new Turkmenistan - China pipeline which commenced operation in 2010, and flowed 3.6 bcm in that year ${ }^{19}$, and which is expected to reach 30 to 40 bcma by 2015. LNG tradeflows, both in the form of imports from outside the Asia region and between Asian countries amounted to $184 \mathrm{bcm}$ in $2010^{20}$. The Asian LNG importing markets are Japan, Korea and Taiwan (all of which have little if any domestic gas production) and China and India, which import LNG to supplement domestic gas production and, in the case of China, pipeline imports. Asian natural gas demand growth between 2000 and 2010 was on average 6.9\% per year although this varied significantly between countries. For Japan the average annual demand growth was $2.7 \%$ and for China and India $15.2 \%$ and $8.9 \%$ respectively ${ }^{21}$. Asian demand in 2010 totalled 577 bcm. The majority of LNG tradeflows in Asia are sold under long-term contracts with price linked to a time-averaged value of crude oil. Some contracts

\footnotetext{
${ }^{14}$ Rogers 2010, pp. $4-41$.

${ }^{15}$ EIA 2009

${ }^{16}$ EIA Monthly Data and IEA Monthly Data.

${ }^{17}$ EIA Monthly Data and IEA Monthly Data

${ }^{18}$ BP 2011: Pipeline Trade Page

${ }^{19}$ BP 2011: Pipeline Trade Page

${ }^{20}$ The Asia Waterborne LNG Report, $13^{\text {th }}$ May 2011, P. 18.

${ }^{21}$ BP 2011, Gas Consumption Page
} 
contain price ceilings and floors or an ' $\mathrm{S}$ ' curve which moderates the more extreme oil price impact on the LNG price. ${ }^{22}$ Asian importers also purchase spot LNG cargoes to supplement contracted supplies. Against a background of rapid gas demand growth, the 2000s witnessed the largely unforeseen decline in LNG output from Indonesia's Arun and Bontang liquefaction facilities as natural gas feedstock availability deteriorated. This, coupled with Japan's nuclear reliability issues including the shutdown of the 8.2GW Kashiwazaki Kariwa plant following earthquake damage in 2007, resulted in a tightening LNG market and high spot prices as Asian LNG importers accessed spot cargoes from Atlantic Basin origins ${ }^{23}$. In March 2011 the Fukushima Nuclear plant was damaged and closed after a Tsunami hit Japan's eastern coast. Estimates of the additional LNG Japan will consume as a consequence of nuclear outages range from 12 to $20 \mathrm{bcma}$ for an indeterminate period.

The European market saw a moderation in demand growth in the 2000s (average for 2000 to $20101.7 \%$ per year ${ }^{24}$ ). Demand in 2010 was 595 bcm, an increase of $8.1 \%$ over $2009^{25}$, however lower than average ambient temperatures in the early and late months of the year, rather than economic recovery, played a significant role in this high figure. Europe has relied on pipeline imports from Russia since the 1970s and North Africa since the 1980s. In 2010 gas from these sources plus Iran and Azerbaijan met 33\%of European consumption. LNG imports into Europe began in the 1970s and met 15\% of European consumption in $2010^{26}$. Europe's domestic production is predominantly in Norway, the UK and the Netherlands with lower levels in Denmark, Italy, Germany and Romania and elsewhere. During the 2000s growth in Norwegian production offset domestic production declines elsewhere in Europe although with Norway nearing its production plateau, Europe's production is expected to decline in aggregate in the future.

Given the success of shale gas development in the US, there is much speculation as to the future development of shale gas in Europe. The main conclusion of a paper by Florence Gény ${ }^{27}$ is that shale gas production is unlikely to be significant in Europe prior to 2020 and, even if successful thereafter, is more likely to have an impact at a national rather than a regional level. Drilling in Europe is at the early exploratory stage and it is likely to take several years to establish whether shale gas can be produced in material quantities at a cost which competes with (imported) conventional gas. In addition to geological uncertainties, the challenges to achieving this include cost base challenges, the development of a suitable regulatory and fiscal framework, and the resolution of environmental concerns and general public acceptance.

With the exception of the UK market, which became liberalised in the 1990s, Europe began the 2000s with a market structure dominated by long-term oil indexed contracts for its pipeline and LNG imports and also its domestic production. The European Union has

\footnotetext{
${ }^{22}$ See Appendix 2, pp. 405 - 409, on Asian LNG Prices by A. Flower in Stern 2008.

${ }^{23}$ The Asia Waterborne LNG Report, $30^{\text {th }}$ August 2007, pp. 2-7.

${ }^{24}$ IEA Monthly Data and Eurostat Monthly Data aggregated to annual basis.

${ }^{25}$ IEA Monthly Data and Eurostat Monthly Data aggregated to annual basis.

${ }^{26}$ The European Waterborne LNG Report, $17^{\text {th }}$ March 2011, P. 29., IEA and Eurostat monthly gas data aggregated to annual basis.
}

${ }^{27}$ Gény 2010 
subsequently enacted a series of three legislative packages with the aim of creating a competitive and liberalised market structure ${ }^{28}$. This has been a slow and tortuous process, however the demand reduction caused by the economic recession coinciding with a rapid growth in LNG supply from Qatar resulted in more vigorous activity in the nascent gas trading hubs of Northern Europe and a growing challenge to the oil-indexed paradigm for gas pricing $^{29 .}$ The average German import price in 2010, as reported by the German Federal Office of Economics and Export Control Ministry, (referred to as BAFA), has since 2009 been below the levels expected based on its historic relationship to oil products prices, suggesting that oil-indexed sellers have been offering substantial discounts to contract prices (see Figure 9).

Significant flexibility has been negotiated into many European LNG purchase contracts such that the LNG may be diverted to markets offering higher prices. This creates the potential for Europe to 'optimise' its gas imports to achieve lower average import costs by LNG arbitrage with North America, within contractual and physical constraints. At present, however, with North America requiring only minimal LNG import volumes, this arbitrage is not active and the key dynamic at play is the interaction of flexible LNG supplies, pricing off the UK traded market, competing with long term contract gas priced on a lagged oil products indexed basis at the North West European trading hubs.

As with the UK, the perception is that the future natural gas demand path for Europe will be heavily influenced by the on-going policy drive to reduce $\mathrm{CO}_{2}$ emissions and increase the share of renewables in the energy mix. The extent to which such policies will a) achieve targets for implementation of renewable generation plant and the not inconsiderable infrastructure to connect them to the grid and b) materially impact the demand for natural gas in the power generation sector, is extremely difficult to judge at the European level. For the UK, the analysis contained in Chapter 6 suggests that the growth in wind generation will ensure that gas has a significant and key role to play in providing the flexible back-up generation required due to the inherent variability of wind generation.

As the largest owner of proven gas reserves in the world, Russia also has a gas-intensive economy with $53 \%$ of its primary energy met by gas in $2009^{30}$. Russian gas demand grew at an average $1.6 \%$ per year from 2000 to $2010^{31}$ [2.0\% 2000-2008; 2009 fell due to recession, 2010 rose due to cold weather], this despite an increase in its state-regulated domestic gas prices. Russia is a crucial supplier of natural gas to Europe. Exports to Europe, while having grown from 133.7 bcm in 2000 to 158.8 in 2008 fell to 140 bcm in 2009, a figure which did not increase in $2010^{32}$. Russia imports gas from Turkmenistan, Uzbekistan and Kazakhstan which, together with its West Siberian production, is sufficient to meet domestic demand and exports to the CIS ${ }^{33}$ and Europe. In the Far East, Russia exports LNG from the Sakhalin

\footnotetext{
${ }^{28}$ See Rogers 2010, pp. 20, 21

${ }^{29}$ See Stern \& Rogers 2011: 'The Transition to Hub-Based Gas Pricing in Continental Europe', Jonathan Stern and Howard Rogers, NG49, March 2011, OIES.

${ }^{30}$ Pirani, Table 4, P. 9

${ }^{31}$ BP 2011: Gas Consumption Page

${ }^{32}$ Stern,OIES

${ }^{33} 55.9$ bcma to CIS in 2010, Source BP 2011, Natural Gas Pipeline Trade Page.
} 
development and also has the potential to supply China with up to $70 \mathrm{bcma}$ of pipeline gas supply from fields in western and eastern Siberia as and when commercial terms and, critically, prices can be agreed ${ }^{34}$.

As the older West Siberian giant gas fields of Medvezhye, Urengoy, Yamburg and the more recently developed Zapolyarnoe decline, Russia will need to bring on new supplies. Gazprom's new projects include the giant Bovanenkovskoye field in Yamal and the Shtokman field offshore in the Barents Sea. The Bovanenkovskoye field is scheduled to start production towards the end of 2012 and the pace at which the project will be fully completed may be varied depending on the demand for gas in domestic, CIS and European export markets. Shtokman, being a high cost and technically challenging offshore project has been the subject of delay in recent years; its timing is still highly uncertain. Upstream participants other than Gazprom, whether International Oil Companies or Russian oil and gas companies, have a long list of potential gas developments which, subject to reaching agreement with Gazprom, could be brought onstream relatively quickly ${ }^{35}$.

Middle East and North African (MENA) countries hold $45 \%{ }^{36}$ of the world's proven gas reserves, however at present an OIES study suggests that it is far from evident that this will be transformed into significant new export flows in the near term. ${ }^{37}$ A recurring paradox across many of the countries studied in this region is the low, state regulated price of natural gas in the domestic market which, combined with high population growth rates and the desire to create added value through investment in petrochemical industries, has led to a situation where there is little prospect of significant additional export volumes in the period up to 2015 (and perhaps 2020) from all but Qatar and Algeria. In most countries low domestic market prices, combined with the doubling of the international upstream cost base during the 2000s, has undermined the economics of exploring for and developing new domestic gas resources at a sufficient pace. Based on the conclusions of the OIES study, there is a likelihood that Algerian pipeline exports to Europe will begin to decline around the end of the 2010s.

The Caspian region has been the focus of intense European interest given its potential to provide a new significant 'corridor' of pipeline gas supply to Europe. In 2007, Azerbaijan began exports to Turkey which have subsequently reached some $5 \mathrm{bcma}^{38}$. The "Southern Corridor” Nabucco project is a 'much wished-for' pipeline to bring Caspian region gas to a range of southern and central European markets, eventually terminating in Austria. While the second phase of the Azeri Shah Deniz field development may provide around one third of the envisaged 30 bcma required to underpin the project, additional supply sources have so far been difficult to firm up. Likely sources are Turkmenistan (although the necessary pipeline across the Caspian Sea has been blocked by the failure of the littoral states - especially Russia and Iran - to agree on the legal status of the Sea) and Iraq, where political stability has defied setting a concrete timeline for the commitment of existing and future gas resources. Given their relatively modest size, even if the Southern Corridor (Nabucco, TAP and ITGI) projects

\footnotetext{
${ }^{34}$ Stern 2008, P. 263, 'Russia and China Still Far Apart', Platts International Gas Report, July $44^{\text {th }} 2011$, P. 12

${ }^{35}$ Henderson 2010, P. 239.

${ }^{36}$ BP 2011, Gas Reserves Page

${ }^{37}$ A comprehensive assessment of the potential of this region can be found in: Fattouh and Stern 2011

${ }^{38}$ IEA Monthly Data
} 
are successful and begin supplying Europe towards the end of the 2010s, this Caspian region gas may merely offset the decline in Algerian pipeline supplies to Europe.

South America's consumption of natural gas in the period 2000 to 2010 grew by an average of $4.4 \%$ per year and in 2010 totalled $147.7 \mathrm{bcm}^{39}$. Pipeline trade has developed, with Argentina exporting to Chile and Uruguay, Bolivia to Argentina and Brazil, and Columbia to Venezuela. Interaction with other regions has also developed, with Trinidad and Tobago exporting LNG to diverse destinations since 1999 and Peru also becoming an exporter of LNG in 2010. In 2009 Argentina, Brazil and Chile began importing LNG with a bias towards the Southern Hemisphere winter months. In 2010 these countries imported $7.5 \mathrm{bcm}^{40}$ of LNG. Venezuela has the potential for LNG exports although timing is dependent on the country's future political direction and alignment, and Brazil might also become an exporter, depending upon the scale and growth rate of its offshore pre-salt hydrocarbon prospectivity.

Figure 5 shows global natural gas demand from 1990 to 2010 by region with the impact of recession evident in 2009. One general trend which has become established in this period is the increasing need for 'long distance' gas as regional market demand outpaces growth in domestic and immediately proximate supplies. This is effect is shown in Figure 6. Long distance gas is classified as all LNG (blue) and pipeline tradeflows from Russia, North Africa, Iran and Azerbaijan into Europe and pipeline flows within Asia and South America (red). In the period 1995-2010 both increased, with LNG on a continuous growth trajectory. The economic recession resulted in a fall in global gas consumption and pipeline tradeflows in 2009, however LNG consumption increased markedly over 2008 levels in 2009 and 2010.

This background has a very direct relevance for the UK market. Even if the UK's future demand for gas does not grow or even if it gradually declines over time, steadily falling domestic production will require imports of gas in the form of LNG from distant suppliers or as pipeline supply from Norway and the European Continent (but this latter ultimately backed by Russian imports across the European border). Both primary sources of future supply have associated uncertainties. For LNG there is the issue of uncertainty of timing on many of the projects which have not yet achieved Final Investment Decision (FID). This uncertainty is driven by the availability of finance, availability of skilled human resources and in many cases geo-politics. In the case of Russian supply to Europe the major uncertainty is how Russia will respond to the growing demands for a shift away from oil-indexation in its long term contracts.

In making a switch to hub-based pricing, the rationale for the continued existence of long term contracts in their current form is questionable. The ability of Russia to deliver timely physical supply to Europe is not in doubt; its willingness to do so under a new market paradigm is yet to be ascertained.

\footnotetext{
${ }^{39}$ BP 2011, Gas Consumption Page

${ }^{40}$ The Americas Waterborne LNG Report, $12^{\text {th }}$ May 2011, P. 14.
} 
Figure 5. Global Gas Consumption by Region 1990 - 2010

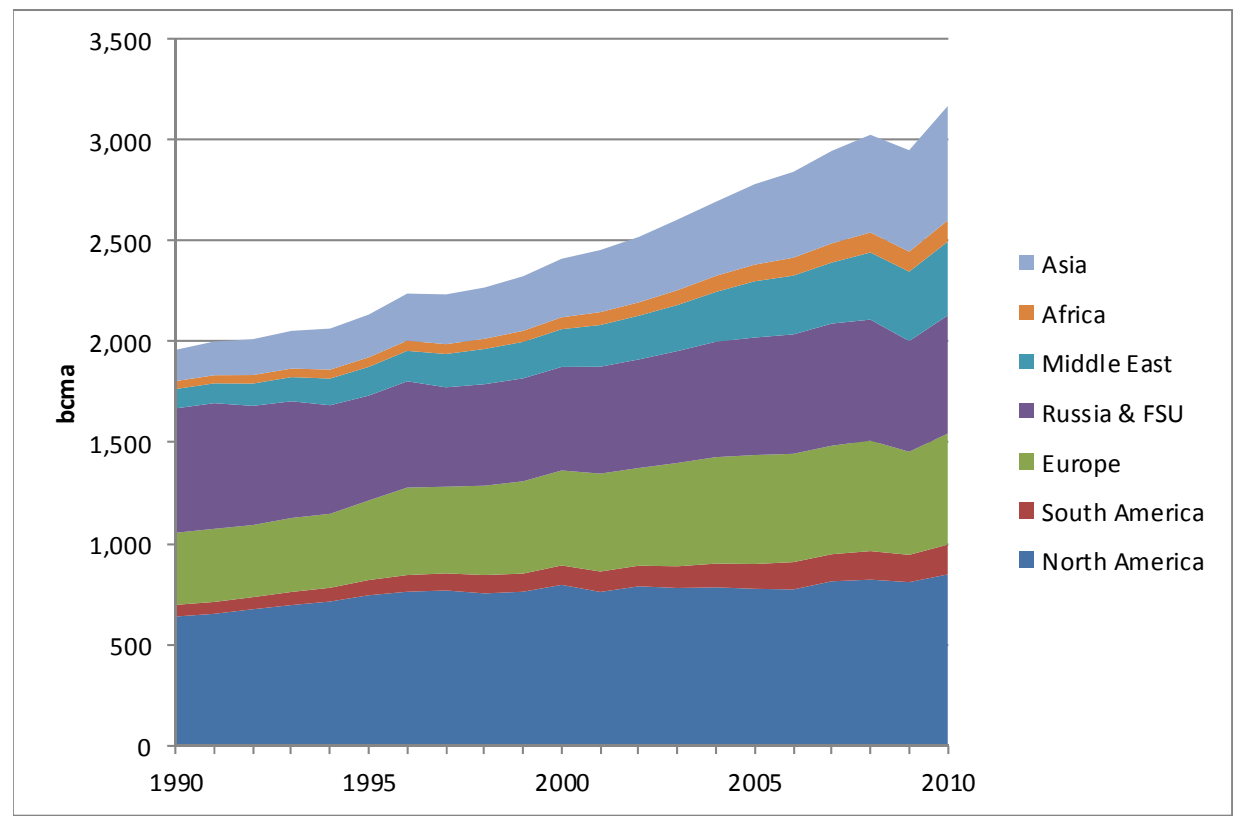

Source: BP Statistical Review of World Energy 2011.

Figure 6. Global Gas Supply Channels 1995 - 2010

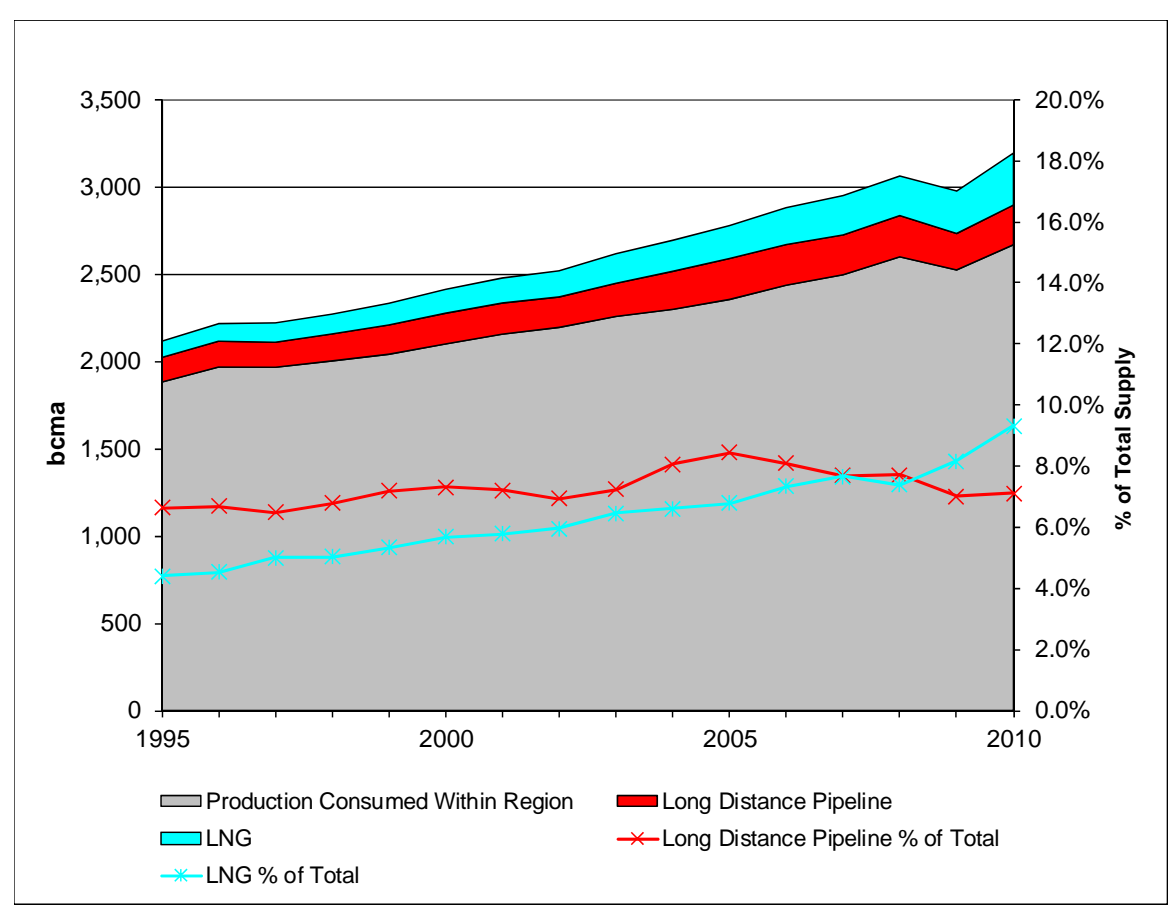

Source: BP Statistical Review of World Energy 2011 


\section{Chapter 3.Key Issues for the UK Gas Market}

Any approach to understanding the future dynamics of the UK gas market's future dynamics must place it within the context of the international market system to which it is connected by flexible LNG and pipeline interconnections. An obvious starting point is understanding the status and dynamics of the UK gas market as it exists at present, based on actual data, before we project forward into a less certain future. For the period 2000 to 2010 Figure 7 illustrates the key trends in the UK market at a monthly level.

In the period 2000 to 2002, the UK met virtually all its gas consumption requirements (red line) from domestic gas production (grey bars) with minor levels of imported gas from Norway (deep blue bars). During the summer months exports through the IUK to Belgium and beyond (orange bars below axis) often reached 30 to $40 \mathrm{mmcm} /$ day. Exports to the Republic of Ireland (green) were relatively constant. Much of the UK's seasonal flexibility was provided by the significant monthly variation of domestic production with, by comparison, only a minor contribution from storage (yellow bars).

In the period 2003 to 2006, the pronounced decline in UK domestic production (grey) and lower summer export through the IUK (orange below the axis) is easy to identify at the same time as the scale of Norwegian pipeline imports increased (dark blue). As UK domestic production seasonality declined, winter month seasonal demand flexibility was met by storage (yellow) but also IUK imports from the European continent (orange bars above the axis) and by the winter-biased shape of Norwegian imports. In winter 2005/2006 LNG imports made a small (but very welcome) ${ }^{41}$ winter contribution (light blue bars).

In the period 2007 to 2010, the decline in the scale and seasonality of UK domestic production continued. Norwegian imports increased significantly with Ormen Lange commencing production and Dutch imports through the BBL line also starting. Both Norwegian and Dutch imports played a major role in providing seasonal flexibility, much more so than UK seasonal storage. In the winter 2009/2010 LNG imports increased significantly with the arrival of Qatari volumes at the South Hook regasification terminal.

Figure 8. compares the sources of seasonal flexibility (bars) against the specific requirement in each year dictated by the difference in seasonal demand (black line). In a typical year between 2000 and 2009, the UK required the equivalent of 12,000 to 15,000 mmcm of storage working volume to meet seasonal demand variation ${ }^{42}$. In 2000 and 2001 this was provided overwhelmingly by domestic production seasonal swing and storage. By 2010, domestic swing provided only some $19 \%$ of seasonal flexibility with Norwegian and Dutch pipeline imports and LNG imports together providing in aggregate 43\%. In 2010 seasonal storage provided $31 \%$ of seasonal flexibility requirements. Seasonal storage capacity at end 2010 stood at $4.76 \mathrm{bcm}$, with a further $1 \mathrm{bcm}$ under development.

\footnotetext{
${ }^{41}$ See later discussion of Rough fire and other events of the 2005/6 winter.

${ }^{42}$ The term 'equivalent storage volume' in this context means the volume of working gas storage volume which would be required to enable the UK's monthly demand profile to be met assuming that gas supply was flat throughout the year.
} 
Figure 7. UK Supply, Demand, Imports and Exports January 2000 -December 2010

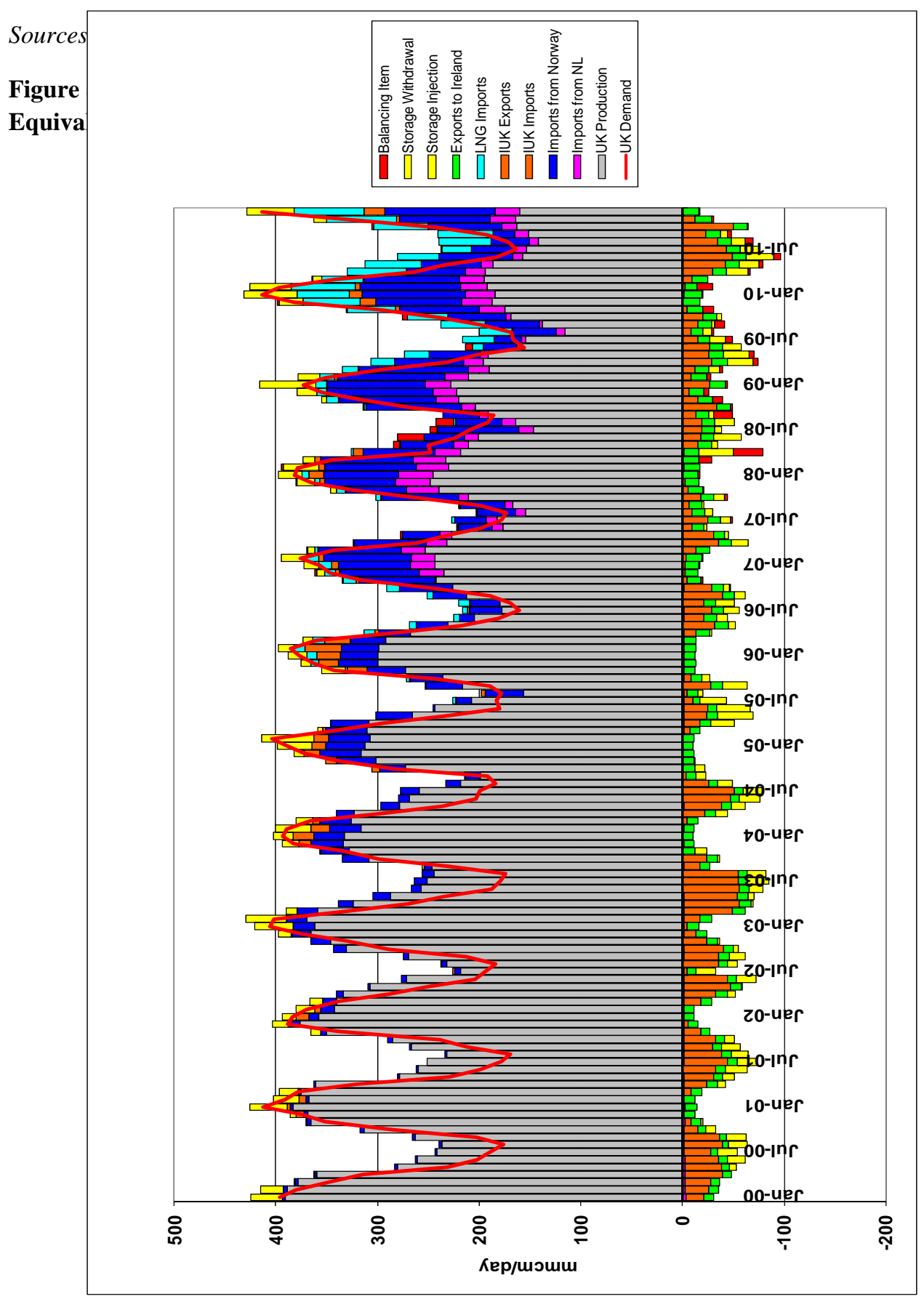




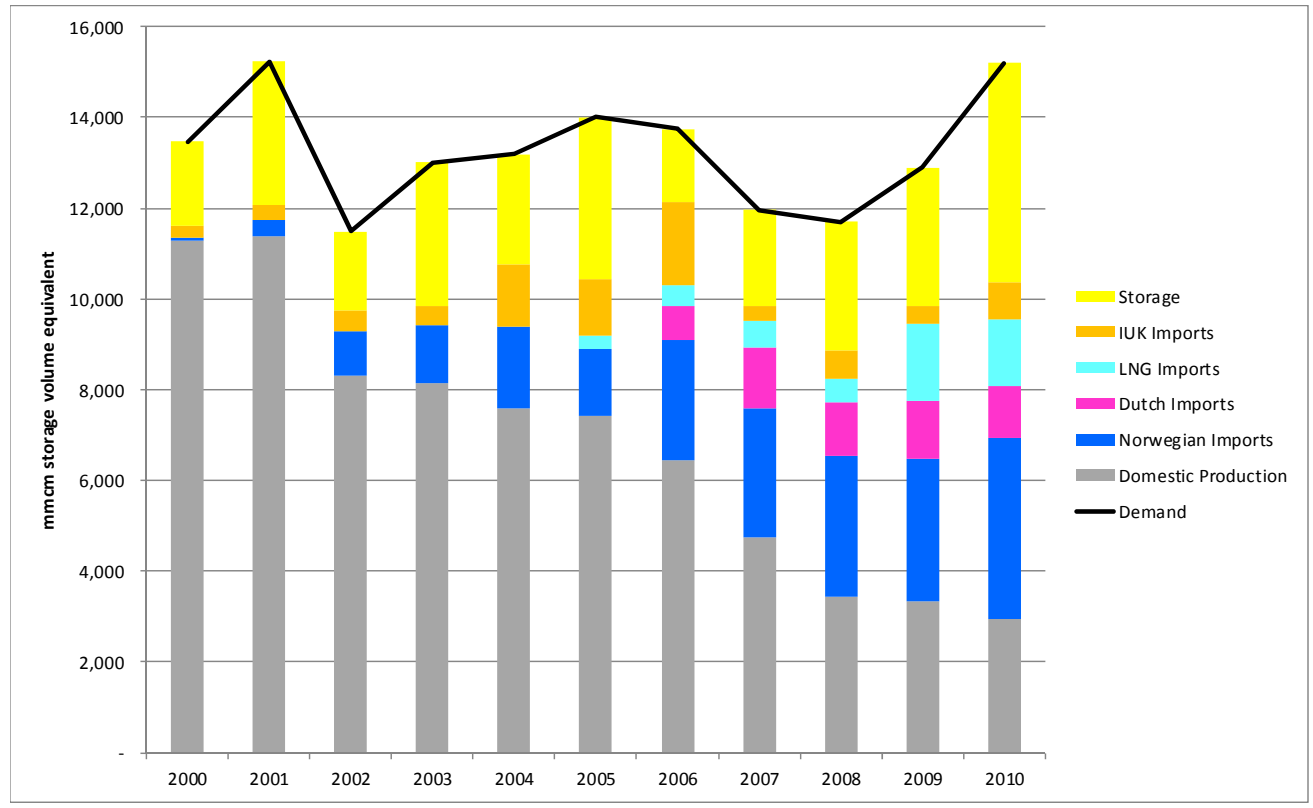

Sources: IEA Monthly Data, DECC, Waterborne LNG, Own Analysis

Figures 7 and 8 starkly illustrate the transition of the UK market from one of supply selfsufficiency to one of import dependency: not only for annual supply but also for seasonal flexibility.

Significant events which occurred through this period are described below:

For the period 2001 to September 2010, Figure 9 shows the UK NBP price (green) and the BAFA price $^{43}$ (brown). With physical connectivity between the UK and Continental European markets provided by the UK - Zeebrugge Interconnector (IUK) since October 1998 the UK price has had a tendency to converge on the oil-indexed European price, which BAFA represents, through trading arbitrage.

In 2001 we observe price convergence between the UK and the Continental price in the colder months but a de-linkage, with the UK price dipping below the Continental price during the summer; a time when the UK was exporting gas in excess of its consumption and storage injection needs. In July and August 2002 problems of hydrocarbon liquids contamination caused periodic shutdown and reduced flowrates through the IUK which reduced UK prices due to the restricted export flows during this period. From September $23^{\text {rd }}$ to October $7^{\text {th }}$ 2003, the IUK experienced water ingress, requiring severely restricted flowrates and a pigging operation to clear the line $\mathrm{e}^{44}$.

Figure 9. UK Market Events 2001 - 2010

\footnotetext{
${ }^{43}$ This is the average border price paid for gas imported to Germany from Russia, Norway, the Netherlands, Denmark and the UK. It is predominantly long term contract gas, priced in relation to oil products.

${ }^{44} \mathrm{http}: / /$ www.interconnector.com/mediacentre/pressreleases2003.htm
} 


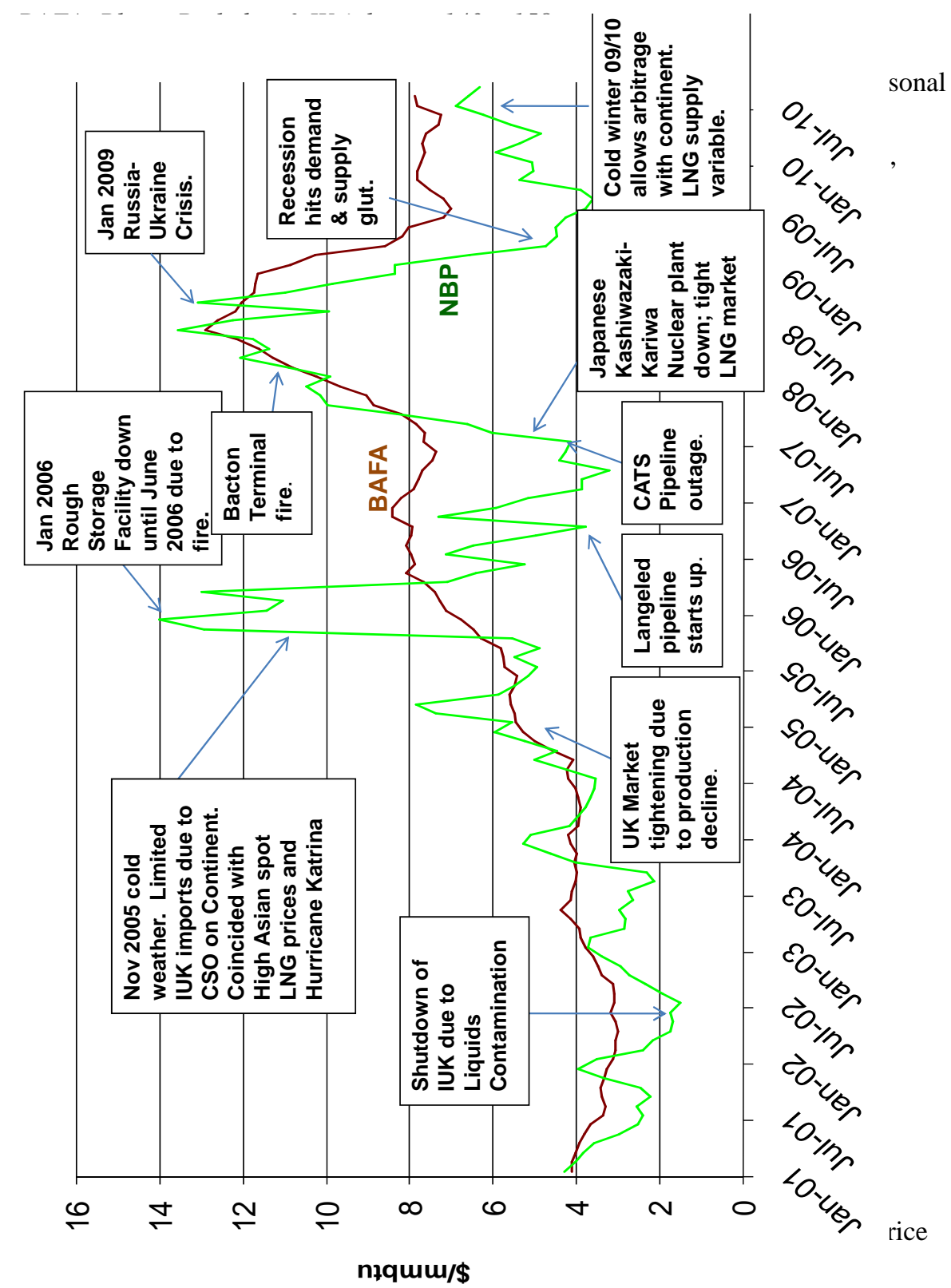

of

Continental suppliers to maintain storage inventories to ensure Public Service Obligations could be met through the remainder of the winter heating season ${ }^{45}$. The situation was compounded by the coincidence of this event with Hurricane Katrina in the US and a tight

\footnotetext{
${ }^{45}$ Directive 2003/55/EC of the European Parliament and of the Council of 26 June 2003 concerning common rules for the internal market in natural gas provides for the possibility for Member States to impose public service obligations to guarantee security of supply, economic and social cohesion objectives, regularity, quality and price of the gas supply and protection of the environment.http://europa.eu/legislation_summaries/energy/internal_energy_market/I27077_en.htm
} 
Asian LNG market due to the growing underperformance of Indonesia as an LNG exporter. The rise in UK prices to between \$12 and 14/mmbtu reflected the price paid for spot LNG cargoes.

This situation was further exacerbated by a fire on the Rough storage facility (which at the time represented $78 \%$ of the UK's seasonal storage capacity), on February $16^{\text {th }} 2006$. The facility was out of operation for the remainder of the space heating season and re-opened in early June 2006.

The start-up of the Langeled pipeline in October 2006 and its main supply source, the Ormen Lange field in September 2007 exerted downward pressure on UK prices. The gas supplied through the pipeline during its commissioning in October 2006 was such that UK within day prices moved into negative territory! ${ }^{46}$

The CATS pipeline, supplying $6 \mathrm{mmcm} /$ day of domestic gas from North Sea fields was shutdown in July 2007 for two months having been damaged by a dragging ship's anchor. ${ }^{47}$ In Japan the Kashiwazaki-Kariwa nuclear power generation facility was damaged by an earthquake also in July 2007. This served to tighten the global LNG market as Japan compensated for the outage of its largest nuclear plant with other generation fuels, including LNG.

In the context of a tighter market and the on-going decline in domestic production, UK prices in the second half of 2007 converged with BAFA prices which were themselves rising steeply as a consequence of the surge in world oil and oil products prices. On February $28^{\text {th }} 2008$ a fire at a sub-terminal at Bacton removed $30 \mathrm{mmcm} /$ day of gas supply until its re-start on $3^{\text {rd }}$ March $2008^{48}$.

As the recession took hold in late 2008, the oil product-linked BAFA price began its lagged fall. UK prices fell more rapidly and remained in the $\$ 4$ to $\$ 5 / \mathrm{mmbtu}$ range for much of 2009. The colder than average winter of 2009-2010 saw the UK market well supplied as a consequence of the ramp-up of new Qatari LNG supplies. Shale gas production growth in the US had reduced the requirement for imports to North America and hence Europe and in particular the UK was spared a weather-related price spike.

It is interesting to note that the January 2009 Russia-Ukraine crisis, whilst resulting in additional depletion of UK storage inventory as a consequence of IUK exports, did not noticeably impact UK prices.

The explanation for the rise in NBP in the period April to September 2010 is also interesting. In addition to absorbing some of the surge of new LNG supply, Continental Europe also imported high volumes of Russian gas over the 2009/2010 winter season. By April 2010 buyers of European pipeline gas had fulfilled in aggregate an estimated 65\% of their Take-orpay commitments for the contract year ending September $30^{\text {th }} 2010$. During the late spring

\footnotetext{
${ }^{46}$ 'Gas spot-price plunges as pipeline floods UK' The Times, October 4th 2006, http://business.timesonline.co.uk/tol/business/industry sectors/natural resources/article659480.ece ${ }^{47}$ Stern 2010, pp.142-3.

${ }^{48}$ Stern 2010, P.143.
} 
and summer months of 2010, these buyers were able to significantly reduce their oil-indexed contract gas nominations and instead purchase spot gas at the European Hubs, much of which was physically supplied from the UK via the IUK. This high demand for UK 'transit' spot gas resulted in higher than expected UK gas prices.

The preceding historical account is illuminating in that it highlights market events or perturbations which fall into three categories:

- The mechanical failure of infrastructure related to either gas supply or flexibility provision. The examples are the IUK liquids contamination and water ingress shutdowns, the Rough Storage fire, the Bacton fire and the CATS outage.

- The mismatch in Market Structure Paradigm or Commercial Behaviour. The single example (but an important one) is the low IUK flow from the Continent during November 2005.

- Supply Surplus or Shortage effects due to external market fundamental events. In this category we can include the 2006 tight Asian LNG market as a consequence of Indonesian LNG underperformance and the impact on the global LNG market due to the Japanese earthquake-induced nuclear outage. Also we might include here the impact of the abrupt start-up of the Langeled pipeline in depressing prices.

The past is not a reliable guide to the future, however the 2000s decade does provide a useful suite of examples to illustrate the extent to which the UK gas market has become increasingly impacted by unforeseen events, some occurring on the other side of the globe.

Clearly to address the future UK supply mix, its dynamics and how best to ensure seasonal flexibility we need to look at scenarios of the entirety of the system in which the UK is now a component i.e. the new LNG-connected world. The following chapter describes the analytical framework used to achieve this.

\section{Chapter 4. Analytical Framework and Scenario Derivation}

\subsection{Future Supply Mix and Seasonal Flexibility Requirements}

The analytical framework developed in a previous paper ${ }^{49}$ consisted of a monthly balance for the LNG-importing world which incorporated a test to see whether North American storage inventory could be brought to historic average levels for the month in question by varying European oil-indexed pipeline imports within the contract flexibility range (bounded by Take or Pay and Annual Contract Quantity). The system so modelled is represented by the schematic in Figure 10.

Figure 10. Schematic Representation of Global LNG System Modelled.

\footnotetext{
${ }^{49}$ Rogers 2010, P. 48.
} 


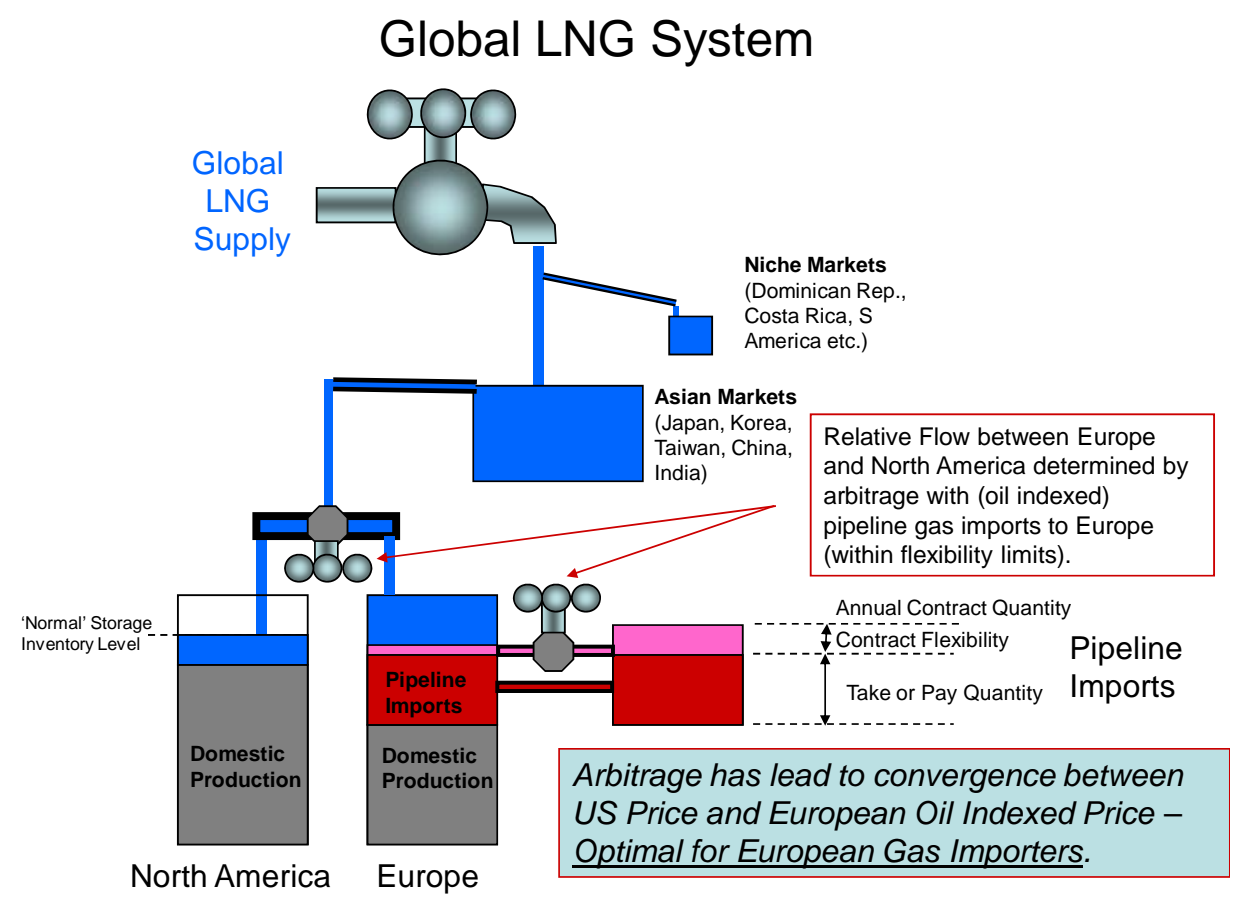

Due to the nature of this model (specifically the limitation of degrees of freedom ${ }^{50}$ ) the resulting balance for Europe is constrained to an aggregate regional level incorporating, at the monthly level, the parameters of total demand, domestic production, LNG imports and exports, pipeline imports and storage inventory.

In order to depict the interaction of the UK gas market with global LNG supplies and pipeline flows to and from the European continent the challenge became one of creating a credible representation of Europe at a country level which, in aggregate, matched the results of the Global Tradeflow Model for the period to 2025.

For a description of the Global Tradeflow Model please refer to Rogers 2010, Chapter 2. The following describes the approach taken to create a country and monthly level European balance within the Global Tradeflow Model solution for a given over-arching assumption set. A description and rationale for key assumptions made in this analysis is provided in Appendix A.

Demand and Domestic Production: For the 30 countries $^{51}$ comprising the European regional gas market, historic demand and production data were already compiled (at a monthly level)

\footnotetext{
${ }^{50}$ Degrees of freedom: the number of values in the final calculation of a statistic that are free to vary.

${ }^{51}$ As defined for the purpose of modelling in this paper Europe includes: Austria, Belgium, Bulgaria, Croatia, Czech Republic, Denmark, Estonia, Finland, France, Germany, Greece, Hungary, Ireland, Italy, Latvia, Lithuania Luxembourg, Netherlands, Norway, Poland, Portugal, Romania, Serbia, Slovakia, Slovenia, Spain, Sweden, Switzerland, Turkey, UK.
} 
in the representation of Europe in the Global Tradeflow Model. Projected future monthly trends had also been prepared for the same purpose. Future projections of monthly demand were, for the majority of countries, based on separate power and non-power sector views in order to incorporate the different monthly 'shapes' of these sectors, based on an average historic derivation.

Inter-Country Tradeflows, Pipeline and LNG Imports: From past Cedigaz (as represented in the BP Statistical Review of World Energy) and IEA monthly data, the key flows between European countries were identified. Also noted was the typical monthly profile of these flows, where a reliable IEA data series was obtainable.

Future Annual Flows: An annual balance matrix was constructed for each country containing demand, production and all export and import flows. Flows between European countries were projected to be broadly in line with domestic production trends in the exporting country.

The remaining challenge was then to complete the individual country balances within the constraint that all assumed country level LNG imports summed to the European LNG import total, as defined in the aggregate Europe solution in the Global Tradeflow Model results. The same process was undertaken for pipeline imports (including Norway). A pragmatic short-cut in this process was to make a judgemental distinction between those countries which could actively vary LNG versus pipeline imports, and those which were effectively captive to a defined supply source.

Although this was a somewhat daunting semi-manual process, the constraints imposed by the need to converge on aggregate European supply from a specific importing source resulted in convergence being obtained within a manageable timeframe.

Future Monthly Flows: For the countries which are 'captive' to defined import sources, future monthly imports and exports were determined by multiplying the annual flow values by the monthly shape derived by averaging historic values (as described above). For countries which are exposed to trade-offs between pipeline and LNG imports, the balance of aggregate European monthly flows (after subtracting the captive market flows) was distributed to these markets on the basis of the relative size of their annual requirement from the annual matrix.

Future Monthly Storage Inventory Changes: At an individual country level storage inventory changes were determined by subtracting demand and exports from production and imports. The exceptions to this process are the UK and Belgium (see below). Obviously the sum of individual country storage inventories must sum to the aggregate European value in the Global Tradeflow Model solution.

UK - Continent Interaction: For the UK, an assumption of future storage capacity was translated into a pre-determined storage inventory monthly time series. The future monthly balance of the UK market would then determine the net inflow or outflow of gas through the Bacton - Zeebrugge Interconnector. Belgium is a relatively small market with limited storage capacity. For future periods the monthly UK and Belgium storage inventory change was pre- 
defined and excess or deficit flows were forced to flow to France and Germany where they were absorbed into their storage.

Various checks were made to ensure that all monthly flows at the country level summed to equal the value for Europe in aggregate from the Global Tradeflow Model.

The level of complexity of this modelling approach can be judged by the following dimensions:

The number of European countries:

- with demand derived from historic data and future projections: $30^{52}$.

- with historic data and future estimates for production: 20

- importing Russian pipeline gas (currently or potentially in the future): 23

- importing Norwegian pipeline gas (currently or potentially in the future): 13

- importing Algerian pipeline gas: $3^{53}$

- importing Azeri gas: 1

- importing Iranian gas: 1

- importing LNG (currently or potentially): 10

- exporting LNG: 1 (Norway)

The number of trade flows between European countries (excluding gas from Norway): 20

\subsection{Future UK Supply Scenario Rationale}

The UK market can increasingly be described as 'an island market connected to global gas supply'. At present declining UK production is supplemented by pipeline imports from Norway and the Netherlands and most recently LNG (see Figure 7). As Norwegian and Netherlands production declines post 2015, the UK's residual gas requirements will be met by a combination of:

- Higher imports of LNG from a global supply pool contested by Asia, Continental Europe and the emerging new LNG importers of South America and the Middle East.

- Pipeline gas flowing from the European Continent via the IUK and the BBL line, ultimately back-filled by Russian gas flowing into central and north-west Europe.

In the first instance this appears to be a very broad canvas on which to base views of a future UK gas supply mix, however it is justified by the following perspectives:

- The UK is an open, liberalised gas market with total import infrastructure capacity of some 150 bcma (50 bcma LNG, 100bcma pipelines) ${ }^{54}$, compared with its annual consumption, typically between 90 and 100 bcma.

\footnotetext{
${ }^{52}$ Including Serbia with an assumed flat profile of $3 \mathrm{bcma}$.

${ }^{53}$ Algeria to Slovenia flows are not specifically modelled; these are minor ( $0.38 \mathrm{bcm}$ in 2010).

${ }^{54}$ See Table 3, page 50
} 
- Apart from the uncertain potential for unconventional (including shale) gas development post 2020, there would appear to be limited prospects of other growing supply sources becoming available for the UK from within Europe.

- Global LNG supply is expected to grow and the UK market is an attractive destination for Atlantic Basin and Middle Eastern suppliers, depending on relative price offers from other markets.

- Russia currently has, and is expected to retain a production and export capacity significantly in excess of its current exports to Europe. This is especially the case when the production potential of the non-Gazprom producers is taken into account ${ }^{55}$.

The progress made to date towards a liberalised, competitive gas market in Continental Europe, whilst still to be regarded as a 'work in progress', has nevertheless given rise to changes which will influence the future supply dynamics of the UK and European market. The key changes in this regard include:

- The removal of destination clauses in long term contracts.

- Improved third party access to pipeline capacity and storage (whether existing or new facilities).

- The unbundling of transportation and marketing functions, including the sale of networks.

- The establishment of trading hubs as an alternative to less flexible oil-indexed contractual arrangements.

- The merger of nationally-focussed gas utility companies into trans-regional gas and power companies with a more pronounced shareholder and trading mind-set.

As has been clearly observed during 2010, these changes have allowed Europe to absorb significantly increased volumes of LNG, either as direct imports in the notable cases of Turkey and Italy or in the form of 'overflow' from the UK, which for most of 2010 acted as an 'LNG transit market'. Whilst exceptionally cold weather in the early and late months of 2010 allowed for an aggregate increase in European pipeline imports compared with 2009, the summer and shoulder months witnessed an LNG 'supply push' and an accompanying pipeline (especially Russian) gas retreat. The mechanics of the Russian retreat were driven by the lower contract nominations by European buyers who saw a price advantage in purchasing the cheaper hub gas, much of which was originated by UK interconnector overflow.

Such a dynamic is assumed in the approach to scenario construction, where Russian imports are the swing source of supply responding to a given level of LNG imports to balance Europe.

Stern and Rogers have argued that it is highly likely that Europe will transition away from oil-indexation in pipeline projects towards hub pricing. ${ }^{56}$ However, either through the process of arbitration-induced contract termination, or a realisation on the part of Gazprom that hubindexed contracts offer no additional value to direct hub sales, such a transition could result

\footnotetext{
${ }^{55}$ Henderson 2010, P. 239.

${ }^{56}$ See Stern \& Rogers 2011.
} 
in Europe's import requirement being partially reliant on discretionary volumes under Gazprom's direct control.

However, under these circumstances, it is not clear that the resulting supply dynamics between LNG and Russian gas would be markedly different. It is reasonable to assume that Gazprom would have little desire to defend market share, by increasing supply to Europe, at the expense of lowering hub price levels. On the other hand, withholding supply to maintain high hub prices would invite (possibly limited) LNG diversions from other markets in the short term, but encourage the development of other supplies (new Atlantic Basin LNG projects, Caspian pipeline gas or European shale gas) in the medium term; thus further eroding longer term Russian market share in Europe.

Either in the context of the current world of a hybrid hub and oil indexed market, or in a future world of discretionary Gazprom supplies to Europe, the model of Russian pipeline gas responding to the ebb and flow of European LNG supply would appear the most plausible approach to constructing European and hence UK future supply mix scenarios.

\subsection{Future Global LNG Supply and European Pipeline Imports}

The experience of the 2000s reminds us just how uncertain future projections of LNG supply can be. Figure 11 shows how industry expectations of future global LNG supply changed between 2004 and 2009 as projects slipped. The main reasons for the slippage were a) delays in reaching Final Investment Decision due to project scale and complexity and b) the limited capacity of the liquefaction contracting industry to progress numerous projects in parallel. This latter factor both delayed the commencement of individual projects and caused schedule slippage post construction start. Limited contracting capacity also resulted in significant unit cost escalation. Uncertainty on the commencement and timing of future LNG projects is a key consideration in future global natural gas supply estimation.

Figure 11. Slippage in LNG Supply Expectations 2004 - 2009 


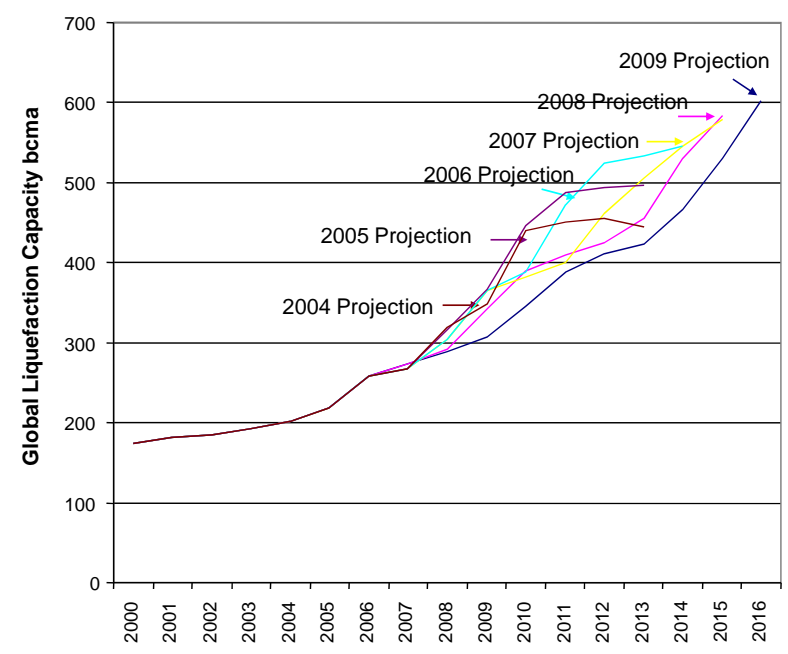

Source: Poten 2008

\section{Figure 12. Global LNG Supply Sources}
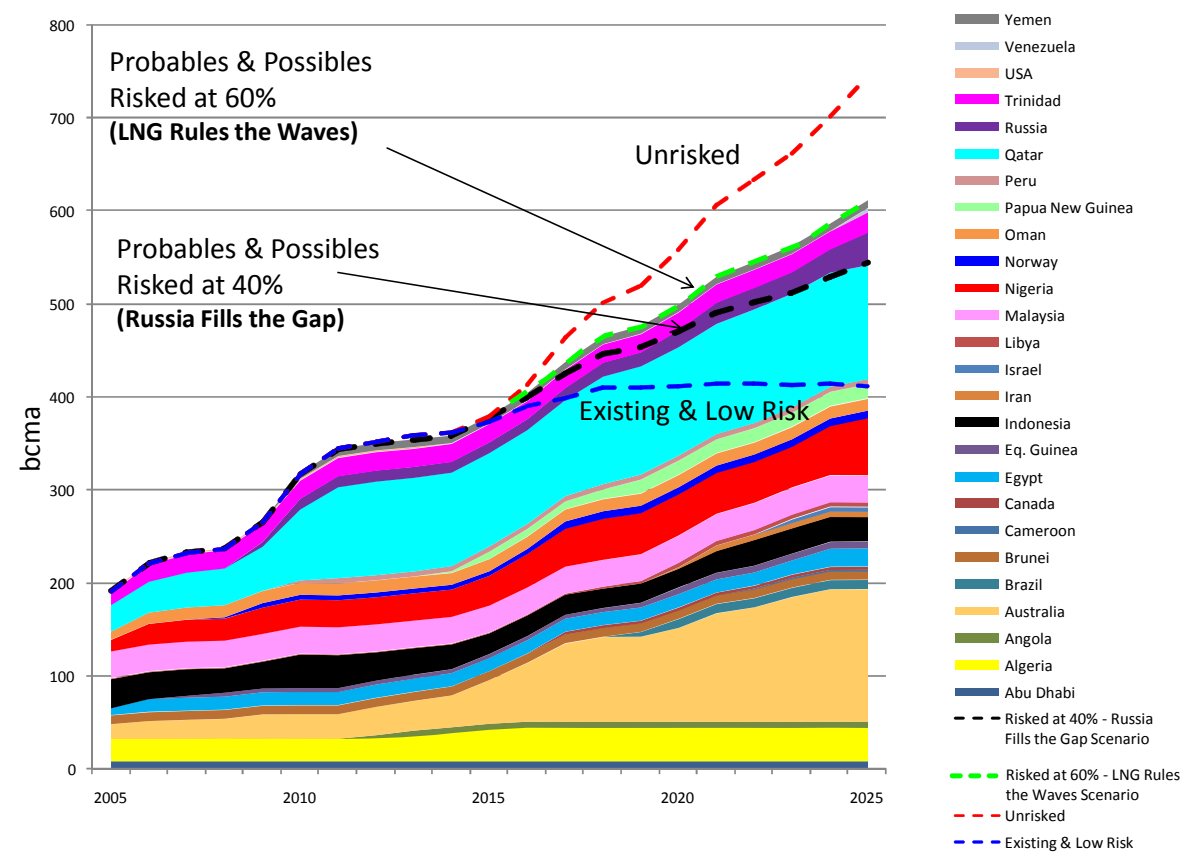

Sources: Based on methodology by D Ledesma, OIES, data from Waterborne LNG, other industry reports and own analysis. 
Two scenarios are labelled in Figure 12: 'LNG Rules the Waves', where future probable and possible LNG projects are risked at a $60 \%$ probability; and 'Russia Fills the Gap' where future probable and possible LNG projects are risked at a $40 \%$ probability. Figure 13 shows the path for European pipeline imports for the two scenarios. These include pipeline supplies from Russia, Algeria, Libya, Iran and Azerbaijan, however, by far the largest source of incremental supply change between the scenarios is likely to be from Russia.

Figure 13. European Pipeline Imports

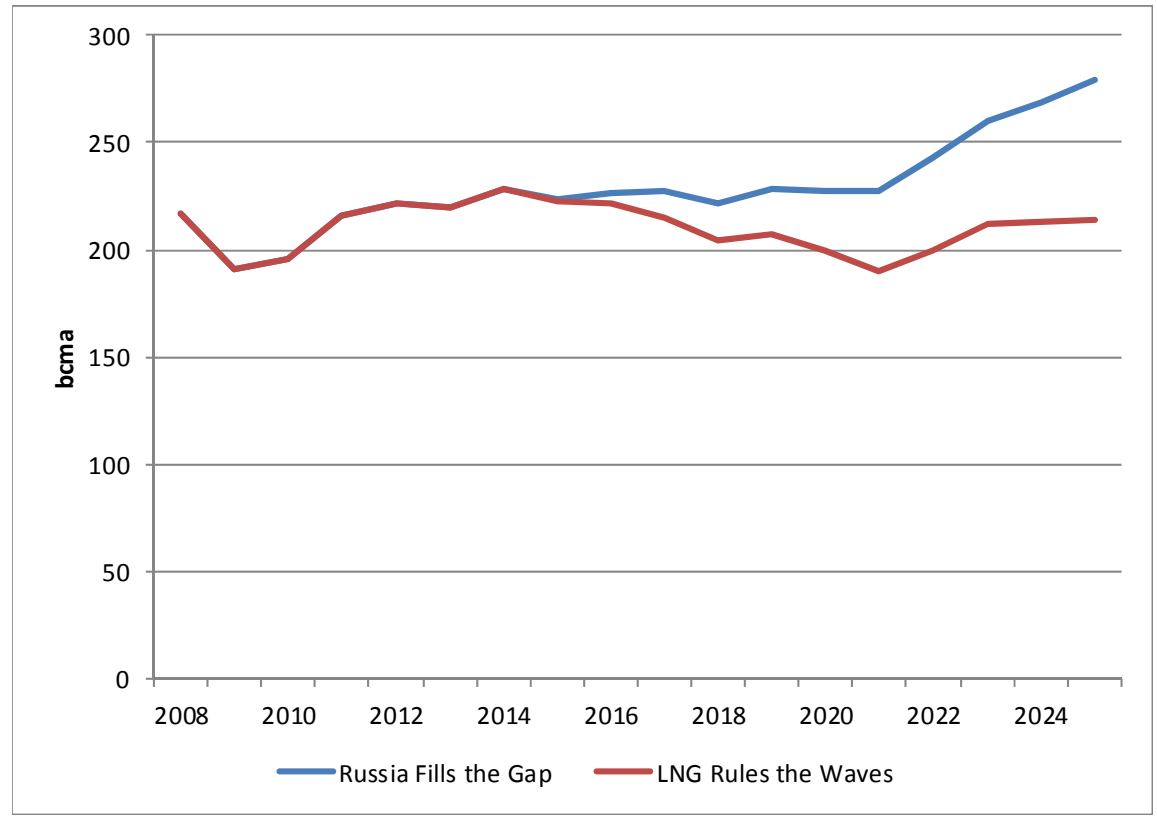

Sources: IEA Monthly Data, Cedigaz 2008, Own Analysis

\subsection{Other Major Future Uncertainties}

It must be stressed that while the scenarios derived here depict a range of 'reasonable views of the future' these should not be construed as forecasts. In addition to the uncertainty in future LNG supply specifically addressed above, the other two factors which might significantly change global natural gas fundamentals in the 2015 to 2020 period are:

- Asian LNG demand: while currently augmented by increased Japanese import requirements post-Fukushima, the first two months of 2011 showed a year-on-year increase in Asian LNG imports of $11 \%$ over the same period in 2010. This is significantly above the long run assumption in this analysis of 3.7\%. A continuation of high Asian LNG demand growth would tend to push the UK and Europe more towards a 'Russia Fills the Gap' future.

- North American LNG Exports: While informed commentators exhibit a bi-polar view on the sustainability of US shale gas growth, it appears quite possible that US LNG export projects will progress and be operational by 2015. Indicative economics suggest that such schemes are economically viable when the spread between US 
prices and those of the destination markets is at least $\$ 3.50 / \mathrm{mmbtu}^{57}$. In principle one might expect a succession of such LNG export schemes to be built until North American net internal supply reaches equilibrium with domestic demand at Asian or European natural gas prices less $\$ 3.50 / \mathrm{mmbtu}$ i.e. US gas prices would likely rise from the current mid-2011 levels of $\$ 4.50 / \mathrm{mmbtu}$.

If US shale gas production continues to show strong growth, and such growth responds vigorously to higher US prices, the future volumes of North American LNG exports could be substantial. On the other hand, if shale gas production disappoints its proponents and is not significantly boosted by rising US natural gas prices then LNG export volumes would be more modest at the point where the \$3.50 spread 'equilibrium' is achieved. The optimistic view, where significant volumes of LNG are exported, would tend to drive the UK and Europe towards an 'LNG Rules the Waves' future.

Even if much of the North American LNG exports were targeted towards Asia, they would, in effect, displace the flexible LNG (which Asia would have imported from other suppliers) towards Europe. The only caveat here is the situation where other Pacific LNG suppliers delay the implementation of future liquefaction projects in response to growing North American LNG exports.

The period 2020 to 2025 is particularly uncertain as it is possible for the following to change the supply-demand balance significantly:

- Shale gas development in Europe, China, India and elsewhere, if successful from a technology and cost base perspective, could make a significant contribution to supply.The markets would re-balance by adjusting LNG tradeflow patterns. The impact on the UK and Europe would depend on where shale gas success was highest. If this is in Asia, this would tend to drive the UK towards the LNG Rules the Waves future; if Europe, more towards the 'Russia fills the Gap' import pattern.

- New conventional gas provinces could by 2025 yield additional production for LNG export, for example East Africa and Brazil. For the UK and Europe, this would tend to drive towards the 'LNG Rules the Waves' future.

- An Asian gas demand slowdown driven by changes in macro-economic trajectory. Although this feels a remote possibility in 2011, so too did the limit on Japan's economic growth viewed from a 1980s perspective. This would tend to drive the UK towards an 'LNG Rules the Waves' future.

- Increased European gas demand as a consequence of post-Fukushima nuclear caution. The consequences of such a trend would, all other things being equal, increase the call on Russian gas imports to Europe but the overall impact on the UK in terms of supply mix is difficult to judge.

\footnotetext{
${ }^{57}$ This comprises an estimated $\$ 2.00 / \mathrm{mmbtu}$ liquefaction tolling fee, a $\$ 1.00 / \mathrm{mmbtu}$ LNG shipping cost and a $\$ 0.50 / \mathrm{mmbtu}$ regasification fee.
} 


\subsection{Future UK Storage Capacity Levels}

Figure 14. Future UK Storage Cases Assumed

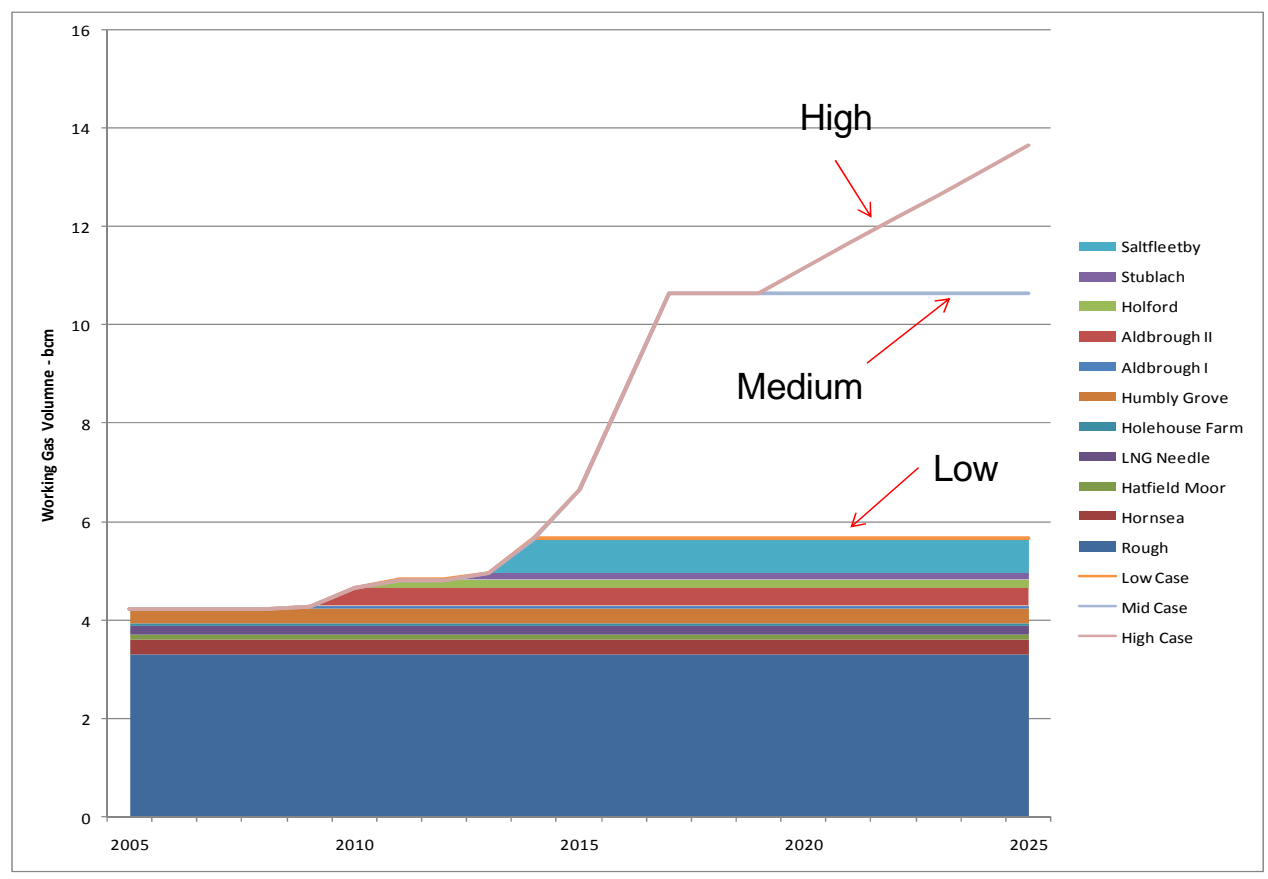

Sources: National Grid 2010a, Own Analysis

For each of the two scenarios, the impact of three levels of future UK seasonal storage was explored. Figure 14 depicts these three storage 'cases'.

The 'Low Case' includes existing UK facilities plus those storage projects which are classified as being 'under construction'. Once all these facilities are operational, the UK will have 5.7 bcm of working gas volume.

The 'Medium Case' includes the addition of a $5 \mathrm{bcm}$ facility which is assumed to be brought into operation over a three year period from 2015, taking the UK total storage to $10.7 \mathrm{bcm}$. This is a representation of the Deborah - Hewitt facility which is under consideration as a potential project.

The 'High Case' assumes a succession of hypothetical $0.5 \mathrm{bcm}$ storage facilities coming onstream every year from 2020 onwards.

\subsection{Modelling Approach for UK and Continental Europe}

The modelling approach is described by the following step-wise summary:

- The Global Tradeflow Model was run with 'LNG Rules the Waves' scenario assumptions for LNG availability and provided with sufficient Russian pipeline gas 
availability to achieve a balance. Initially for the UK the 'Low Case' storage assumption was used.

- The annual balance matrix was completed to ensure that Europe balanced at a country level and that European imports and exports were equal to those of the aggregate representation of Europe in the Global Tradeflow Model.

- The resulting UK and Continental monthly balances were derived (as described in Section 4.1) and of particular interest was the future monthly flow pattern through the Bacton - Zeebrugge Interconnector.

- The above steps were repeated for the Medium and High UK Storage Cases.

- All the above steps were repeated for the 'Russia Fills the Gap' scenario assumptions.

The key findings from this analysis are presented in the following chapter and the wider implications discussed. 


\section{Chapter 5. Results by Scenario for Different Storage Levels}

This Chapter examines the future UK supply mix on the two scenarios described in Chapter 4 and the implications of differing levels of seasonal storage on the UK market. The assumptions of future trends of the key variables incorporated into this analysis are discussed in Appendix A.

\subsection{UK and Continental Europe Annual Supply \& Demand - 'LNG Rules the Waves' Scenario.}

Figure 15 shows UK market supply and demand for the period 2005 to 2025 (with actual data for the 2005 - 2010 period). Future UK gas demand is assumed to decline to 85 bcma by 2025 due to assumed on-going energy efficiency measures deployed in the residential space heating sector (see Appendix A).

The grey bars represent UK domestic production which, after a hiatus around 2015, due mainly to the start-up of West of Shetlands production, continues its long term decline.

Figure 15. UK Annual Supply and Demand in the 'LNG Rules the Waves' Scenario, Low Storage Case

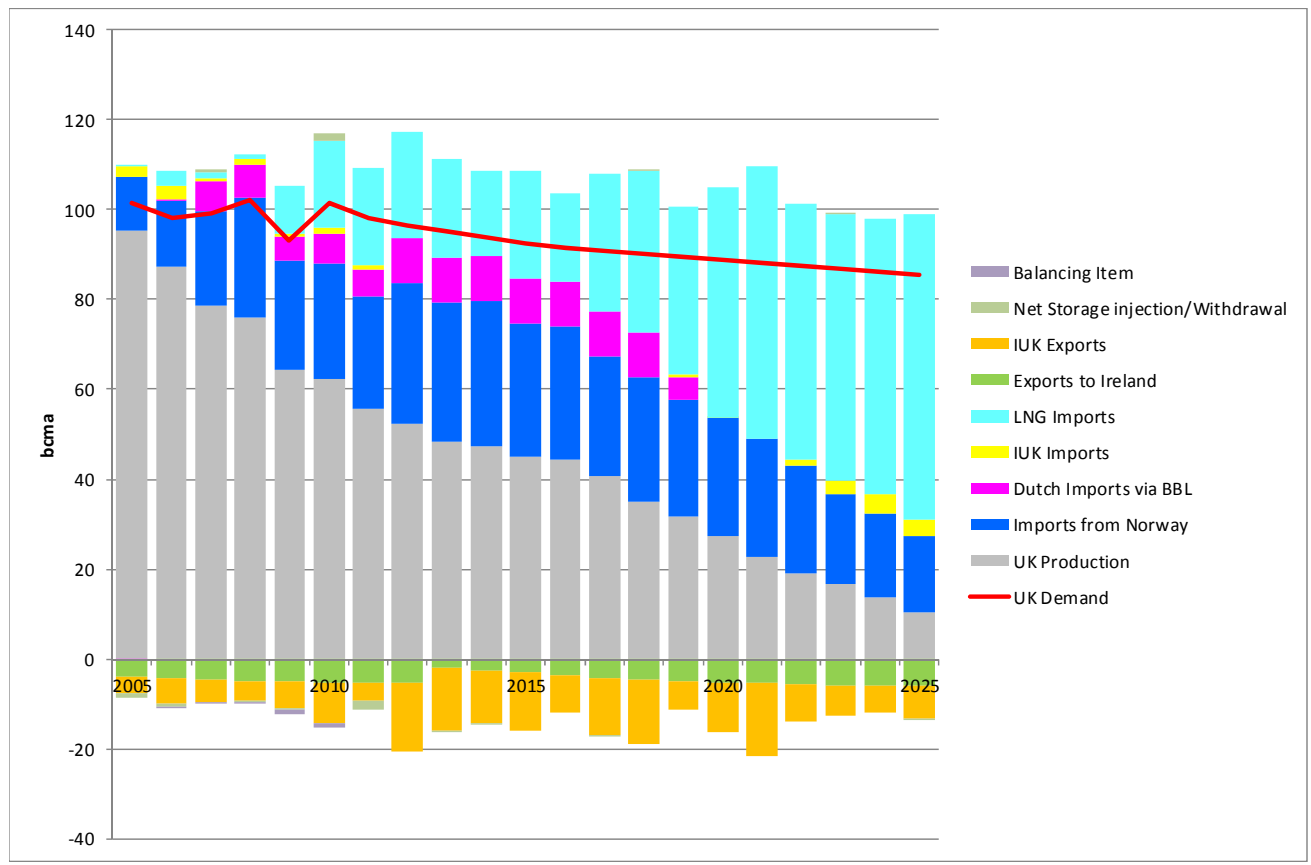

Sources: IEA Monthly Data, DECC, Waterborne LNG, Own Analysis

Norwegian pipeline imports are shown in dark blue and reach a peak of some 32 bcma in 2014, declining thereafter. Dutch pipeline imports (via the BBL line) are shown in purple. These are assumed to cease in 2019 as the Netherlands' domestic production declines. The 
yellow bars represent imports via the Bacton-Zeebrugge Interconnector (IUK). The light blue bars represent LNG imports.

Below the axis in Figure 15, the green bars represent exports to the Republic of Ireland (reduced in 2013 and beyond by the assumed start-up of the Corrib field) and the orange bars exports through the IUK to the Continent.

This projection of the UK supply and demand position is based on the Low Storage Case and depicts the UK behaving as an LNG transit market for the post 2010 period, on a net annualised basis.

Figure 16. Continental Europe Annual Supply and Demand in the 'LNG Rules the Waves' Scenario, Low Storage Case

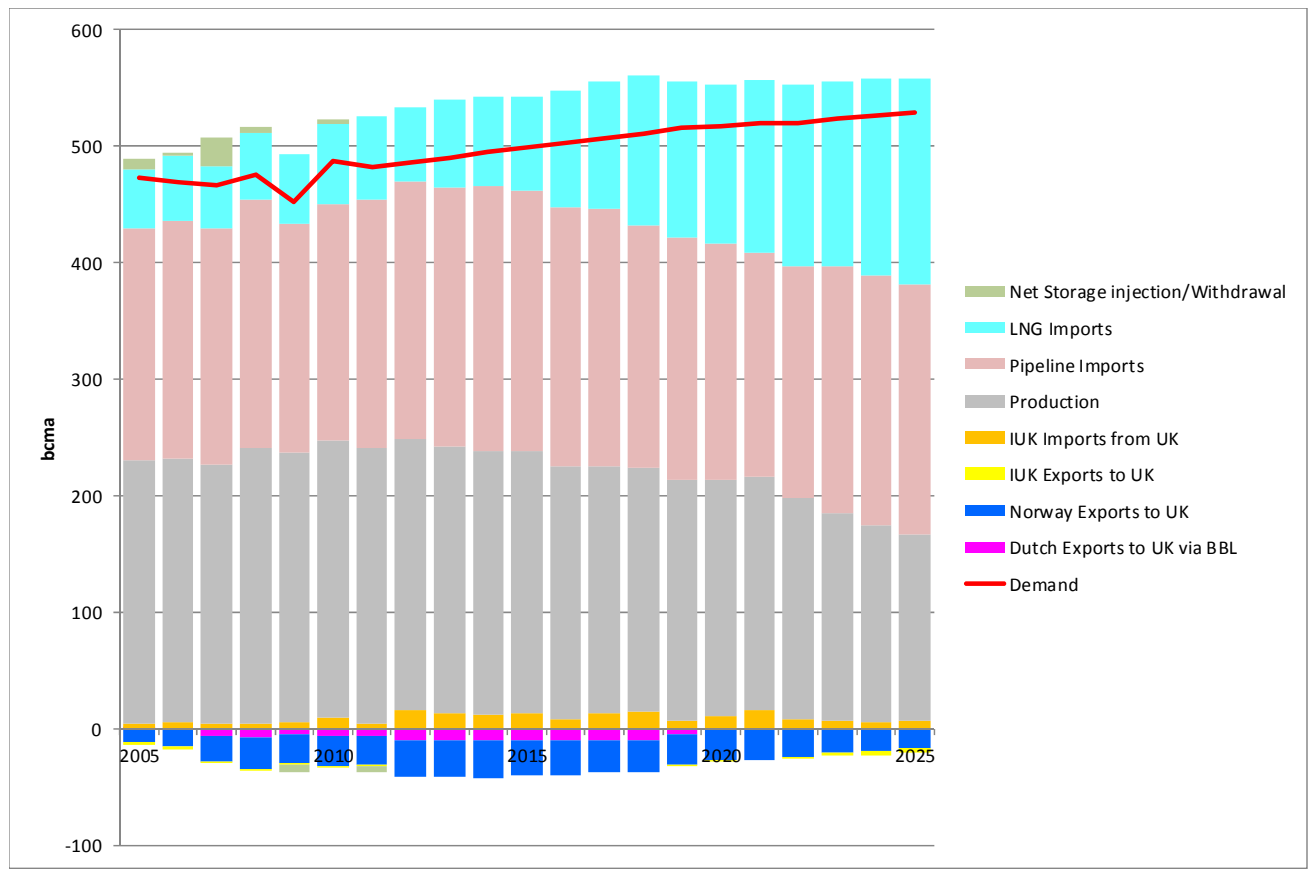

Sources: IEA Monthly Data, Waterborne LNG, Own Analysis

Figure 16 shows the corresponding annual supply and demand projection for 28 Continental European countries ${ }^{58}$ in the 'LNG Rules the Waves' scenario. The demand assumption is represented by the red line (see Appendix A for underlying assumptions).

\footnotetext{
${ }^{58}$ See the list of countries in note 51 , minus UK and Ireland
} 
Figure 17. UK Monthly Supply and Demand Balance in the 'LNG Rules the Waves' Scenario, Low Storage Case.

Sources: IEA Mor

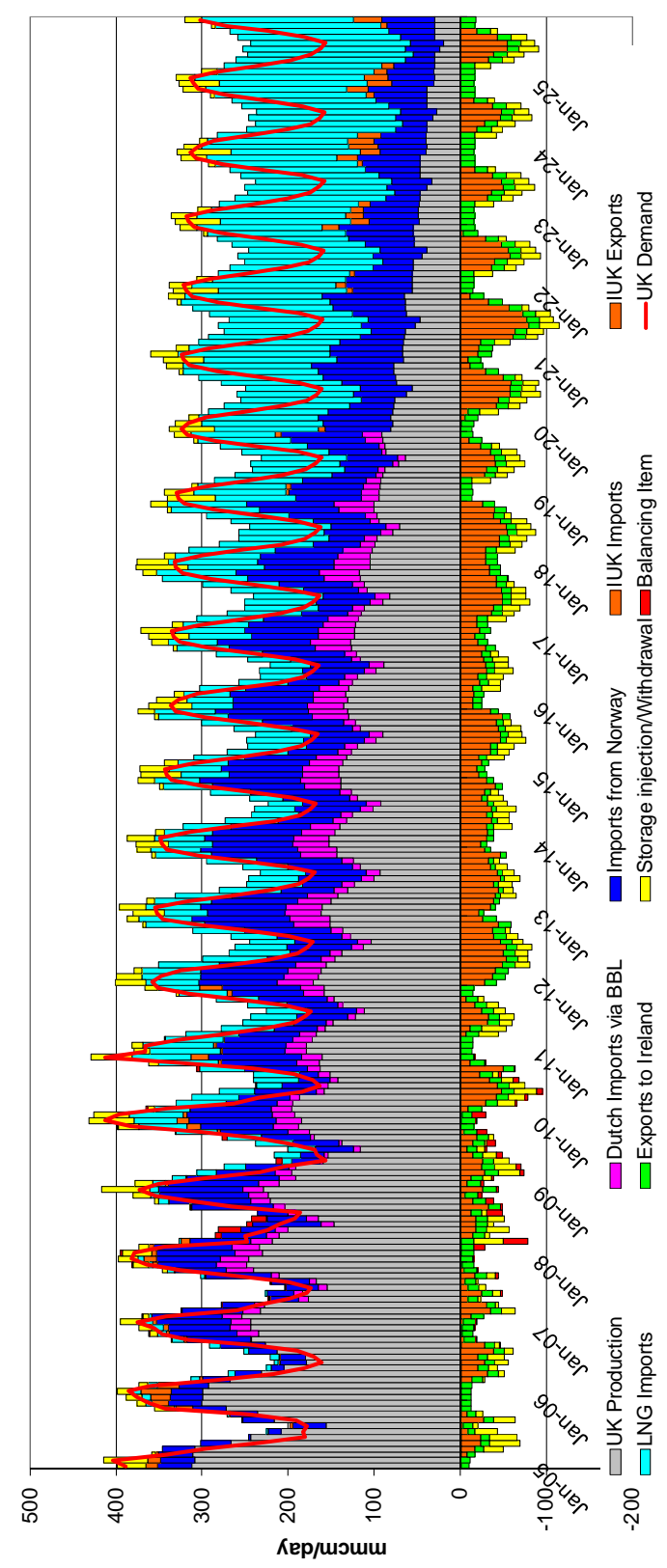


Continental indigenous production (grey) declines from 2012 onwards, pipeline imports (pink) increase in the period 2011 to 2015 in response to a small decrease in LNG imports (light blue). The drivers behind this are an assumed increase in Asian LNG imports during the 2011 to 2015 period when global LNG supply is growing at a relatively slow rate in comparison to the 2008 - 2010 period. The orange bars above the axis represent imports from the UK via the IUK. The deep blue and purple bars below the axis represent Norwegian and Dutch gas exports to the $\mathrm{UK}^{59}$.

The monthly UK supply and demand balance in the 'LNG Rules the Waves' scenario with the Low Storage Case assumptions is shown in Figure 17. Data on the graph are actual, historic values to December 2010 for all variables except LNG imports (actual until February 2011).

The trends post 2010 show:

- A continuation of significant seasonal flexibility from Norway and the Dutch import flows as the scale and seasonal variation of UK domestic production declines through time.

- The significant growth in LNG imports, especially post 2015 when Norwegian and Dutch import flows begin to decline.

- The predominance of IUK exports to the Continent for most of the period to 2022, after which winter IUK imports to the UK become a significant feature.

- The relatively low contribution of UK storage to the provision of winter supply.

Whilst this analysis paints a rich and interesting picture of one possible future UK market scenario, clearly it is desirable to derive a means by which the three storage cases can be compared.

The selected comparator was the monthly IUK export or import flows. Export flow from the UK is typically an 'overspill' of supply i.e. it represents, at the margin, surplus LNG or pipeline gas imported. Import flows represent a call on gas supplies from the Continent using the IUK as an infrastructure link to Continental storage inventories.

Figure 18 shows monthly IUK flows for the period 2005 to 2025. Data up to December 2010 are actual figures from the IUK website ${ }^{60}$; future values are the results of modelling, as described above.

The Low Case UK storage plot (deep red line) shows significant summer - winter seasonal variation; a result of the use of Continental storage to provide the required seasonal flexibility for the UK market. The Medium Case (in which an additional $5 \mathrm{bcm}$ of storage is added from 2014 to 2016) is the orange plot and shows significantly less seasonal variation, at least until around 2022, indicating that up to this time the UK does not rely on Continental storage and

\footnotetext{
${ }^{59}$ Note that post 2015, Dutch gas, if it flows to the UK is assumed to be part of the yellow stream which in that time period is assumed to be an aggregate of IUK and BBL flows.

${ }^{60}$ IUK, Interconnector UK website: http://www.interconnector.com/onlineservices/historicflows.htm
} 
the IUK for seasonal flexibility. Beyond 2022 a seasonal pattern begins to emerge, although noticeably less pronounced than in the Low Storage Case.

Figure 18. IUK Flows for Three Storage Cases in the 'LNG Rules the Waves' Scenario

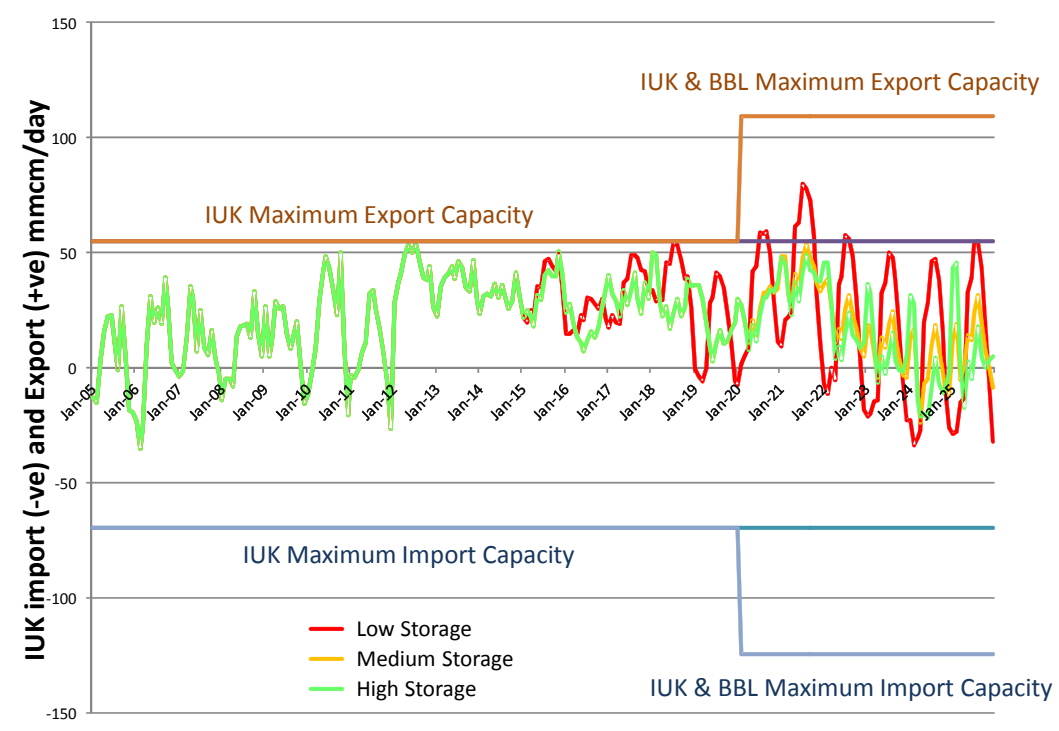

Sources: IUK Monthly Data, Own Analysis

The High Storage Case (green line) diverges from the Medium Case in the early 2020s as the additional $0.5 \mathrm{bcm}$ of storage volume is added annually. From 2023 we observe the growth of IUK exports to the Continent during the winter season. This is a direct consequence of the modelling approach which 'forces' UK storage capacity to be used. This has the effect of pushing excess winter supply through the IUK to the Continent. This could be viewed as indicating that the High Storage Case in the 'LNG Rules the Waves' scenario is one where the UK has an excess of storage capacity, which in reality might not be fully utilised on a commercial basis, but would nevertheless be vital in the event of a supply security event.

\subsection{UK and Continental Europe Annual Supply \& Demand - 'Russia Fills the Gap' Scenario.}

Figure 19 shows UK market supply and demand for the period 2005 to 2025 for the 'Russia Fills the Gap'which represents the other end of a band of uncertainty on future global LNG supply when compared to the 'LNG Rules the Waves' scenario. This projection of the UK supply and demand position is based on the Low Storage Case.

The significant difference here is the relative size, post 2015, of LNG imports in light blue (smaller), and IUK imports in yellow (larger). 
Figure 19. UK Annual Supply and Demand in the 'Russia Fills the Gap' Scenario, Low Storage Case

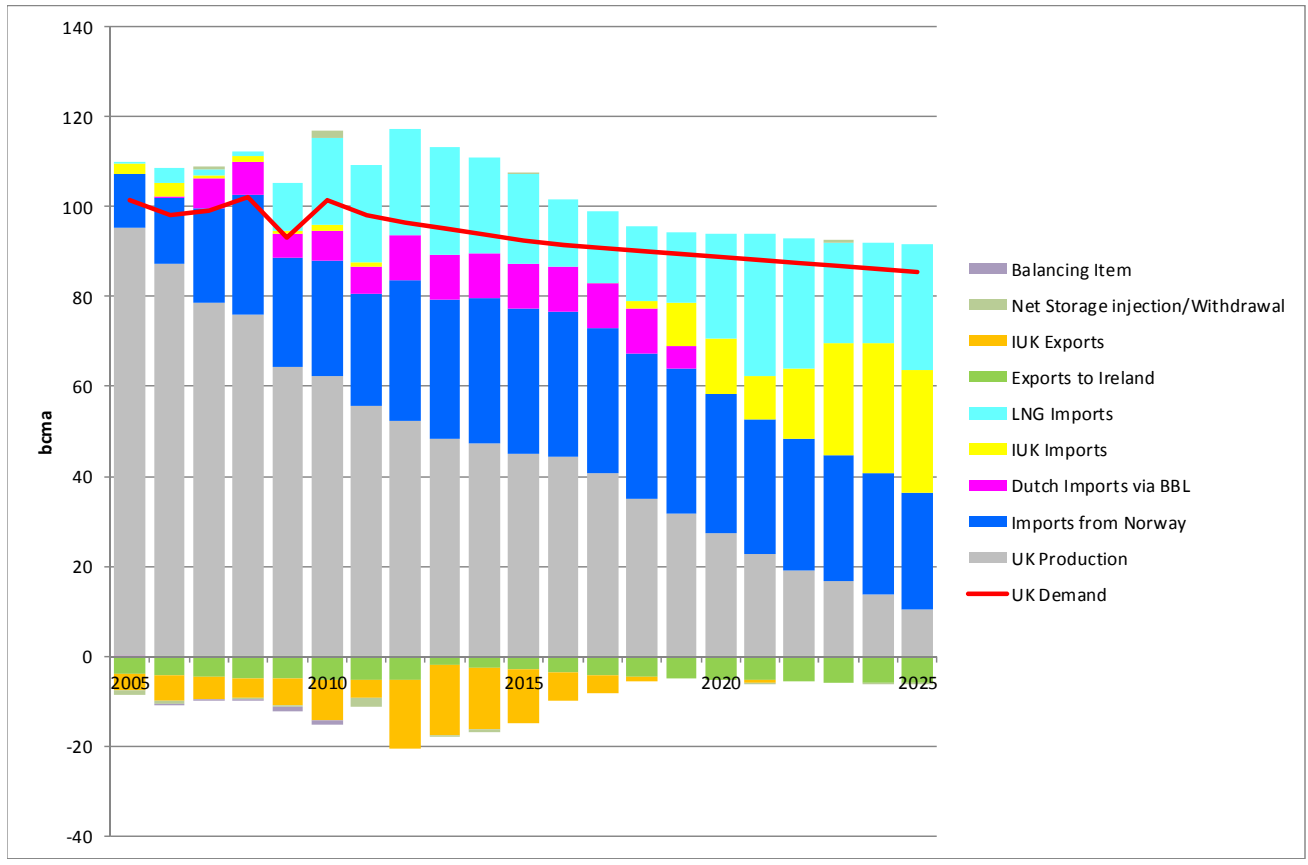

Sources: IEA Monthly Data, DECC, Waterborne LNG, Own Analysis

Beyond 2017 the UK no longer acts as an LNG transit market as it relies more heavily on imports from the Continent to meet its demand requirements. Again, although IUK import volumes are shown separately from the Dutch BBL line, for the purpose of this analysis it has been assumed that post 2020 such imports, which are not tagged to a specific national Continental European source, are able to flow through either the BBL line or the IUK. 
Figure 20. Continental Europe Annual Supply and Demand in the 'Russia Fills the Gap’ Scenario, Low Storage Case

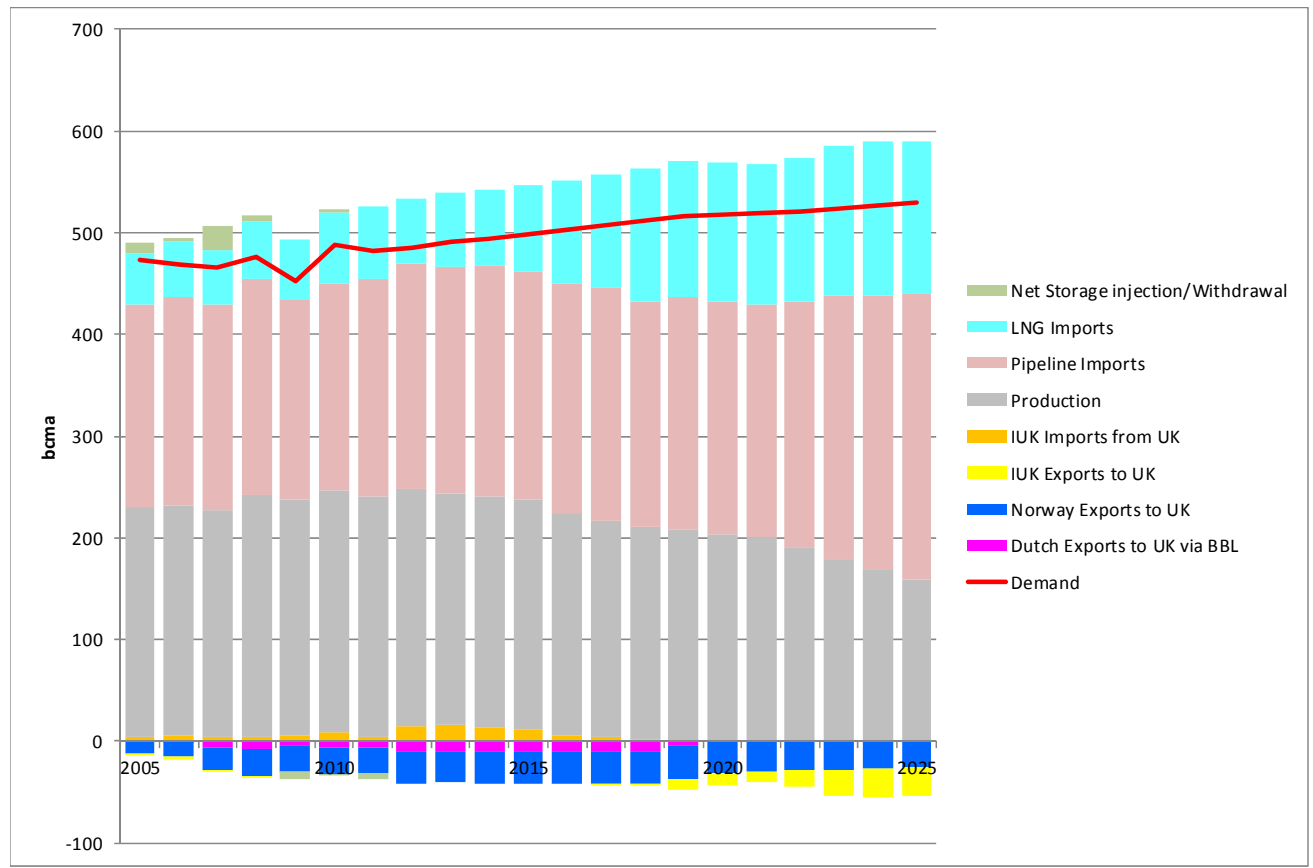

Sources: IEA Monthly Data, Waterborne LNG, Own Analysis

Figure 20 shows the corresponding annual supply and demand projection for Continental Europe in the 'Russia Fills the Gap' scenario/Low UK Storage Case. Compared with the 'LNG Rules the Waves' scenario, LNG imports post 2015 are lower and, to meet the same assumed trend of future Continental European Demand, pipeline imports are higher. The yellow bars representing IUK exports to the UK are noticeably higher towards the end of the period.

The monthly UK supply and demand balance in the 'Russia Fills the Gap' scenario with the Low Storage Case assumptions is shown in Figure 21. Data on the graph are actual, historic values to December 2010 for all variables except LNG imports (actual until February 2011). 
Figure 21. UK Monthly Supply and Demand Balance in the 'Russia Fills the Gap' Scenario, Low Storage Case.

Sources: IEA Monthi

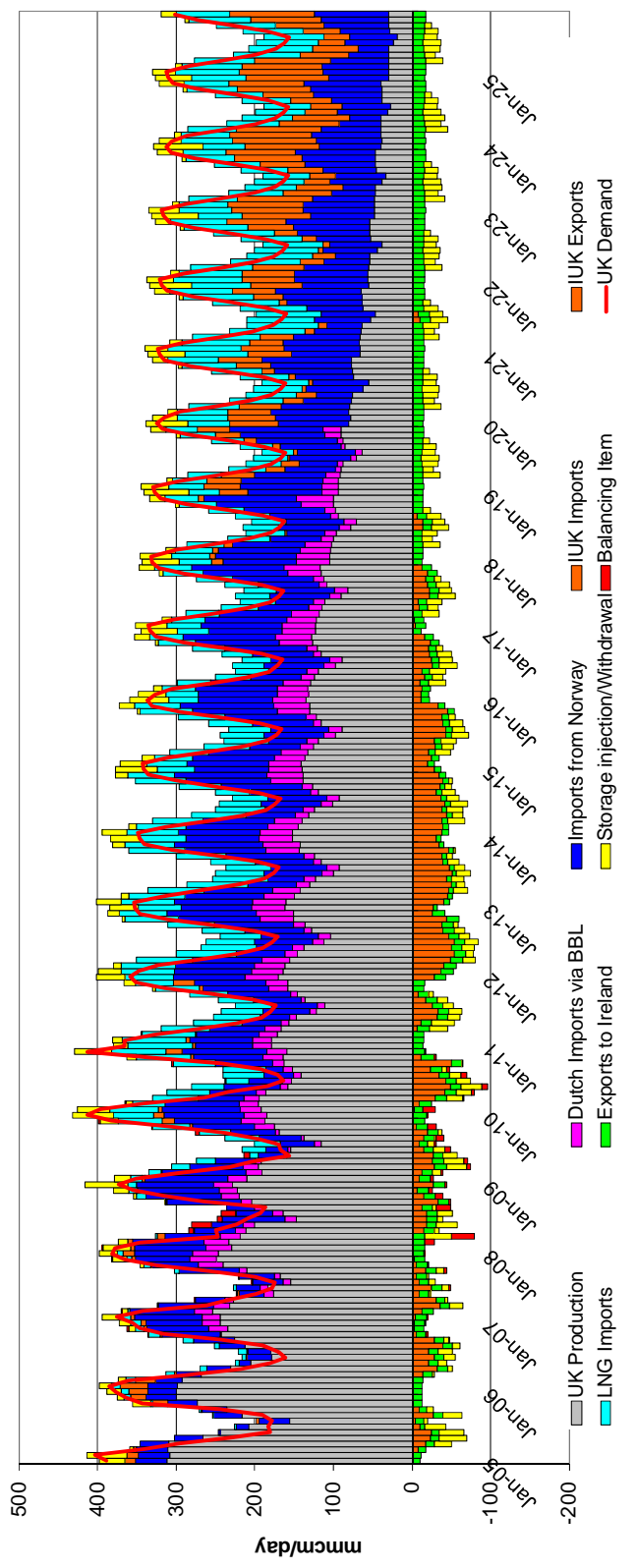


The trends post 2010 show:

- A continuation of significant seasonal flexibility from Norway and Netherlands import flows as the scale and seasonal variation of UK domestic production declines through time.

- The muted and uneven growth in LNG imports.

- The predominance of IUK imports from the Continent for the period to 2018to 2025.

- The relatively low contribution of UK storage to the provision of winter supply.

Figure 22 shows monthly IUK flows for the period 2005 to 2025. Data up to December 2010 are actual figures from the IUK website ${ }^{61}$; future values are the results of modelling, as described above.

Figure 22. IUK Flows for Three Storage Cases in the Russia Fills the Gap Scenario

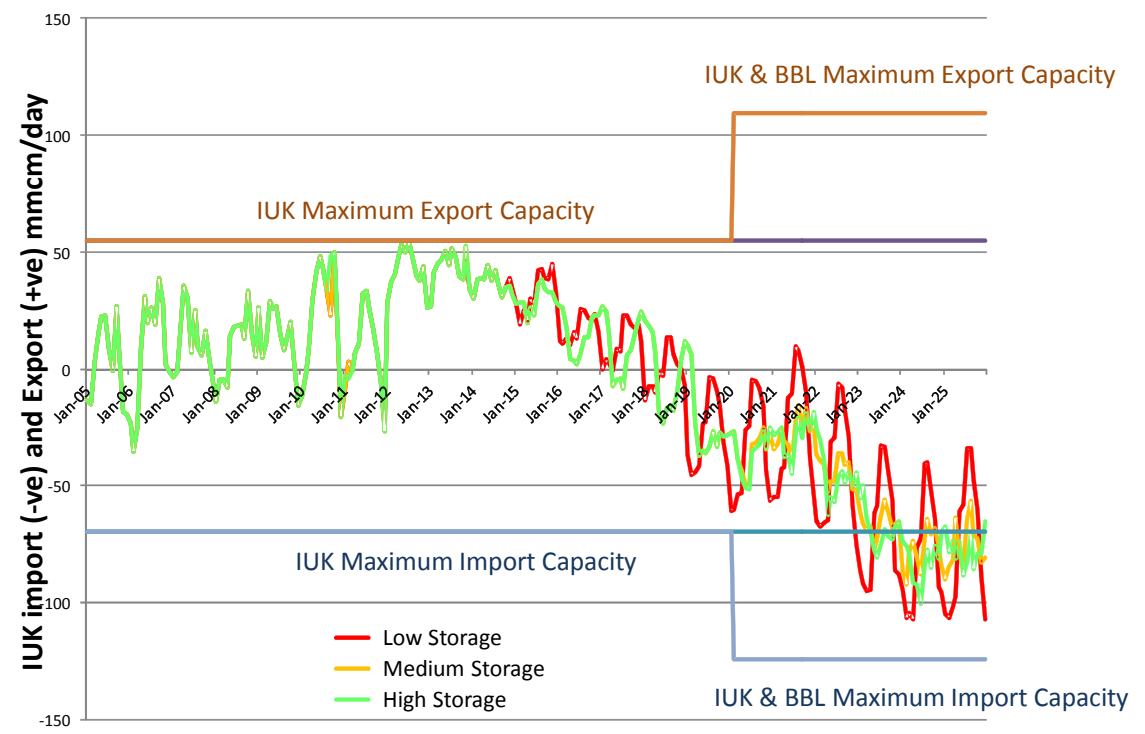

\section{Sources: IUK Monthly Data, Own Analysis}

The Low Case UK storage plot (deep red line) shows significant summer - winter seasonal variation; a result of the use of Continental storage to provide the required seasonal flexibility for the UK market. The Medium Case (in which an additional $5 \mathrm{bcm}$ of storage is added from 2014 to 2016) is the orange plot and shows significantly less seasonal variation, at least until around 2022, indicating that up to this time the UK is not required to rely on Continental storage and the IUK for seasonal flexibility. The High Storage Case (green line) diverges

${ }^{61}$ http://www.interconnector.com/onlineservices/historicflows.htm 
from the Medium Case in the early 2020s as the additional $0.5 \mathrm{bcm}$ of storage volume is added annually.

It should be noted that this scenario, which for the UK is essentially one of continued import growth from the Continent, could eventually (post 2025) require additional import capacity to be built compared with that shown on Figure 21. This is especially the case for the Low Storage Case, due to its greater seasonal fluctuations.

Before discussing the wider implications of the modelled future IUK flow profiles, it should be noted that these are predicated on a continuation of winter-biased Norwegian imports (as shown in Figures 17 and 21). For the two scenarios, the historic and future UK imports of pipeline gas from Norway are shown Figure $23^{62}$. The derivation of future Norwegian production levels is described in Appendix A. The future profile of flows to the UK is based upon the average monthly pattern over the past five years. The Norwegian Troll field provides much of Norway's export flexibility and the WoodMackenzie forecast confirms the longevity of this field's production level. If however Norway's ability to provide seasonal supply flexibility to the UK is in future impaired or diminished this will require the UK to secure this from other sources, most obviously additional new storage build and/or increased use of IUK seasonal flows.

Figure 23. Historic and Future UK Monthly Imports of Pipeline Gas from Norway

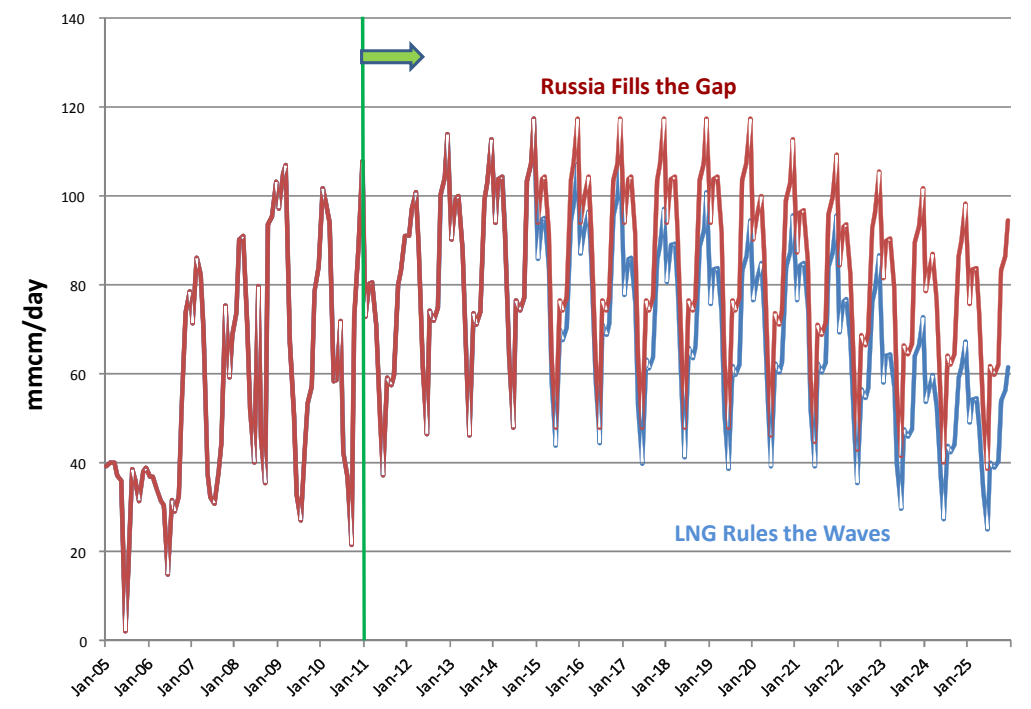

Sources: DECC, own analysis based on Norwegian Ministry of Petroleum, Wood Mackenzie.

\footnotetext{
${ }^{62}$ Note that the difference in flows to the UK from Norway between these two scenarios is offset by a change in the assumed flow of Norwegian gas to Germany. This is reflected in the annual and monthly European model balance.
} 


\subsection{Review of Scenario Results.}

Figure 24 shows IUK monthly flows for both scenarios and for each storage case.

\section{Figure 24. IUK Flows for Both Scenarios by Storage Case}

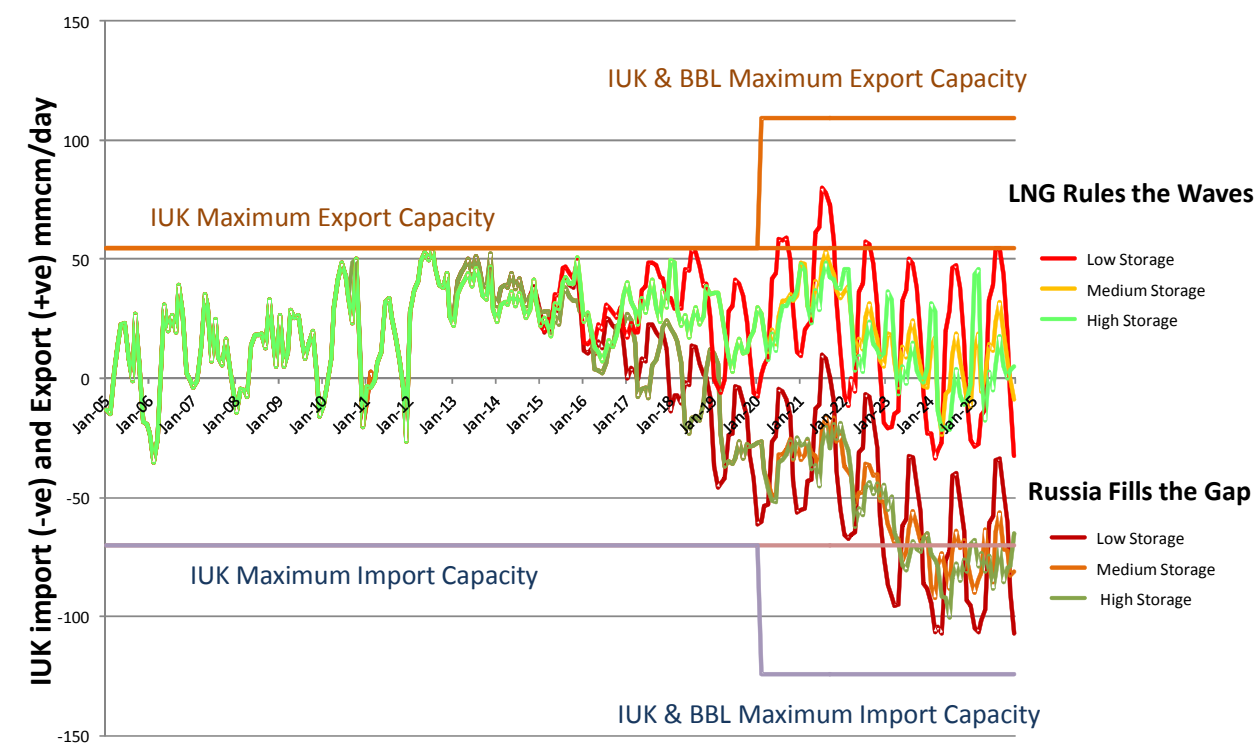

\section{Sources: IUK, Own Analysis}

The red plots represent the low storage case in each scenario, and show the range in flows over the spectrum whose end points are represented by the two scenarios. These lines represent cases where the IUK connects the UK to storage capacity in Continental North West Europe which is assumed to operate to service the required seasonal flexibility. As we move to the orange/brown lines (mid storage case) and through to the green lines (high storage case), the seasonal amplitude is dampened, as would be expected by the additional seasonal flexibility provided by UK storage.

The case for building additional seasonal storage in the UK (i.e. over and above the Low Case) is explored by answering the following questions:

- If no additional storage is built, what would the UK rely upon to achieve a 'balanced market' with no extreme price excursions and accompanying volatility?

- What does the futures market expect future seasonal price differentials to be, and how does that compare with the commercial viability of future storage facilities?

- What is a credible high-impact supply security event and what would be the consequences for the UK market? 


\section{If no additional storage is built, what would the UK rely upon to achieved a 'balanced market' with no extreme price excursions and accompanying volatility?}

In physical terms the UK would rely on its domestic production, Norwegian imports, LNG and on the ability of the IUK and BBL lines to operate without technical problems. The UK would also rely on there being sufficient seasonal storage in North West Continental Europe to serve the UK market as well as Continental needs. In terms of market dynamics, the UK would also rely on the preservation of a liquid traded gas market in North West Continental Europe such that midstream market participants with storage capacity would respond to price signals by changing their storage inventory.

In terms of reliability of supply and import infrastructure the following incidents are noted:

- The Bacton-Zeebrugge Interconnector. As already referred to in Chapter 3, in the period 2000 to 2011 flows were stopped for a 34 day period between $2^{\text {nd }}$ July 2002 and $5^{\text {th }}$ August 2002 due to liquids carryover and again for an 8 day period between $15^{\text {th }}$ August 2002 and $23^{\text {rd }}$ August 2002. Throughput was also severely restricted for a 14 day period in 2003 due to water ingress.

- The Rough Storage facility was shut down for over 3 months in 2006 due to a fire.

- The CATS pipeline was shut down for 64 days in 2007 due to accidental damage caused by a ship's anchor.

- The Shell Bacton sub-terminal was out of action for 4 days from February $28^{\text {th }}$ until March $3^{\text {rd }} 2008$ due to a fire.

- The BBL Line experienced problems with a spare compressor on February $9^{\text {th }} 2009$, although this did not affect flowrates ${ }^{63}$.

- The Langeled pipeline from Norway has experienced a number of flow variations relating to unplanned shutdowns and incidents at the related Kollnes gas processing plant. A cursory review of media coverage revealed 5 such short-duration shutdowns over the period May 2010 to February 2011 due to power supply failure, gas leaks and condensate leaks.

- LNG Supply: Following unplanned trips on some of the large new Qatari trains in March 2010 an intensive maintenance programme was instigated in June - August 2010 to rectify the problem. This resulted in lower than expected supplies of LNG to the UK for a brief period (estimated to be $0.4 \mathrm{bcm}$ due to the March 2010 trips and 1.3 bcm during the subsequent maintenance period). ${ }^{64}$

In the main these have been events which the UK market has coped with through temporary increased flows from other supply sources and through recourse to existing storage capacity. The most significant event was the IUK shutdown in 2002, however its timing in the middle of summer, did not give rise to a supply shortage.

\footnotetext{
${ }^{63}$ 'Technical problem at Noord-Holland compressor station: flow continues', BBL News Archive, February $9^{\text {th }}$ 2009, http://info.bblcompany.com/

${ }^{64}$ Based on data from The European Waterborne LNG Report, $17^{\text {th }}$ March 2011, P. 29.
} 
The North West European market is undergoing a period of growth in the development of gas trading hubs. Although these lack the depth of the UK NBP it is noticeable that month ahead prices are closely converged on NBP. This is illustrated in Figure 25.

Figure 25. Month Ahead Prices for NBP, NCG, TTF and Zeebrugge, January 2010 January 2011 (Euros/MWh)

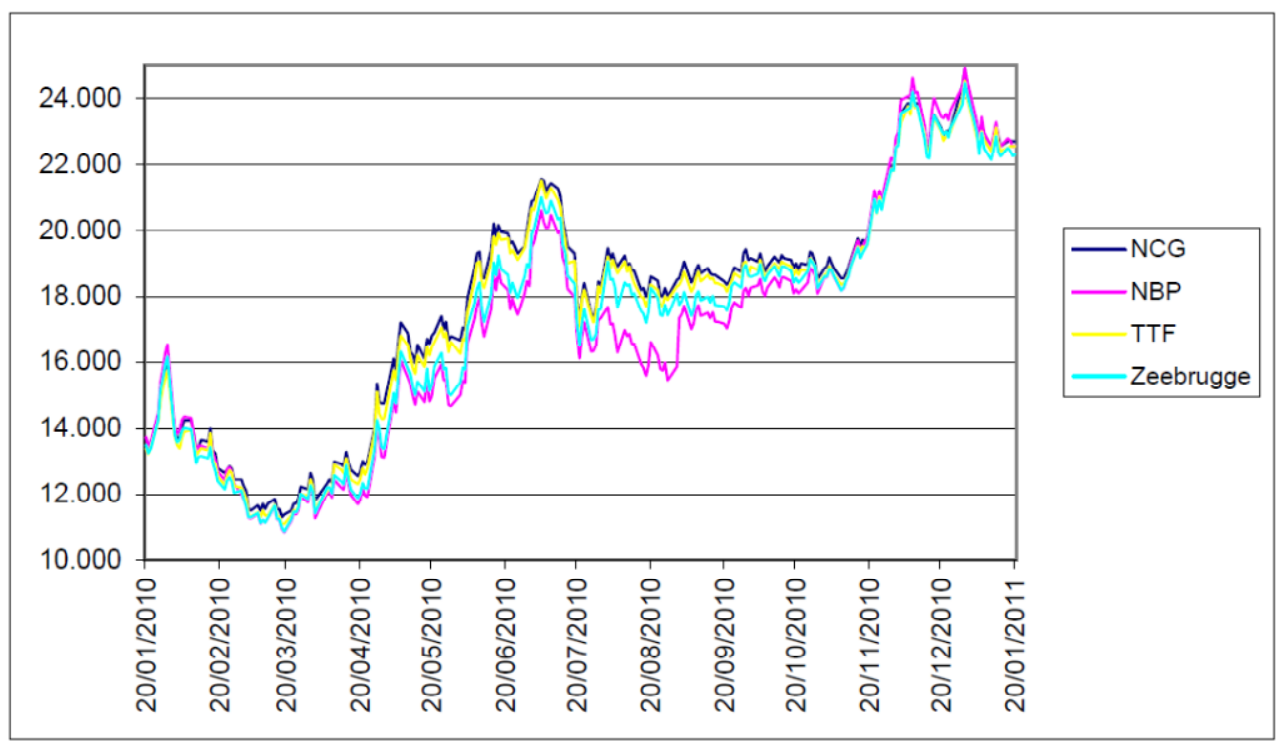

Source: ICIS-Heren, Figure 8, P. 32.

A discussion of the status of the various European gas trading hubs can be found in Stern and Rogers $2011 .^{65}$

Continental Europe appears to be undergoing a period of rapid storage expansion with some $26.7 \mathrm{bcm}$ of working gas capacity under construction, according to Gas Storage Europe ${ }^{66}$ but also including the $4.1 \mathrm{bcm}$ Bergermeer project which gained approval in May 2011. Figure 26 shows the growth in Continental storage capacity from 2008 to some $80 \mathrm{bcm}$ by 2010 . Facilities under construction will take this total to some 104 bcm by 2015 .

\footnotetext{
${ }^{65}$ Stern and Rogers 2011, pp. 11-17, see also Heather, OIES,(forthcoming 2011). ${ }^{66}$ GSE 2010
} 
Figure 26. Existing and Under Construction Storage Capacity in Continental Europe

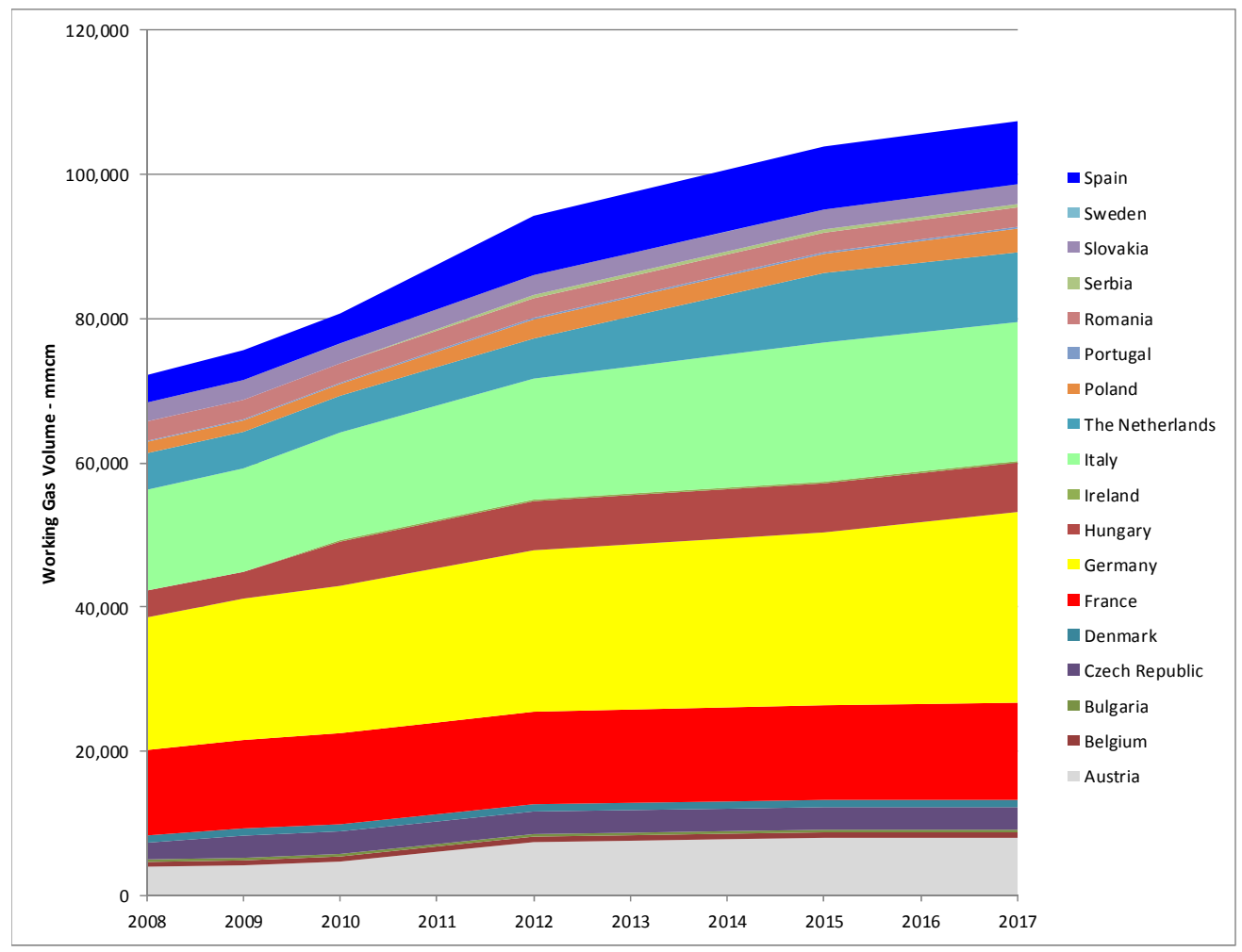

Source: Gas Storage Europe based on successive versions of the storage database at http://www.gie.eu.com/maps_data/storage.html

Table 1. Gas Storage Under Construction by Location and Type 2010

mmcm Working Gas Volume

\begin{tabular}{|c|c|c|c|c|c|}
\hline & Depleted Gas Field & Aquifer & Salt Cavern & LNG Peak Shaver & Total \\
\hline SW Europe & 2,080 & 1,350 & 60 & 1,176 & 4,666 \\
\hline S \& E Europe & 6,504 & - & 680 & - & 7,184 \\
\hline NW Europe & 7,834 & 600 & 6,387 & - & 14,821 \\
\hline Total & 16,418 & 1,950 & 7,127 & 1,176 & 26,671 \\
\hline \multicolumn{6}{|l|}{ NW Europe: } \\
\hline Austria & 3,295 & - & - & - & 3,295 \\
\hline Belgium & - & 50 & - & - & 50 \\
\hline Denmark & - & 30 & - & - & 30 \\
\hline France & 80 & 520 & 240 & - & 840 \\
\hline Germany & 359 & - & 5,667 & - & 6,026 \\
\hline Netherlands & 4,100 & - & 480 & - & 4,580 \\
\hline Total N W Europe & 7,834 & 600 & 6,387 & - & 14,821 \\
\hline
\end{tabular}

Source: GSE 2010

Table 1 shows the geographic distribution of new storage facilities in Continental Europe by storage type, (including the Bergermeer (depleted field) facility). Of the $26.7 \mathrm{bcm}$ of storage 
under construction in Continental Europe, some $14.8 \mathrm{bcm}$ is in NW Europe. To place the figure of $104 \mathrm{bcm}$ of Continental Storage by 2015 in context, in a normal gas year,

Continental Europe uses only 35 to $45 \mathrm{bcm}$ of working gas volume (see Appendix A). Some $6.4 \mathrm{bcm}$ of the NW Europe new storage capacity is in salt cavern facilities which can respond relatively quickly in terms of injection and withdrawal.

In answer to this first question therefore, in a future where the UK builds no additional storage it would be reliant on physical connectivity to expanded Continental storage capacity and a liquid trading market in North West Europe. Conditions which are favourable to this modus operandi appear to be developing.

What does the futures market expect future seasonal price differentials to be, and how does that compare with the economics of future storage facilities?

Although forward curves in the traded NBP market have rarely been a reliable indicator of actual outcomes, they do reflect the prevailing view of market participants. Figure 27 shows the NBP forward curve on $6^{\text {th }}$ July 2011.

Figure 27. UK Gas Price Forward Curve on 6 $^{\text {th }}$ July 2011

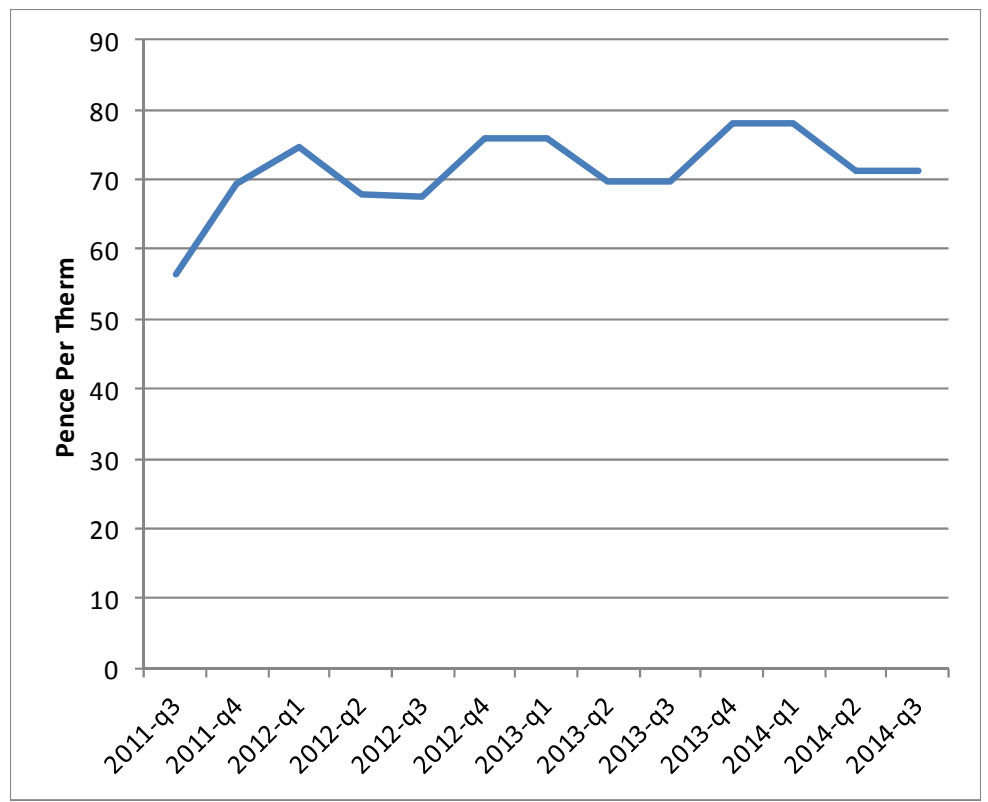

Source: Platts European Gas Daily, July $6^{\text {th }}$ 2011, P. 2.

The summer - winter price differential in 2012/13 and 2013/14 is around 8 pence per therm.

Escobar and Artega ${ }^{67}$ studied the economics of a new build offshore UK depleted field storage facility with a working gas capacity of $3.3 \mathrm{bcm}$. Capital costs were estimated at $£ 804$ million and the cost of cushion gas at $£ 1,040$ million. To achieve a $10 \%$ rate of return

${ }^{67}$ Escobar and Artega 2011 
(nominal) a summer - winter price differential of 24 pence per therm (approximately $\$ 3.8 / \mathrm{mmbtu}$ ) was required. As we have just seen, in July 2011 the forward curve for UK gas prices did not foresee seasonal price differentials of the magnitude required to support investment in new offshore depleted field reservoirs on these assumptions.

Little in the way of current data on UK storage project economics exists in the public domain, however Oxera ${ }^{68}$ presented the following analysis for offshore seasonal, offshore mid-range and onshore short range (salt cavern) facilities in 2010.

Table 2.UK Gas Storage Economics Under Different Market Scenarios

\begin{tabular}{lrrrr} 
& Business as usual & $\begin{array}{r}\text { Low volatility, } \\
\text { low spread }\end{array}$ & $\begin{array}{r}\text { High volatility, } \\
\text { low spread }\end{array}$ & $\begin{array}{r}\text { Low volatility, } \\
\text { high spread }\end{array}$ \\
\hline Post-tax net present value $(\mathbf{E m})$ & & & -0.8 & 327.3 \\
\hline Offshore seasonal & 78.0 & -407.0 & 224.4 & 310.2 \\
\hline Offshore mid-range & 213.2 & -93.6 & 130.4 & 74.4 \\
\hline Onshore short-range & 80.5 & -44.0 & & 10.0 \\
\hline Post-tax internal rate of return (\%) & & 6.6 & 13.8 & 12.4 \\
\hline Offshore seasonal & 10.6 & 8.3 & 16.4 & 15.2 \\
\hline Offshore mid-range & 13.7 & 7.6 & & 13.7 \\
\hline Onshore short-range & 14.0 & & & \\
\hline
\end{tabular}

Source: Oxera 2010

Data from the same source ${ }^{69}$ provided more information on specific assumptions. The 'Business as Usual' cases assumed a seasonal spread of 21 pence per therm (approximately $\$ 3.3 / \mathrm{mmbtu}$ ). The $10.6 \%$ rate of return for the offshore seasonal storage project is very comparable to the Escobar and Artega result described above. The economics of the offshore mid-range and onshore short range (salt cavern storage) projects are more attractive at $13.7 \%$ and $14.0 \%$ rates of return respectively. The low spread case assumed a 10.5 pence per therm seasonal differential (similar to that shown in Figure 27) and the high case assumed a differential of 30 pence per therm. Volatility levels were expressed as \% daily volatility and were $100 \%, 150 \%$ and $200 \%$ for the low, business as usual and high volatility cases respectively. While insufficient data is presented here to interpolate with a high degree of confidence, we conclude that:

- Onshore salt cavern storage schemes have more robust economics compared with offshore seasonal projects.

- All projects benefit from higher levels of daily price volatility.

- At a seasonal spread level of 10 pence per therm all projects require daily price volatility above $100 \%$ in order to be economically attractive.

In more general terms however, we can say that the seasonal spread of the forward curve current in the $1^{\text {st }}$ half of 2011 (shown in Figure 27) would not justify a commercial decision

\footnotetext{
${ }^{68}$ Oxera 2010

${ }^{69}$ Oxera 2010
} 
to build seasonal storage facilities at low price volatility levels. This is not to say however, that potential investors in storage schemes will necessarily base their investment case on current market conditions.

\section{What is a credible high-impact supply security event and what would be the consequence for the UK market?}

The most obvious high-impact supply security event to consider would be the loss of the IUK in a 'Russia Fills the Gap' scenario during the winter season towards the end of the current decade. For simplicity it is assumed that the shutdown of the IUK was for one month (i.e. similar to the 2002 event). The sequence of response would likely be as follows:

- UK prompt and near term curve prices rise in response to the loss of winter supply.

- The UK begins to withdraw gas from its own storage.

- With the IUK line down, the BBL line would takeover the role of key Continental Europe exporter to the UK market. Although its capacity is not as large as that of the IUK (19.2 bcma versus 25.5) it could certainly make good a significant portion of the lost supply. It is likely however that some time would elapse before this switch-over could be completed e.g. arranging capacity in continental pipeline systems.

- In response to UK prices Norwegian supply could be diverted away from the continent towards the UK via the Langeled and Vesterled pipelines, subject to spare pipeline capacity being available.

- LNG cargoes would be re-directed from Belgium and the Netherlands (and elsewhere) in response to the price signal.

What is critical here is to judge what the response times of the supply re-direction would be and to balance that against the adequacy of existing UK storage capacity to cope with the intervening short situation. To provide a broad estimate of the volumetrics at stake here, one full month of IUK import flows, at full capacity, amounts to some $2.1 \mathrm{bcm}$ of gas.

A second more prolonged event to consider could be one outside of the spectrum defined by the 'LNG Rules the Waves' and the 'Russia Fills the Gap' scenarios. Such a situation can be described as follows:

Due to sustained and rapid demand growth for LNG in Asia the global market has become 'tight'. Oil indexed contracts have been superseded by hub-based pricing in North West Europe. Russia has decided to maximise price at the expense of volume and is constraining supply to Europe accordingly. Competition for a fixed pool of LNG has resulted in spot or uncontracted LNG being priced against crude oil (this being a fuel which competes with LNG in the power sectors of Japan and Korea).

Superficially this situation should be one where one would expect a high European seasonal hub price differential, given that the high space heating demand season for Europe coincides with that of Japan and Korea. Again however we must remember the large volume of storage which is currently under construction in NW Europe. This would seek to erode the seasonal price spread on European hubs, notwithstanding the high absolute level of gas prices. In order 
for this situation to become one which is explicitly supportive of new UK storage build, one has to invoke a failure of critical infrastructure linking the UK with NW Continental Europe. As we have seen above however, this would likely trigger supply flexibility measures such as the BBL line backing up the IUK, Norwegian supply re-direction and LNG diversions.

The UK gas market since the early 2000s has become increasingly dependent on imports of gas in the form of pipeline gas and LNG. Fortunately a combination of adequate import capacity provision, a diversity of suppliers and an open, easily accessed liberalised market has resulted in a market which will quickly respond to failures of an individual supply channel. The response sequence (as described above) initially involves an increase in price i.e. a 'signal' to attract supply. If supply is forthcoming (either the supply stranded by the infrastructure failure being re-routed or supply diverted from other markets with alternative supply) then the price signal may be relatively modest. In the absence of a supply response, the UK price (as it did in winter 2005/2006) will rise to levels at which demand is reduced. Generally this is manifested by temporary shutdown of energy intensive industrial plant (and a consequent loss of GDP) or a switching of generation capacity to coal (and a consequent increase in $\mathrm{CO}_{2}$ emissions).

The corollary of this argument is that the absence of long-term contracts for gas makes the UK vulnerable in a tight global market ${ }^{70}$ for gas. On the surface this appears to be selfevident, the UK market would have to attract supply away from other markets by offering higher prices. However, with the erosion of destination clauses for long term contracts in the European market and the rise in trading and arbitrage activity in both pipeline gas and LNG, the situation is less clear cut, even if we assume that long term contracts will generally prevail in Europe. This is illustrated below in the context of a tight global gas market:

- If the UK market price rises above the European pipeline contract price one would expect buyers under such contracts to increase nominations to sell-on the extra gas to traded hubs physically connected to the UK market. One would also expect that upstream suppliers under such long term contracts would sell gas directly onto those hubs using their in-house marketing and trading capabilities to take advantage of the price premium.

- LNG long term contracts frequently contain diversion rights, to allow buyer and seller to divert supplies to a higher priced market and thus to share the price premium. If LNG was imported into the UK under such long term contracts it would be subject to such diversions if other regions (e.g. Asian Markets) offered a higher price. Conversely the UK, as a liberalised market, could equally bid away cargoes under contract to other destination markets through the price mechanism.

What is difficult to wholly quantify is the adequacy of the current level of UK storage capacity to provide sufficient supply in the immediate aftermath of a supply security event, i.e. before other supply channels are able to respond. Two contrasting approaches are:

\footnotetext{
${ }^{70}$ The term 'global gas market' refers to the gas supply and demand network which is connected by LNG, namely the Asian LNG importers, Europe and possibly North America.
} 
- 'Common Sense, Judgement and Rule of Thumb' This approach is at least clear and uncluttered but founders when one tries to set an absolute figure. One could take neighbouring markets and look at the percentage of annual consumption covered by storage. Figure 28 shows the wide variation of this measure between European countries. There is no clear 'normative' level of storage cover which is immediately apparent from this data.

Figure 28. Storage Volume in 2010 as \% of 2010 Consumption for European Markets

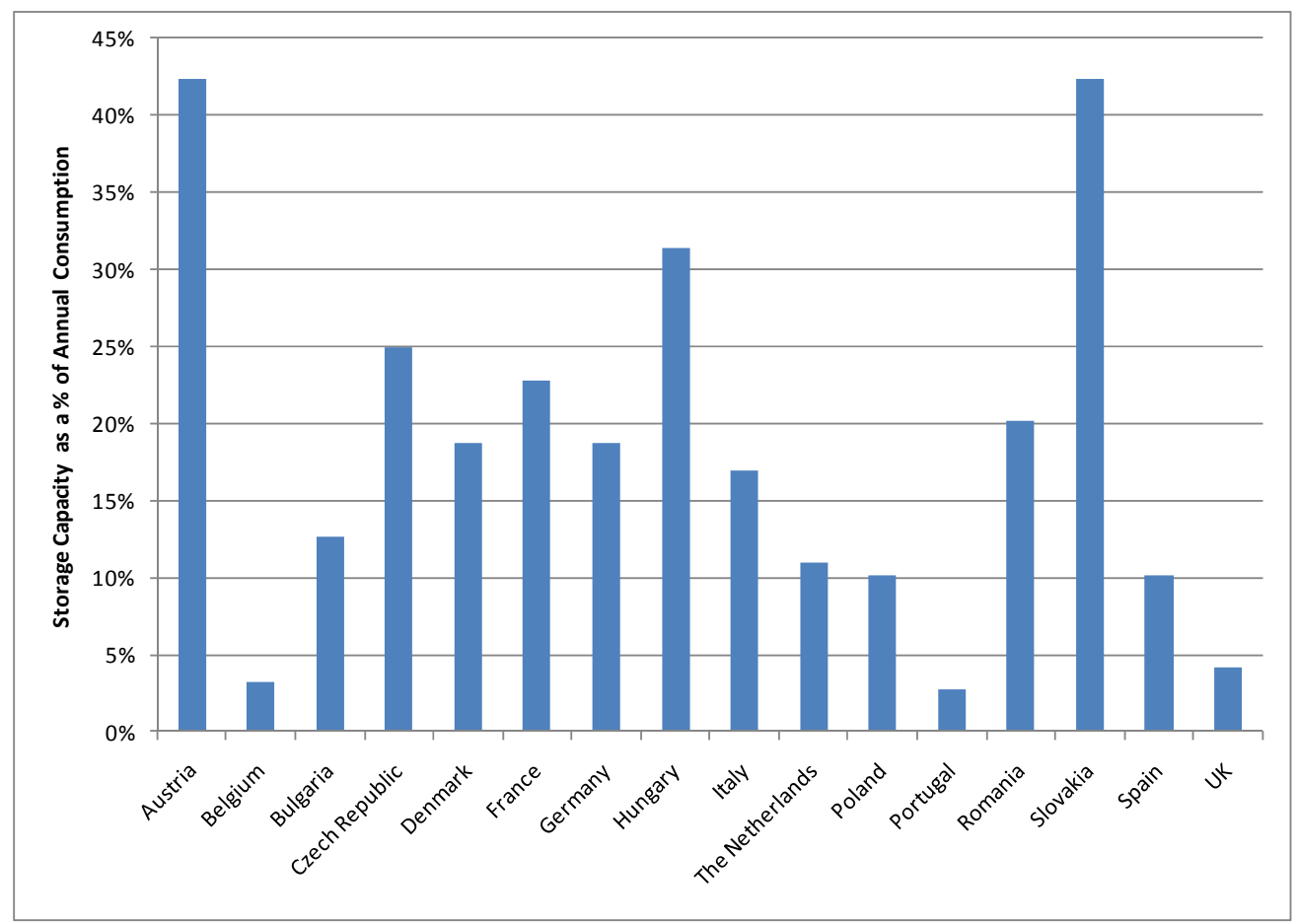

Sources: IEA Monthly Data, GSE 2010

- 'Intensive modelling of low probability, but potentially high impact events' By contrast this approach would look specifically at events such as that described above in response to the question: 'What is a credible high-impact supply security event and what would be the consequence for the UK market?' and attempt to quantify the potential supply shortfall required to be covered by storage. There are two issues here. The first is to set the boundary on the probability limit of a high impact event. The second is the need to anticipate the response times and other competing priorities of the entities which will respond to making good the UK's supply short-fall as signalled by a high price excursion. This is by no means a straightforward task.

Neither of these approaches will necessarily provide a firm basis for a commercial case for storage investment, however this is not to say that the case for additional seasonal storage in the UK is a 'lost cause'. Given the reliance of the UK power sector on natural gas as well as its high penetration of the space heating market, the impact of even a short duration supply 
restriction would be highly significant and, in the eyes of the voting public, a major undermining of confidence in the government of the day.

Despite the seemingly low probability of multiple supply threats, they have happened. The example is the winter of 2005/2006 discussed on page 19, where a lack of flow from the Continent though the IUK in response to price signals was exacerbated by a subsequent fire at the Rough storage facility at a time when the global LNG market was tight, partly as a result of Hurricane Katrina in the US.

It is worth noting that even when all storage projects in the UK currently under construction are completed, the Rough facility will still represent $58 \%$ of total storage capacity, and therefore the UK will still be highly exposed in the event of technical problems on this facility which has been operational for 26 years.

\subsection{Past UK Storage Policy Evolution}

The main developments in the UK policy response to security of gas supply and storage can be summarised as follows. ${ }^{71}$

Whilst through the late 1980s and the 1990s policy focussed on liberalising and demonopolising the gas market, it became clear in the early 2000s that the UK would require significant imports of gas as its domestic production declined. While in 2002, the first Joint Energy Security of Supply (JESS) Working Group report noted the substantial limitations of gas storage capacity, subsequent reports did not extend the analysis of the consequences of gas supply shortfalls. Stern ${ }^{72}$ highlights that the April 2006 JESS report, published a few weeks after the Rough fire, while the facility was still out of action, made no mention of the incident, which was arguably the most serious gas security incident ever to have taken place in the UK.

\section{Table 3. Existing UK Import Infrastructure}

\begin{tabular}{|l|l|l|l|c|}
\hline Import Project & Operator / Developer & Type & Location & $\begin{array}{c}\text { Capacity } \\
\text { (bcm/y) }\end{array}$ \\
\hline Interconnector & IUK & Pipe & Bacton & 25.5 \\
\hline BBL Pipeline & BBL Company & Pipe & Bacton & 19.9 \\
\hline Isle of Grain 1-3 & Isle of Grain LNG & LNG & Isle of Grain & 20.3 \\
\hline GasPort & Excelerate & LNG & Teesside & 4.1 \\
\hline South Hook 1\&2 & Qatar Petroleum \& ExxonMobil & LNG & Milford Haven & 21.0 \\
\hline Dragon 1 & BG Group / Petronas & LNG & Milford Haven & 6.0 \\
\hline Langeled & Gassco & Pipe & Easington & 25.8 \\
\hline Vesterled & Gassco & Pipe & St Fergus & 13.1 \\
\hline Tampen & Gassco & Pipe & St Fergus & 9.1 \\
\hline Gjøa Gas Pipeline & Gassco & Pipe & St Fergus & 6.2 \\
\hline & & & Total & 151.0 \\
\hline
\end{tabular}

Source: National Grid 2010a: Table 4.7 A, P. 61,

\footnotetext{
${ }^{71}$ For details see Stern 2010, pp. 147-152.

72 ibid
} 
The mid 2000s saw the development of significant UK import infrastructure capacity as shown in Table 3. With the exception of expansions in IUK capacity and possibly the BBL line, all this infrastructure had been developed as the downstream 'market access' components of upstream projects i.e. its investment economics were incorporated in typical high risk - high reward investment return projects. From the viewpoint of UK policy makers this rapid expansion of import infrastructure was a confirmation of the UK liberalised market model, i.e. the 'market' had responded to the need to provide timely import capacity.

The 2007 Energy White Paper acknowledged that storage capacity needed to be available to avoid 'socially unacceptable levels of interruption to physical supply and excessive cost to the economy from unexpectedly high or volatile prices'. The forward intention was to reform the planning system in order to make onshore and offshore gas storage projects easier to achieve.

The 2008 Energy Markets Outlook (BERR 2008) recognised to need for additional gas storage in the future as UKCS supplies declined and the UK became more dependent on imports. This more urgent tone was followed by two 2009 studies. The Wicks report ${ }^{73}$ looked at energy security and Ofgem's Project Discovery Scenarios drew attention to the need for changes in the organisation of energy markets. ${ }^{74}$ This repeated the National Grid base case that by 2020 the UK should have storage equivalent to $10 \%$ of its demand (i.e. circa $10 \mathrm{bcm}$ ).

Just prior to the publication of the Wicks report the government's view of the role of gas in the UK was thrown into question by the publication of the Low Carbon Transition Plan which projected UK gas consumption by 2015 and 2020 to be 11\% and 29\% lower than 2008 levels. Such projections did little to engender a sense of urgency in relation to security of supply and the need for more storage. What had seemed to be a growing sense of unease in current levels of gas storage appeared to be countered by the April 2010 gas security of supply policy statement which said that DECC had found the probability of a very severe winter combined with interruption of gas supplies from international markets '...is very low and our gas market is resilient'. ${ }^{75}$

The UK has debated the creation of strategic storage capacity i.e. storage created with the specific purpose of providing gas to essential users in the event of a catastrophic failure of either gas supply or infrastructure. A government-commissioned report in $2006^{76}$ concluded that commercial investment by market participants was unlikely to provide sufficient capacity to provide for a high impact low probability event without some form of government intervention. The 2006 Energy Review ${ }^{77}$ [reference] responded by downplaying the likelihood of an energy security event and fears that government-controlled strategic storage would undermine the case for investment in commercial storage. In 2009 Wicks warned that if commercial storage was not installed at the predicted rate the government would need to

\footnotetext{
${ }^{73}$ Wicks 2009

${ }^{74}$ Ofgem 2009

${ }^{75}$ DECC 2010a: Para 6.2, P. 59

${ }^{76}$ ILEX 2006, xii - xiv

${ }^{77}$ DTI 2006, para 4.41.
} 
reconsider the issue. He viewed strategic storage as an insurance policy against unpredictable developments in the wider gas market.

The 2010 gas security statement ${ }^{78}$ firmly refuted the need for 'government-commissioned storage' on the basis that it interfered with markets, created competition with commercial storage, undermined demand side response and that government was unable to judge the correct level of storage.

At present there appears to be little prospect of direct government incentives to increase the UK's storage capacity either through direct investment or through requiring gas suppliers to hold (and as a consequence underwrite the construction of) a defined volume of physical reserve inventory through a form of 'Customer Service Obligation'.

Let us look at some simple numbers to bring some perspective to this:

- To take the UK's storage capacity to $10 \mathrm{bcma}$ (in line with the Wicks report and National Grid's recommendations) would require an additional $4 \mathrm{bcm}$ of storage over and above existing facilities and those under construction.

- Based on the figures from Escobar and Artega, the capital cost involved would be some $£ 2.2$ bn.

- The investment required for Ofgem's ‘Green Stimulus’ and ‘Green Transition’ Project Discovery Scenarios is£190 and £200bn respectively ${ }^{79}$.

Given the uncertainty surrounding the UK's future natural gas supply mix between pipeline gas from the European Continent and LNG, and the increasing need for seasonal flexibility as the UK's domestic production continues to decline, it would seem rational for the Government in its future energy policies to incorporate provisions to ensure that the UK develops a seasonal storage capacity of at least $10 \%$ of annual consumption to cope with the consequences of critical infrastructure failures of the type observed in the last decade.

\footnotetext{
${ }^{78}$ DECC 2010a: Para's 5.83-5.98, pp. 56-58

${ }^{79}$ Poyry 2010: Figure 11. P. 20.
} 


\section{Chapter 6. Wind Intermittency}

\subsection{Introduction and Context}

The EU and the UK are committed to significant reductions in carbon emissions. In July 2009, the European Commission authorised a national plan proposed by the UK that introduces a trading system for emissions of the greenhouse gas carbon dioxide related to energy consumption, rather than energy production ${ }^{80}$. This system, the Carbon Reduction Commitment, applies to non-energy intensive sectors not already covered by climate change agreements and the EU Emissions Trading System. Following the passing of the Climate Change Act in November 2008, the UK is now legally required to cut its greenhouse gas emissions by at least 80 percent by 2050, and 34 percent by 2020 relative to 1990 levels.

Figure 29. Cumulative installed wind capacity in UK and Germany 1996 - 2007 and projected UK 2008 - 2020 in the Committee on Climate Change 2008 Report.

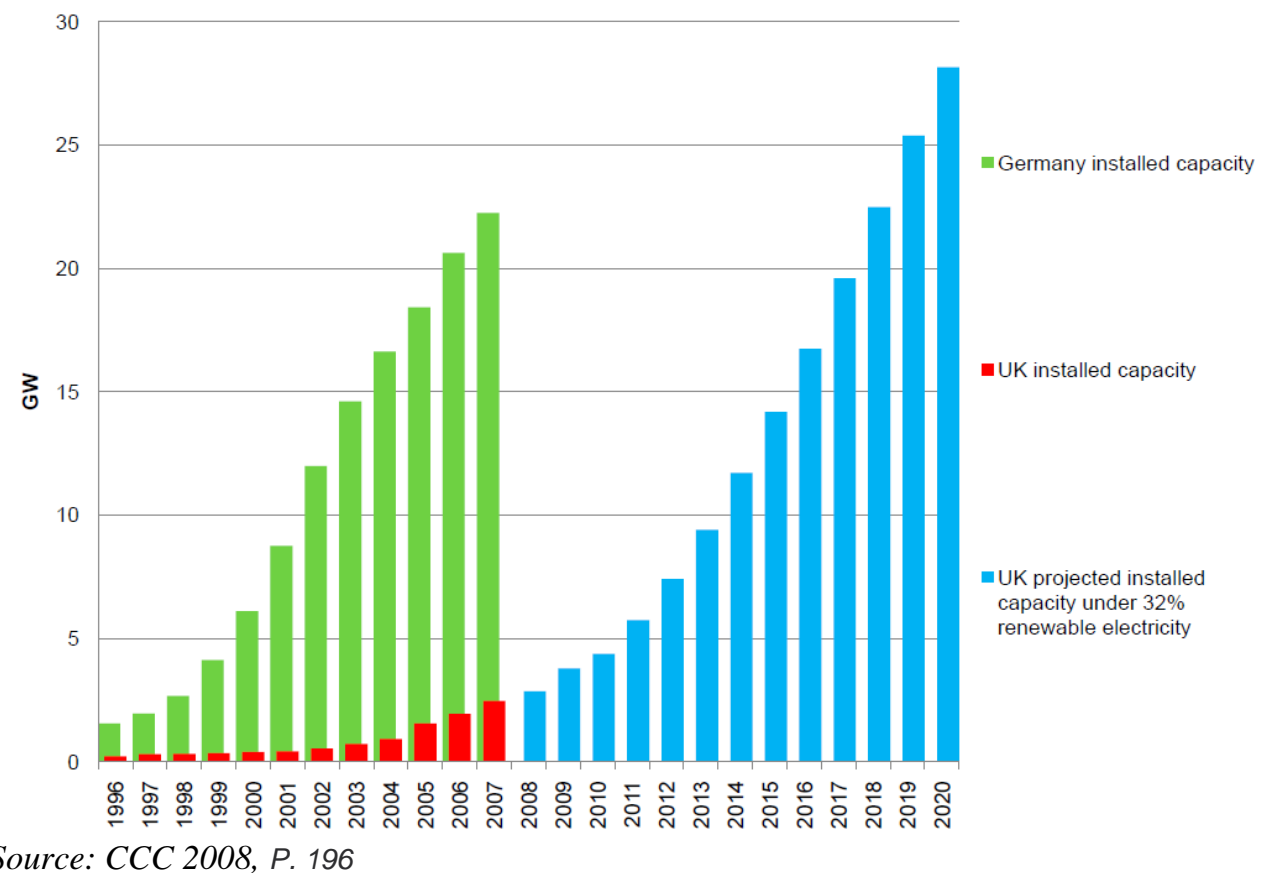

Much activity and analysis has been expended by, among others, DECC and Ofgem in portraying scenarios under which such commitments might be met. This paper is not concerned with assessing or commenting on the likely success or failure of such aspirations or the not inconsiderable cost of achieving them. The focus of this section is on the interaction between wind and gas generation in the 2009 to 2025 period as installed wind generation capacity grows.

${ }^{80}$ EU Endorses British Carbon Reduction Commitment, Environmental News Service, July 14, 2009, http://www.ens-newswire.com/ens/jul2009/2009-07-14-01.htmI\# 
A specific future trajectory of wind generation capacity is provided in the Committee on Climate Change 2008 report 'Building a low-carbon economy' where levels of wind generation capacity of $14 \mathrm{GW}$ by 2015 and $28 \mathrm{GW}$ by 2020 are shown ${ }^{81}$. The relevant graphic from the report is shown in Figure 29.

However there is a considerable range of uncertainty on future wind generation capacity as is shown in Table 4. This is based directly on information and data contained within the UK Government's 2050 Pathway Analysis, published in 2010. ${ }^{82}$ The various levels shown in Table 4 are cumulative and relate to different build rate assumptions. For comparison the trend to 2020 contained in Poyry 2010,p 5, representing its High Feasible Scenario are shown, which for 2020 most closely matches DECC Level 2.

Table 4. Potential Future Wind Generation Capacity (GW)

\begin{tabular}{|l|r|r|r|r|}
\hline Onshore Wind & 2009 & 2015 & 2020 & 2025 \\
\hline Level 1 & 3 & 5 & 9 & 11 \\
\hline Level 2 & 3 & 8 & 14 & 18 \\
\hline Level 3 & 3 & 10 & 18 & 25 \\
\hline Level 4 & 3 & 10 & 20 & 33 \\
\hline & & & & \\
\hline Offshore Wind & 2009 & 2015 & 2020 & 2025 \\
\hline & 1 & 4 & 6 & 8 \\
\hline Level 1 & 1 & 10 & 16 & 30 \\
\hline Level 2 & 1 & 10 & 25 & 45 \\
\hline Level 3 & 1 & 10 & 33 & 60 \\
\hline Level 4 & & & & \\
\hline & & & & \\
\hline Onshore and Offshore Wind Total & & \\
\hline & 2009 & 2015 & 2020 & 2025 \\
\hline Level 1 & 4 & 9 & 15 & 19 \\
\hline Level 2 & 4 & 18 & 30 & 48 \\
\hline Level 3 & 4 & 20 & 43 & 70 \\
\hline Level 4 & 4 & 20 & 53 & 93 \\
\hline Poyry & 4 & 13 & 27 & n/a \\
\hline
\end{tabular}

Sources: DECC 2010 bp. 182 - 187, Poyry 2009,P. 5.

To place these figures in context, the UK's 2009 total generation capacity (all fuels and technologies) was $82.6 \mathrm{GW}^{83}$ and the average generation rate during the year was 37.1

\footnotetext{
${ }^{81}$ CCC 2008: P. 196.

${ }^{82}$ DECC 2010b: pp. $182-194$

${ }^{83}$ National Grid 2010b, P. 10, Figure 3.2.
} 
$\mathrm{GW}^{84}$. The wide range of potential wind generation capacity in Table 4 for 2020 and 2025 already begs the question of how to place such open-ended ranges within a coherent national generation plan. A related question is on what basis are more conventional power generation investments meant to proceed given this uncertainty band on wind power investment?

The realpolitik of the 2020 commitments is that wind power is likely perceived to be the best hope government has in meeting its 2020 goals given:

- the immaturity of Carbon Sequestration and Storage deployment projects and their cost challenges,

- the immaturity of wave power,

- local resistance to tidal barrage schemes

- and the likely set back to general acceptance of new nuclear build in the wake of the Fukushima incident.

In the period to 2020 there are two other two demand-side developments promising energy consumption reductions, namely improved efficiency in the residential space heating sector and the deployment of smart meters.

The critical question is the scale of the impact these measures are likely to make by 2020 . Table 5, from British Gas shows the main energy savings coming from the installation of more energy efficient boilers and loft and cavity wall insulation. The impact of smart meters is significantly less. Efficiency savings assumed to be made are partially offset by 'economic' factors, presumably consumers raising thermostat settings as the UK economy recovers and consumer confidence increases.

Table 5. Forecast Impact on Domestic Gas Consumption Amongst British Gas Customers If All Measures Implemented, Annual Percentage Change

\begin{tabular}{|c|c|c|c|c|c|c|}
\hline & $\begin{array}{c}2010 \\
\text { Actual }\end{array}$ & $\begin{array}{c}2011 \\
\text { Forecast }\end{array}$ & $\begin{array}{c}2012 \\
\text { Forecast }\end{array}$ & $\begin{array}{c}2013 \\
\text { Forecast }\end{array}$ & $\begin{array}{c}2014 \\
\text { Forecast }\end{array}$ & $\begin{array}{c}2015 \\
\text { Forecast }\end{array}$ \\
\hline Direct effects & $-3.3 \%$ & $-3.4 \%$ & $-3.7 \%$ & $-3.8 \%$ & $-3.8 \%$ & $-3.8 \%$ \\
\hline Energy efficient boilers & $-1.2 \%$ & $-1.2 \%$ & $-1.2 \%$ & $-1.3 \%$ & $-1.3 \%$ & $-1.3 \%$ \\
\hline Loft and cavity wall insulation & $-1.2 \%$ & $-1.2 \%$ & $-1.3 \%$ & $-1.3 \%$ & $-1.3 \%$ & $-1.3 \%$ \\
\hline Energy efficiency advice & $-0.9 \%$ & $-0.9 \%$ & $-0.9 \%$ & $-0.9 \%$ & $-0.9 \%$ & $-0.9 \%$ \\
\hline Smart meters & $0.0 \%$ & $-0.1 \%$ & $-0.3 \%$ & $-0.3 \%$ & $-0.3 \%$ & $-0.3 \%$ \\
\hline Indirect effects & $-2.0 \%$ & $-2.0 \%$ & $0.7 \%$ & $1.4 \%$ & $2.1 \%$ & $2.9 \%$ \\
\hline Economic & $0.9 \%$ & $0.9 \%$ & $3.6 \%$ & $4.4 \%$ & $5.0 \%$ & $5.8 \%$ \\
\hline Other factors & $-2.9 \%$ & $-2.9 \%$ & $-2.9 \%$ & $-2.9 \%$ & $-2.9 \%$ & $-2.9 \%$ \\
\hline TOTAL & $-5.3 \%$ & $-5.4 \%$ & $-3.0 \%$ & $-2.4 \%$ & $-1.7 \%$ & $-0.9 \%$ \\
\hline
\end{tabular}

Source: British Gas 2011:Table 3, page 8

Smart meters and 'demand side management' certainly have the potential to reduce heat and power consumption in the home but this will be limited prior to the installation of integrated systems to directly control domestic appliances. The UK government recently set out the strategy and timetable for the installation of 53 million smart meters in 30 million homes over the next 20 years. ${ }^{85}$ From the press release the following statement is telling: 'Consumers will have real time information on their energy consumption to help them control energy use, save

\footnotetext{
${ }^{84}$ Ibid, derived from Table 7.

85 'DECC lays foundation for smart meters rollout', Press Release, $30^{\text {th }}$ March

2011, http://www.decc.gov.uk/en/content/cms/news/pn11 032/pn11 032.aspx
} 
money and reduce emissions. By 2020 the average consumer (with both electricity and gas) is expected to save around $£ 23$ per year on their energy bill as a result of smart metering.' $£ 23$ per year represents only a $2.1 \%$ reduction on the average gas and electricity bill of $£ 1,075$ for $2010 .^{86}$

Beyond 2020 it is clear that, with sufficient investment, demand side management using smart meters could play a significant role in both reducing energy consumption and in peak smoothing, however this is not without its challenges as noted by Poyry (see page 75). However, with the general state of UK household finances in 2011, it is unlikely that consumers would prioritise investments to reduce energy consumption over more pressing expenditure needs. It is of course possible that the UK government could mandate the installation of efficient measures in a move analogous to the modification of gas appliances in the switch from town gas to natural gas in the 1960s and 1970s, however the cost and affordability of such a move is not known, let alone its political acceptability.

The objective of this section of the paper is to examine the consequences for gas of a rising wind generation capacity to 2025 using a transparent methodology. The purpose of such analysis is to reach broad conclusions on:

- The impact on power sector gas consumption as wind generation capacity grows through time;

- The variability in gas-fired generation needed to 'buffer' the changing wind generation profile as wind speed fluctuates;

A summary of the methodology used is contained in Appendix B.

\subsection{Data Assembly}

Hourly wind speed data for 2009 was acquired from the British Atmospheric Data Centre ${ }^{87}$ online meteorological database for weather stations corresponding to the 13 onshore and 7 offshore areas shown in Figure 30. The onshore stations are shown as red dots with yellow margins, the weather stations representing the 7 offshore areas are shown as blue dots with yellow margins.

${ }^{86}$ DECC Energy Price Statistics at http://www.decc.gov.uk/en/content/cms/statistics/prices/prices.aspx ${ }^{87}$ BADC 
Figure 30. UK Area Sub-division with Representative Weather Stations

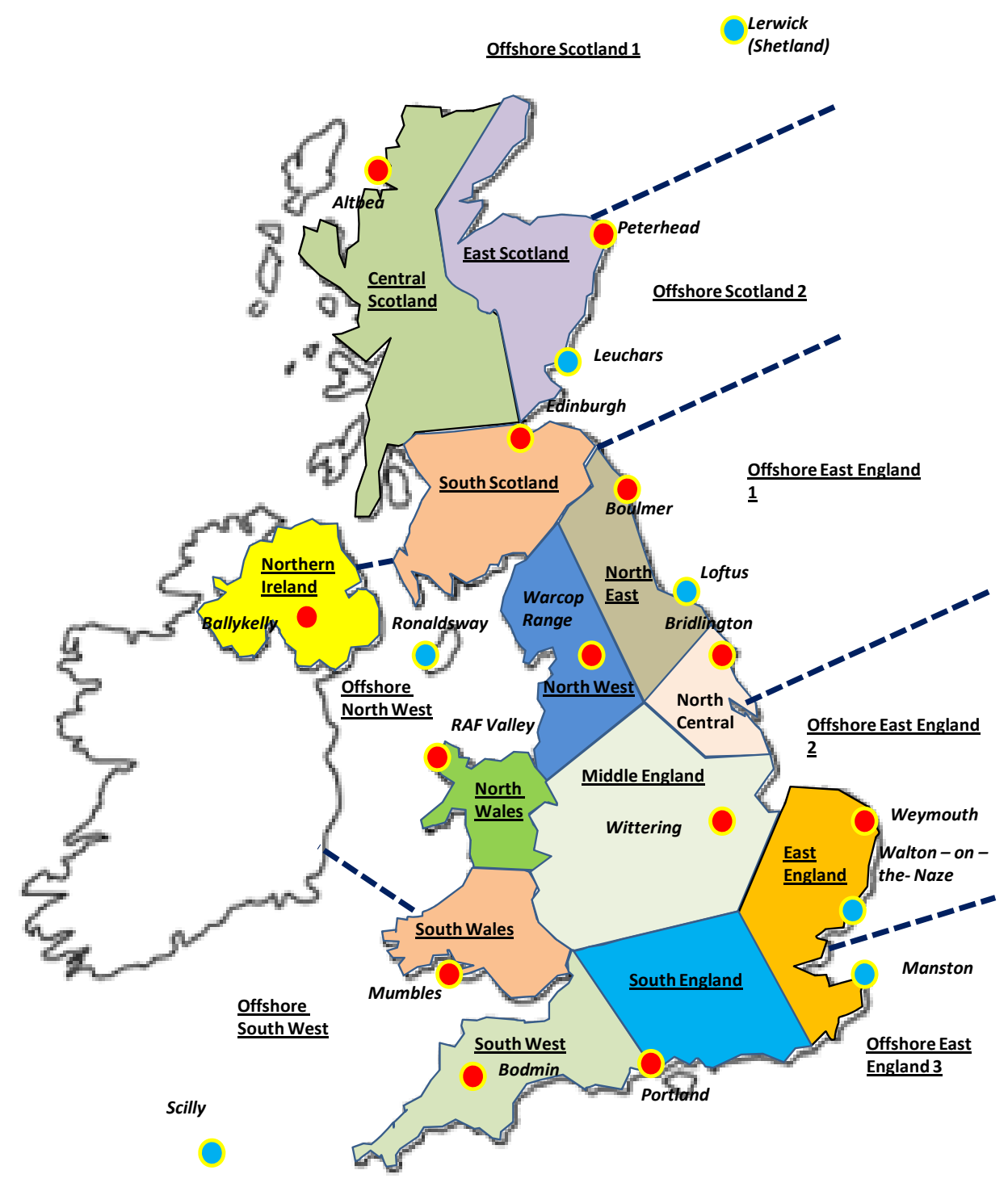

Source: $B A D C$ 
Data for three locations are shown on Figure 31. This figure is included to provide a general impression of the variability of wind speed and to note the degree of co-incidence and contrast in wind speeds at three distant locations.

\section{Figure 31. Hourly Wind Speed for 2009 at Three Selected Locations}

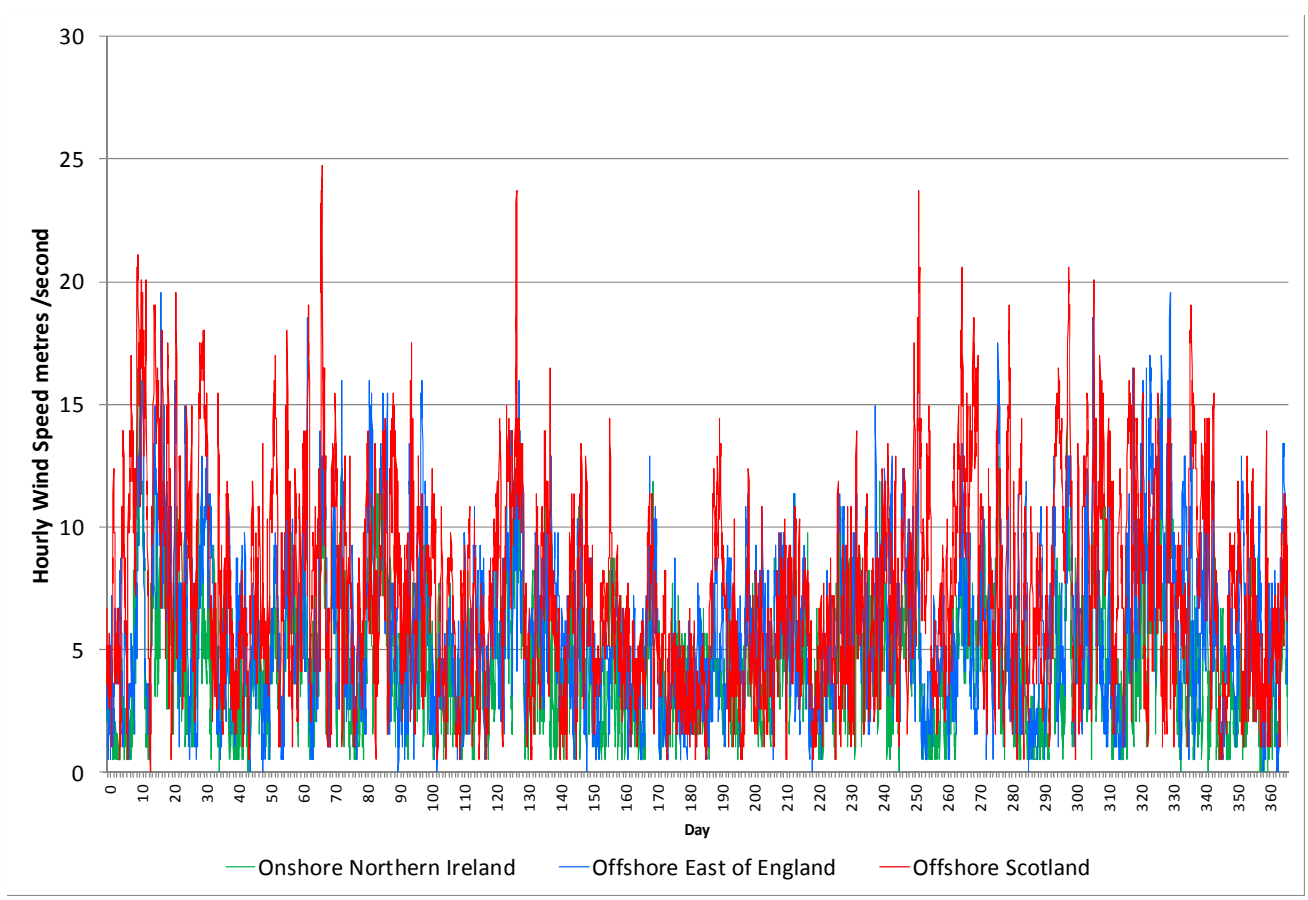

Sources: BADC, Own Analysis

A review of DECC data confirmed that 2009 was a reasonably representative year on which to base this analysis. Figure 32 shows the annual mean wind speed for 2009 which is 4.62 $\mathrm{m} / \mathrm{sec}$. This is within $3 \%$ of the 9 year mean of $4.76 \mathrm{~m} / \mathrm{sec}$.

Data on existing and future wind farms was grouped according to the geographical area designation shown in Figure 30. ${ }^{88}$ As most of the large future wind projects identified tended to be offshore, an estimate was made of potential new (as yet unidentified) onshore projects, assumed to be equally distributed across the 13 onshore areas. By adjusting assumptions of timing and future project probability, the profile of future wind capacity to be used in this analysis was normalised to approximate the 2015 and 2020 levels envisaged in the Committee on Climate Change Report (CCC 2008) and Poyry2009. These comparisons are shown in Figure 33 which also includes the four levels of future wind capacity contained in DECC 2010b. The 2025 level is broadly on trend with the DECC Level 2 line.

${ }^{88}$ BWEA. 
Figure 32. Annual UK Mean Wind Speed Compared with 9 Year Average.

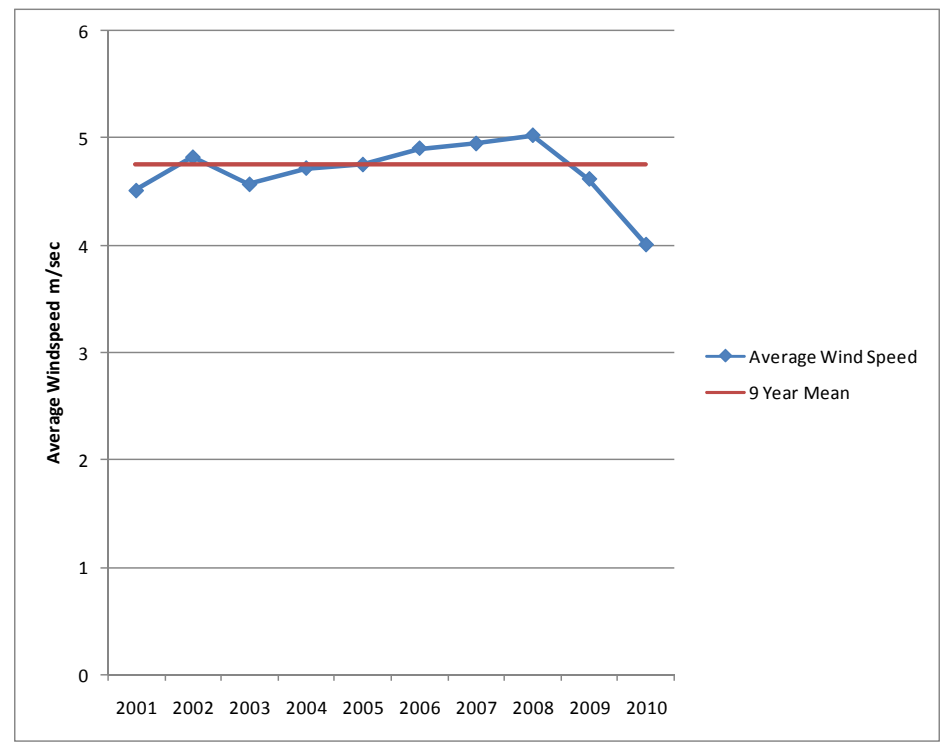

Source: DECC Wind Speed

Figure 33. Future Wind Generation Capacity Assumptions

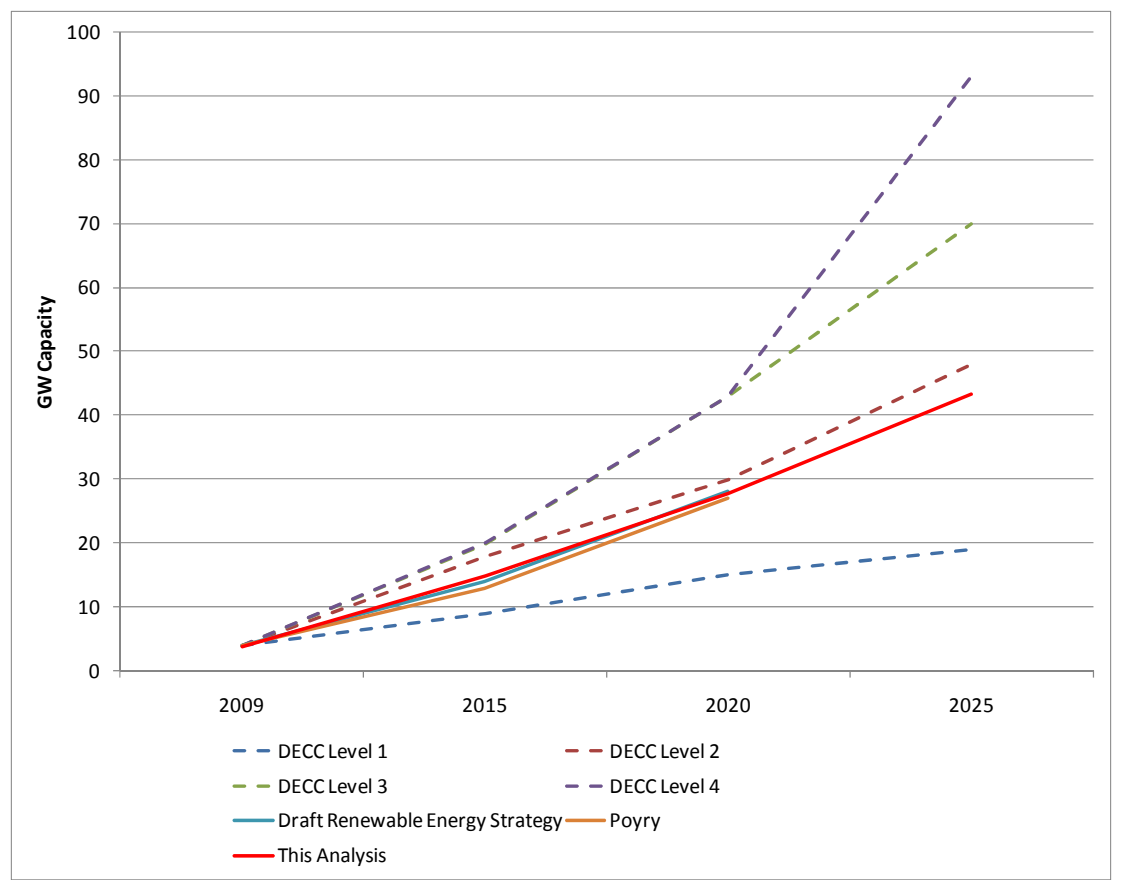




\section{Sources: CCC 2008, Poyry 2009, DECC 2010b, Own Analysis}

The regional distribution of wind generation capacity to be used in this analysis as shown in Figure 34.It is noticeable that much of the future growth in wind capacity is in offshore locations. Onshore capacity is assumed to reach 8 GW between 2015 and 2020.

The final part of the data assembly process lies in understanding how wind turbine output and wind speed are correlated. Tradewind ${ }^{89}$ provides a good overview together with curves showing turbine output versus wind speed. Turbine design and performance is influenced by terrain, and wind farms are thus classified into Lowland (up to $400 \mathrm{~m}$ above sea level), Upland and Offshore. Turbine performance is chiefly influenced by:

- Array efficiency (i.e. the effect of reduction in wind speed due to the wakes of upstream wing turbines, especially relevant for offshore arrays).

- High wind speed cut-out - the turbine controller causes the turbine to cut out at high wind speeds, however due to the difference in wind conditions experienced by individual turbines within a wind farm it is unlikely all will cut out simultaneously. This is reflected in a tail-off in the output to wind speed curve.

- Availability (i.e. maintenance and unplanned downtime due to technical problems).

- Electrical losses in the transmission system.

Figure 34. Regional Distribution of 2009 Wind Capacity and Assumed Distribution for 2015, 2020 and 2025

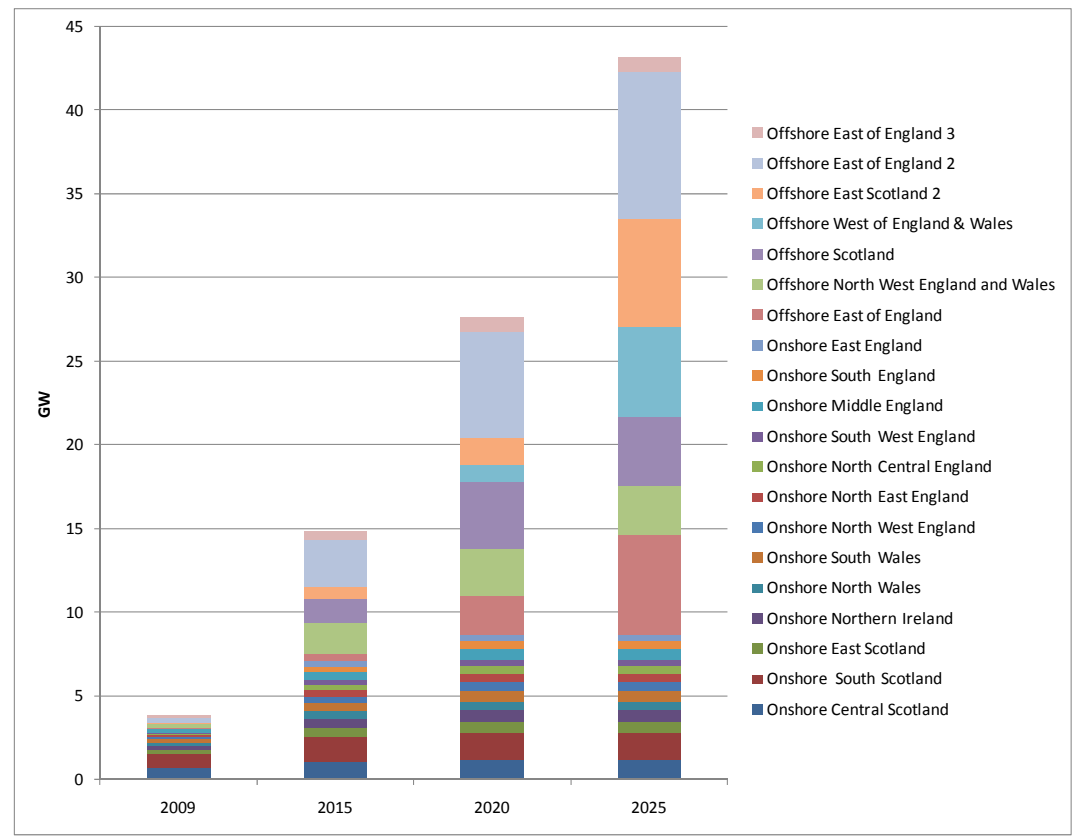

Sources: BWEA, Own Analysis

\footnotetext{
${ }^{89}$ Tradewind 2008a, P. 10.
} 
These factors are combined to produce turbine output curves specific to each terrain classification, as shown in Figure 35.

The remaining factor to be considered is the difference in wind speed between the weather station location and the wind farm location. An estimate of the factors which account for this is provided in Tradewind $2008 \mathrm{~b}^{90}$, i.e. Lowland 1.00, Upland, 1.20, Offshore 1.30.

\section{Figure 35. Present Day Regional Normalised Wind Turbine Power Curves}

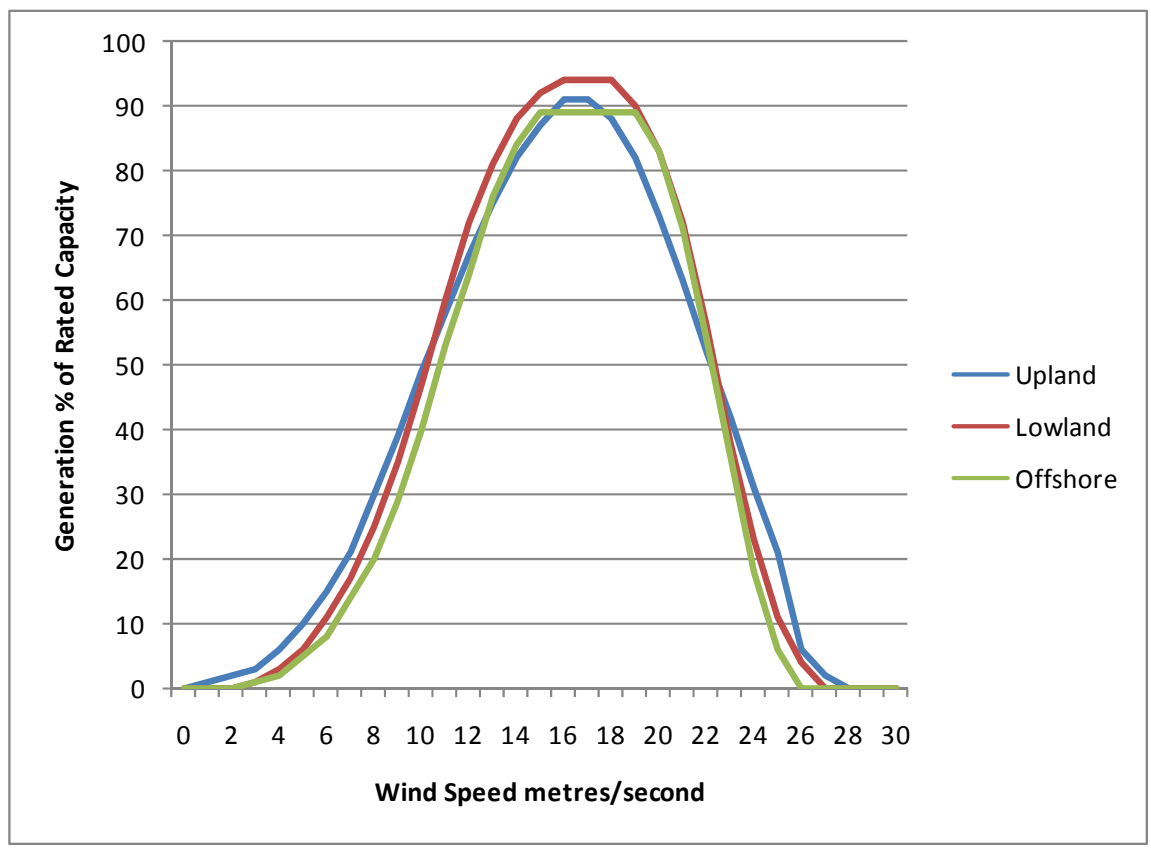

Source: Tradewind 2008a, P.10.

\subsection{Wind Generation History Match and Future Wind Generation Modelling}

An Excel spreadsheet was used to model 2009 wind generation on an hourly basis for each of the UK sub areas by incorporating the information described above. The initial results were compared with DECC reported onshore and offshore wind power generation for 2009. This comparison in shown in Table 6. Offshore generation as modelled was $89 \%$ of the DECC reported value and Onshore $80 \%$ of the DECC value. The three possible explanations for this difference are:

- Despite best efforts, the wind data collected was not fully representative of the wind farm locations resulting in lower recorded wind speeds.

- Even hourly wind data may not be sufficient to account for the effect of wind gusting which would increase turbine wind output. This is particularly important when average wind speeds are in the 4 to 6 metres/second range (i.e. close to UK average).

\footnotetext{
${ }^{90}$ Tradewind 2008b, P. 6.
} 
A gust will add more to power generation than is lost during a lull, due to the asymmetric shape of the power generation curve in Figure 35.

- The allowance for inefficiencies built into the output curves in P35 may be too pessimistic e.g. maintenance downtime allowances and electrical losses.

The model was re-run with a multiplier applied to the hourly wind data such that a match was obtained between the DECC data and modelled outcome for 2009.

Table 6.Wind Power Generation Initial Model Results Compared with DECC Reported Values

DECC

This Analysis

$\%$ of DECC Result

Onshore UK

Total
GWh

1,740

7,564

9,304

1,546

6,047

7,592

$89 \%$

$80 \%$

$82 \%$

\section{Source: DECC Wind Power Statistics}

This model was run for the years 2015, 2020 and 2025 using the 2009 hourly wind speed data and the turbine output curves and other parameters for the tuned 2009 run. The objective was to simulate the wind power generated in future years assuming an identical wind pattern as pertained in 2009. Wind generation capacity and location in future years corresponded to the cases shown in Figure 34.

The wind power generation profiles produced are shown in Figure 36. For the years modelled, the average wind capacity utilisation varies between $28 \%$ and $29 \%$. What is of most interest however is the very significant variability of wind generation output which is clearly evident in Figure 36 and how the UK generating system could cope with such variability at increasing levels of installed wind capacity. 


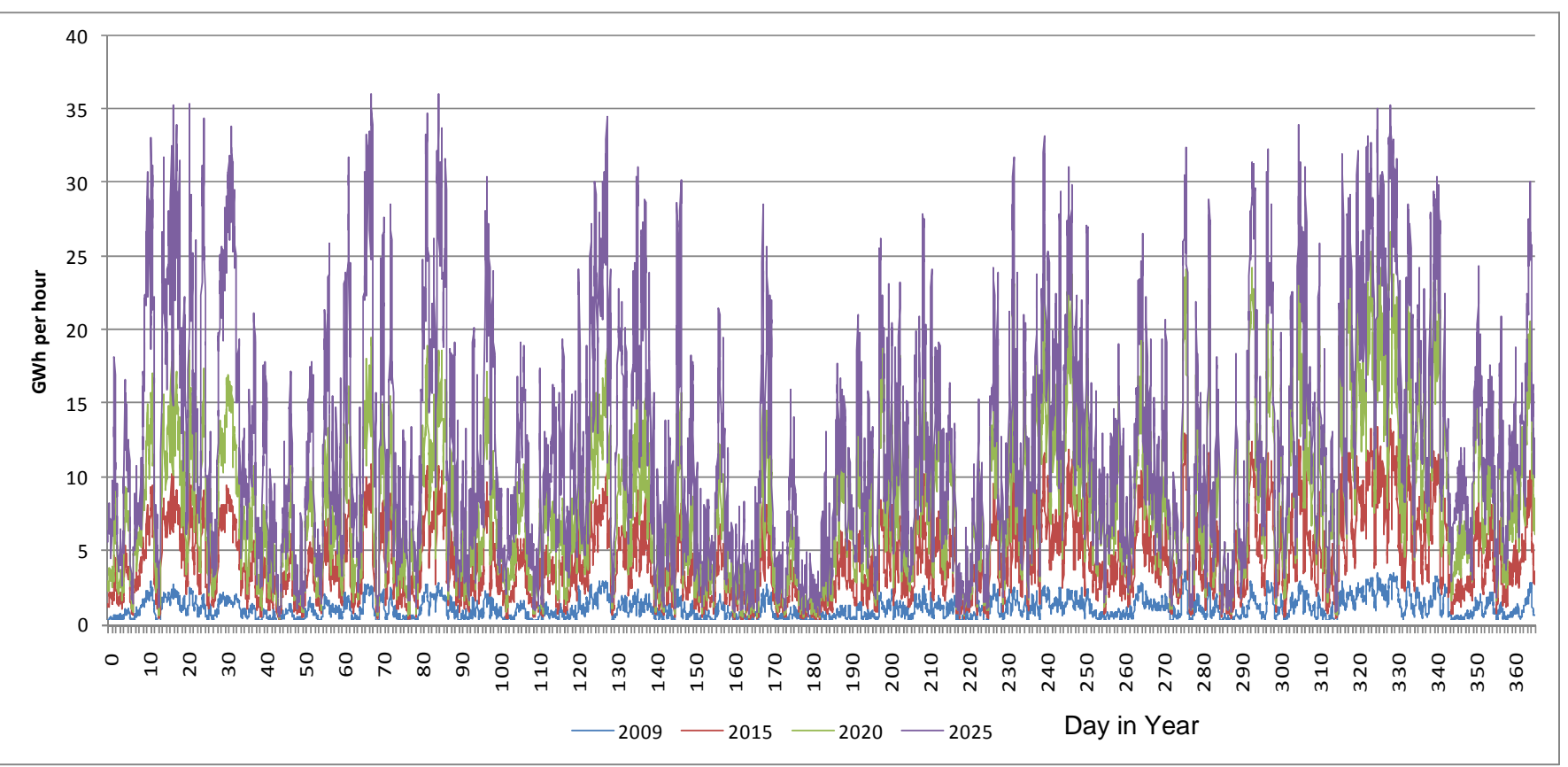

Figure 36.UK Hourly Wind Power Generation 2009, 2015, 2020 and 2025

Source: Own Analysis

\subsection{Future Year Generation Stack Interactions}

In order to analyse the UK generating system and the interactions between wind and other forms of power generation it is necessary to derive a simple but workable portrayal of the system. This has been effected by reference to data contained within National Grid 2010a and National Grid 2010b.

National Grid 2010b, depicts the power demand and sources of generation for a typical winter day and the same for a typical summer day. ${ }^{91}$ The accompanying National Grid spreadsheet provides half-hourly data for each of these graphs. These have been reconstructed on an hourly basis in Figures 37 and 38.

${ }^{91}$ National Grid 2010b, Figure 3.3 b, P.11 and, Figure 3.3 c, P. 12 respectively. 
Figure 37. Typical Winter Demand, Thursday Dec $3^{\text {rd }}, 2009$

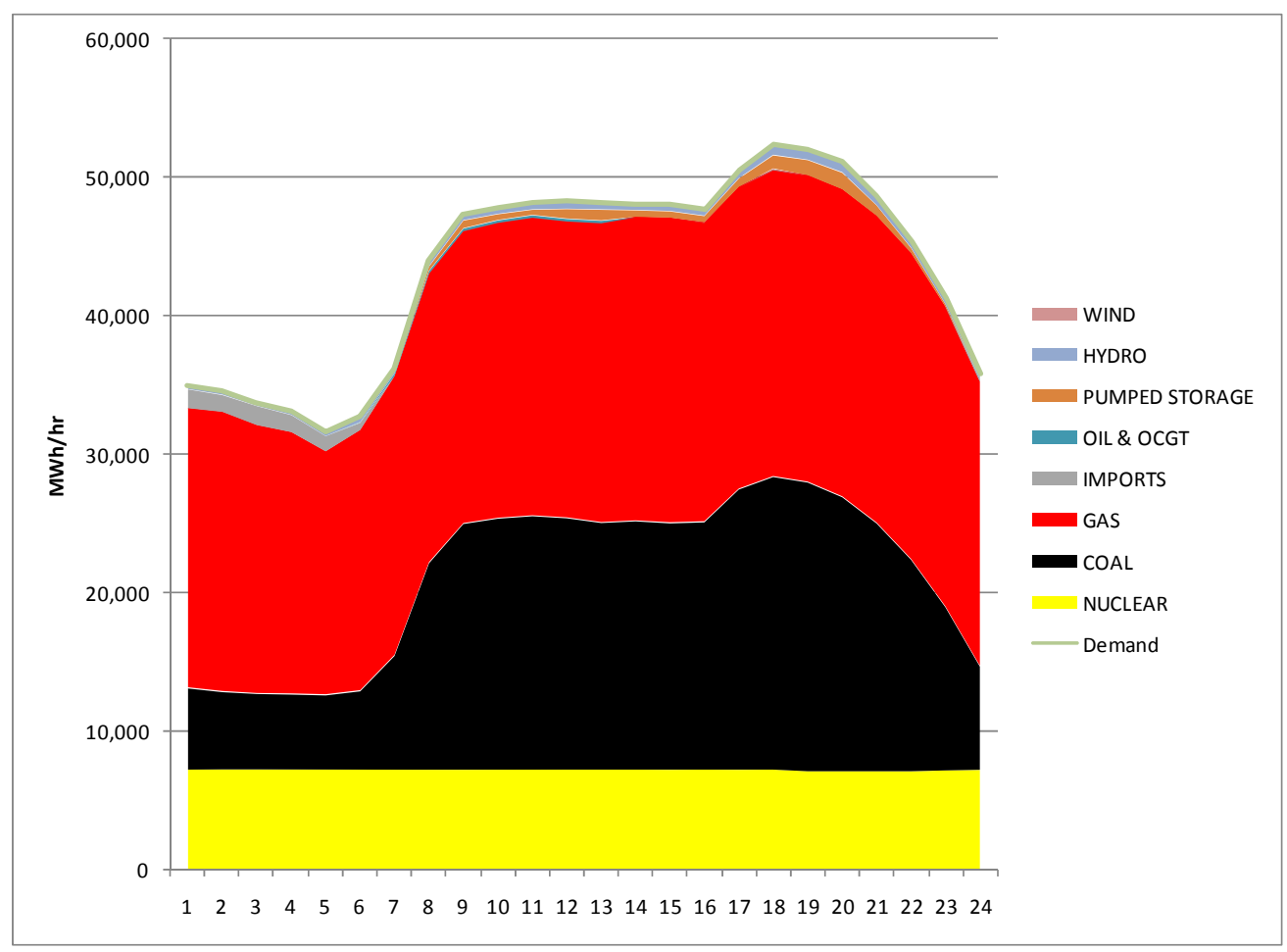

Source: National Grid 2010b, P 11, Figure 3.3 b

Figure 38. Typical Summer Demand, Thursday June $11^{\text {th }}, 2009$ 


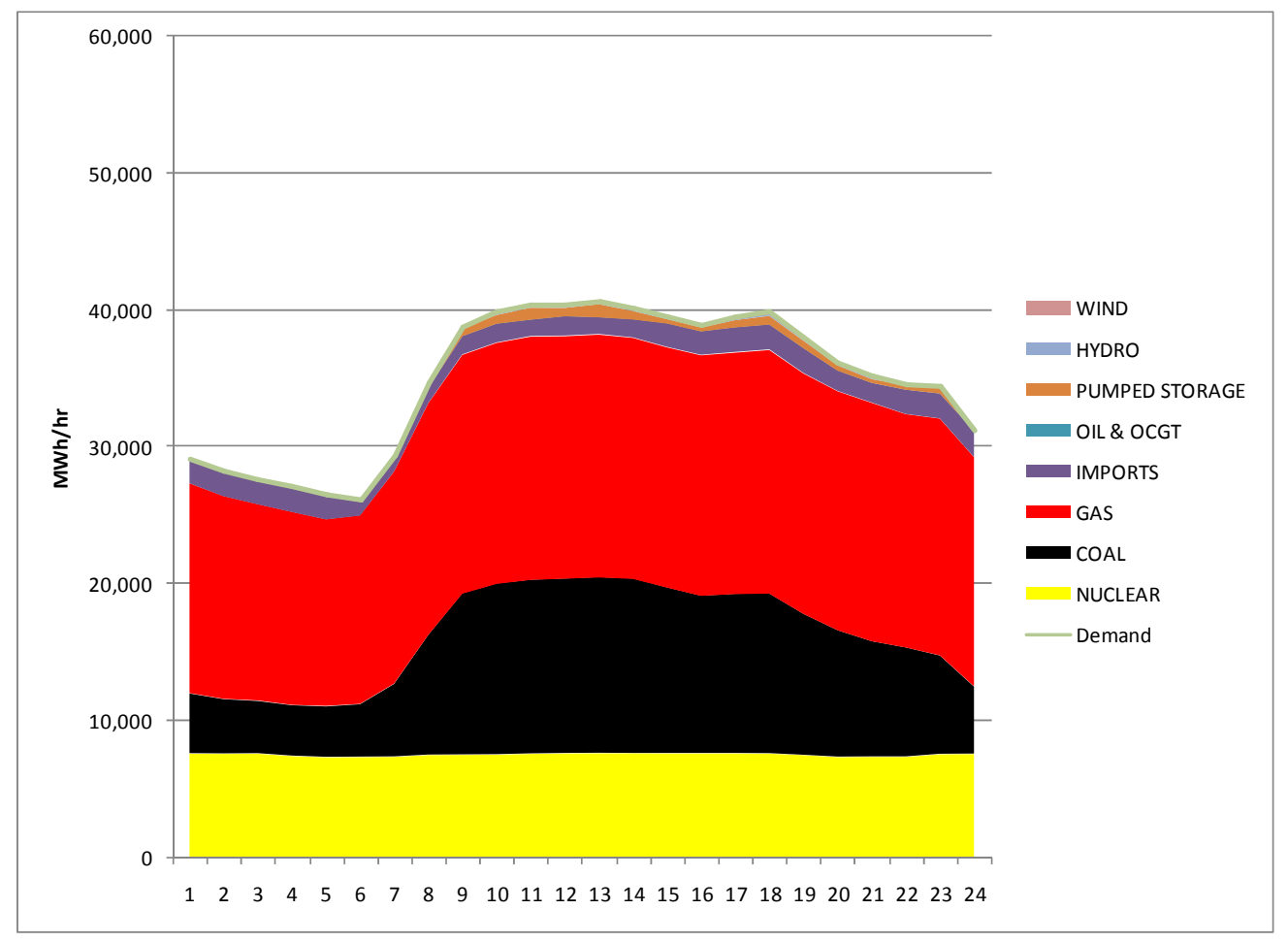

Source: National Grid 2010b, P. 12, Figure 3.3 c

The challenge was to produce an annual power stack from these 'typical day profiles on an hourly and a daily basis. As a first step, data from National Grid 2010 b, Page 5, Figure 2.3 was extracted from the accompanying spreadsheet. This is weekly maximum and minimum power demand for the UK. A simple mean average was taken to represent the actual weekly demand (although this is refined later). This weekly demand data was arranged in a calendar year sequence and the typical winter and typical summer daily demand datasets were 'cloned' and extrapolated in order to match total demand for the week in question.

The values in the assembled hourly 2009 demand and power generation stack were prorated such that power demand for the full year matched that stated by National Grid. The annual power demand for 2009 was taken from National Grid 2010 b and is shown in Table 7. For future years no growth in UK power demand was assumed over 2009, broadly consistent with the Base Forecast in Table 7.

Table 7. National Grid's Annual Electricity Requirement Base Forecast and Scenarios 


\begin{tabular}{|c|c|c|c|}
\hline Year & $\begin{array}{c}\text { Annual } \\
\text { Electricity } \\
\text { Requirements } \\
\text { (TWh) Low } \\
\text { Scenario }\end{array}$ & $\begin{array}{c}\text { Annual } \\
\text { Electricity } \\
\text { Requirements } \\
\text { (TWh) Base } \\
\text { Forecast }\end{array}$ & $\begin{array}{c}\text { Annual } \\
\text { Electricity } \\
\text { Requirements } \\
\text { (TWh) High } \\
\text { Scenario }\end{array}$ \\
\hline $2009 / 10$ & 325.4 & 325.4 & 325.4 \\
\hline $2010 / 11$ & 321.2 & 323.7 & 326.8 \\
\hline $2011 / 12$ & 318.9 & 323.9 & 329.8 \\
\hline $2012 / 13$ & 315.8 & 324.2 & 333.7 \\
\hline $2013 / 14$ & 312.6 & 325.6 & 339.7 \\
\hline $2014 / 15$ & 312.2 & 330.1 & 349.3 \\
\hline $2015 / 16$ & 309.0 & 329.6 & 351.9 \\
\hline $2016 / 17$ & 301.8 & 326.9 & 354.3 \\
\hline
\end{tabular}

Source: National Grid 2010b, P. 15, table $2.4^{92}$

This provided a power generation stack in hourly and daily format from which the impact of future levels of modelled wind power generation could be assessed. The approach adopted for this assessment was to define the following assumed 'rules' for future power generation despatch:

- Wind is allowed to run and generation is assumed to be as modelled (described in section 6.3).

- Initially gas generation is used to buffer the variability in wind generation output.

- If gas generation is reduced to zero, hydro, pumped storage, oil \& open cycle gas turbines and imports are assumed to reduce to absorb peaks in wind generation. Note that these are relatively small in magnitude.

- If the wind generation is unable to be absorbed by a reduction of the above sources of generation, it is modelled as being absorbed by coal and subsequently by nuclear. From a practical point of view this may not be realistic in terms of their ability to undergo significant turn-down at short notice. However, for the purposes of examining system stability it is desirable to note the scale and frequency of such events.

Future levels of nuclear, coal, hydro, pumped storage and interconnector capacity were based upon the data accompanying Figure 3.2 in National Grid 2010 b, shown as Table 8. This formed the basis of their assumed level of generation in the analysis of the generation stack in future years.

Table 8. UK Installed Capacity - Nuclear, Coal, Hydro, Pumped Storage and Interconnector

\footnotetext{
${ }^{92}$ Note that the $2009 / 10$ Actual demand out-turn was 320.7 TWh, i.e. only $1.4 \%$ different to the Base Forecast - National Grid 2011a, P. 11, Table 2.2
} 


\begin{tabular}{|l|r|r|r|r|r|r|r|r|}
\hline \multicolumn{7}{|c|}{ Generation Capacity GW } & & \\
\hline & \multicolumn{3}{|c|}{ Year } & & & & \\
\hline & \multicolumn{1}{|c|}{$09 / 10$} & $10 / 11$ & $11 / 12$ & $12 / 13$ & $13 / 14$ & $14 / 15$ & $15 / 16$ \\
\hline Nuclear & 10.894 & 10.894 & 9.444 & 9.444 & 9.444 & 9.444 & 9.444 \\
\hline Coal & 28.876 & 28.876 & 28.876 & 28.876 & 29.676 & 29.676 & 29.676 \\
\hline Hydro & 1.129 & 1.137 & 1.137 & 1.137 & 1.137 & 1.137 & 1.137 \\
\hline Pumped Storage & 2.744 & 2.744 & 2.744 & 2.744 & 2.744 & 2.744 & 2.744 \\
\hline Interconnector & 2.068 & 3.268 & 3.768 & 3.768 & 3.768 & 3.768 & 3.768 \\
\hline
\end{tabular}

Source: National Grid 2010b, P. 10, Figure 3.2

The results of modelling wind generation in this stack approach are described in the following sections.

\section{Wind and Full Generation Stack (3.8 GW Wind Capacity)}

Figure 39. 2009 UK Modelled Daily Wind Power Generation in Generation Stack

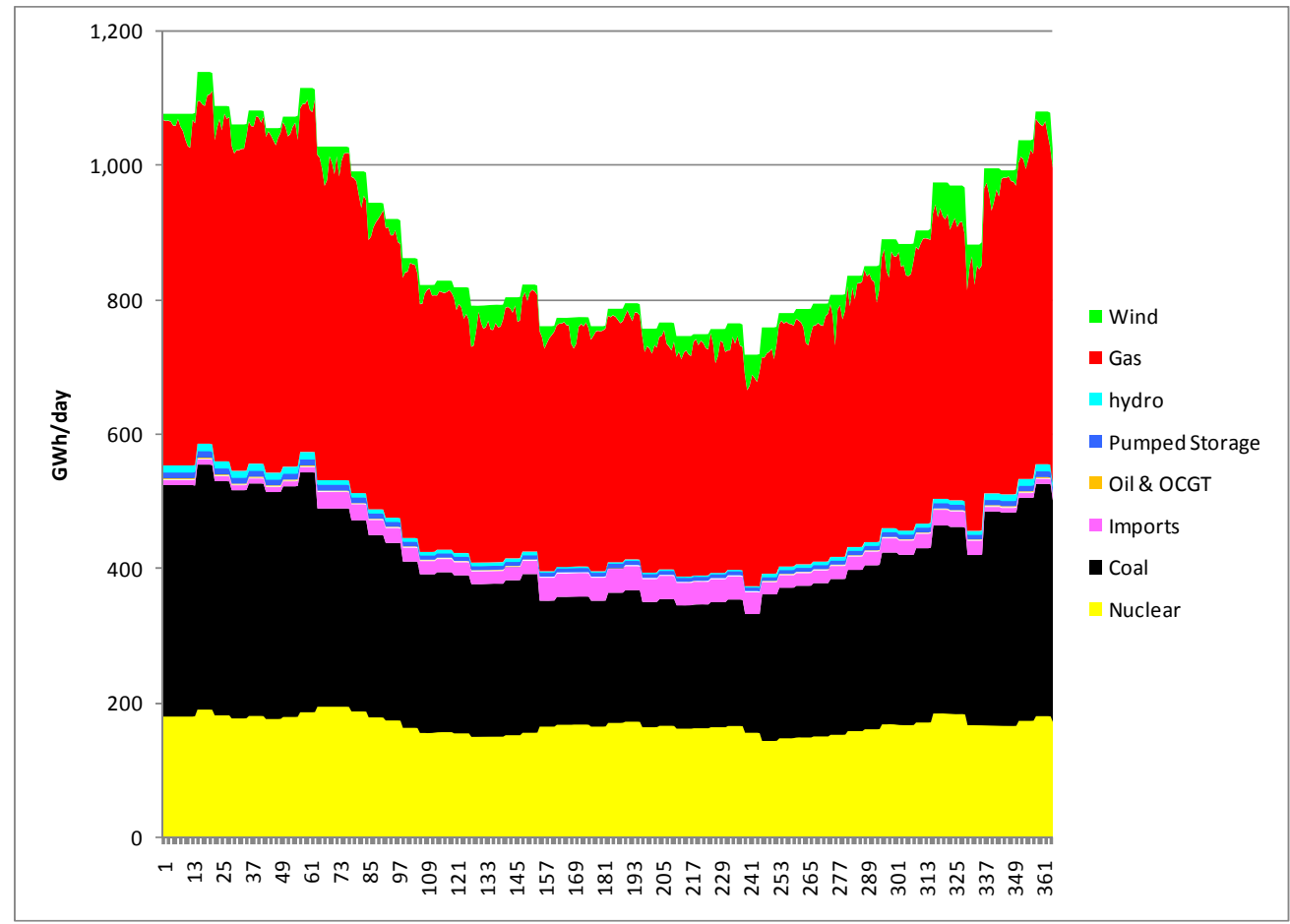

Sources: National Grid data and Own Analysis

Figure 39 shows the generation stack for 2009 on a daily basis with wind generation (green). The seasonal nature of power demand is noted as is the dominance of gas, coal and nuclear in the generation mix. Hydro and pumped storage are very small in comparison, as are power interconnector imports. The scale of wind generation is relatively small and whilst its variability can be clearly seen, this is easily absorbed, or buffered, by gas-fired generation. 


\section{Wind and Full Generation Stack (14.8 GW Wind Capacity)}

The position in 2015 is shown in Figure 40. The assumed generation from nuclear has been reduced in proportion to the capacity reduction in Table 8 . Similarly coal has been increased very slightly. Hydro, pumped storage and imports have been left the same as in the 2009 case. Wind generation is much more significant. While still able to be buffered by gas-fired generation, at times a significant reduction in gas generation is required.

Figure 40. 2015 UK Modelled Daily Wind Power Generation in Generation Stack

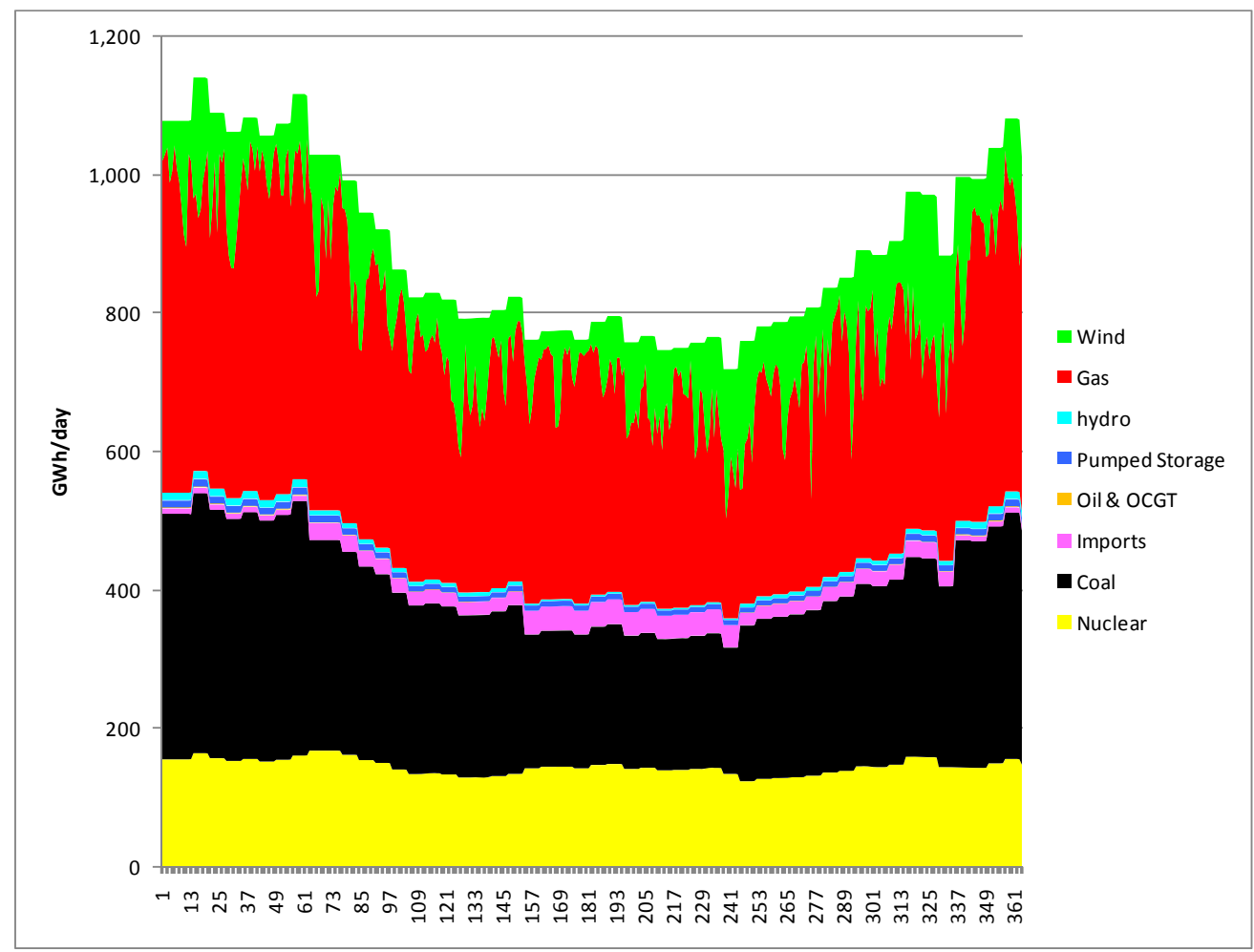

Sources: National Grid data and Own Analysis

\section{Wind and Full Generation Stack (27.6 GW Wind Capacity)}

The position by 2020 is shown in Figure 41. While not covered by the National Grid data in Table 8, it is assumed that nuclear capacity in 2020 is unchanged from 2015 and that coal fired generation has reduced by $50 \%$ (due to retirements required by the Large Plant Combustion Directive). Hydro, pumped storage and imports have been left the same as in the 2009 case.

Figure 41. 2020 UK Modelled Daily Wind Power Generation in Generation Stack 


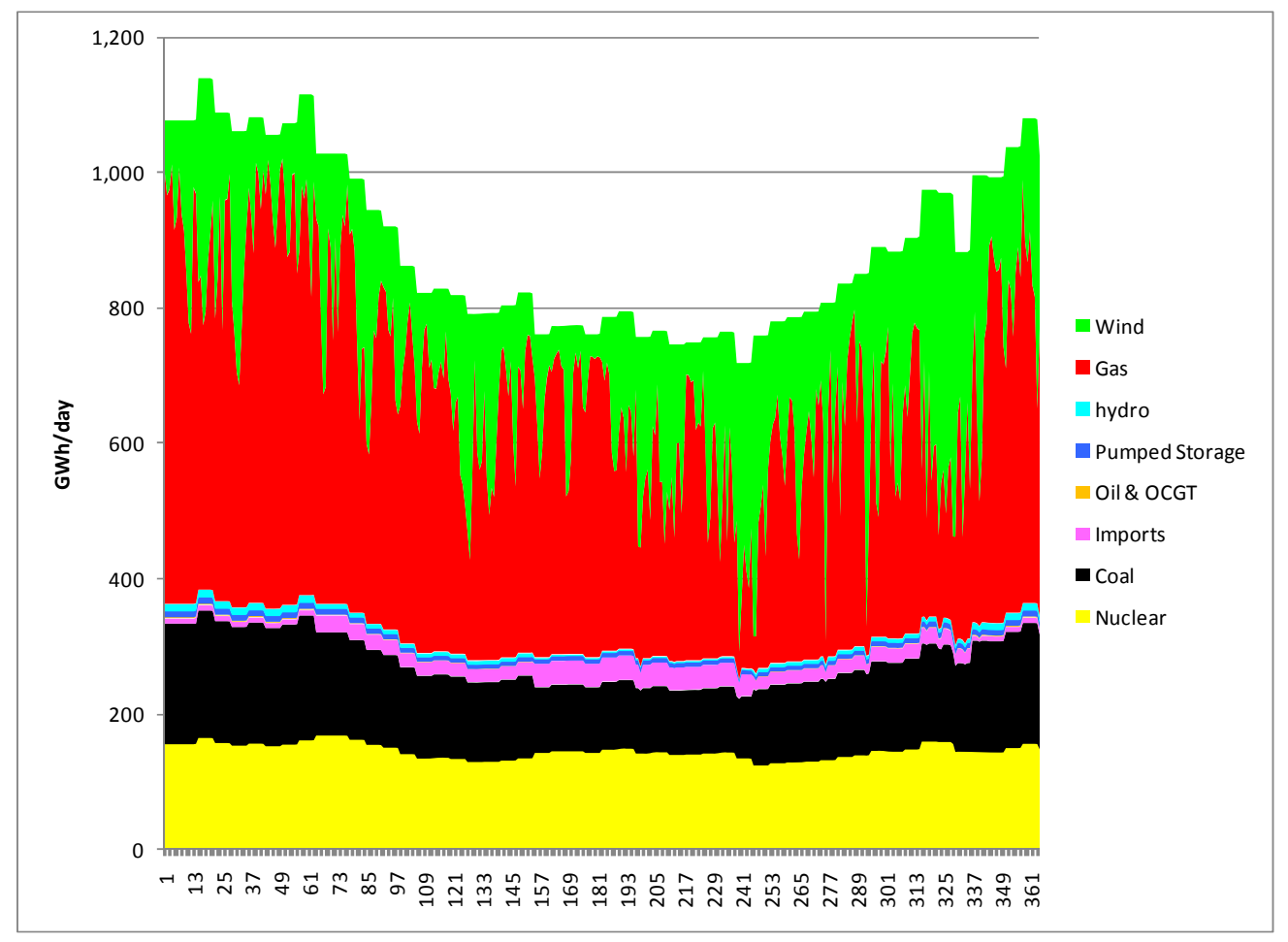

Sources: National Grid data and Own Analysis

The picture in 2020, with $27.6 \mathrm{GW}$ of wind generation, shows very starkly the role of gas in providing a buffer for wind power variability. Note that the potential scope of gas-fired generation has expanded due to the reduction in assumed coal-fired capacity and assumed generation. Figure 41 shows the daily generation situation, however the hourly view is also instructive. Figure 42 shows the hourly generation stack for 2020 for days 337 to 343, a period in early December. We observe two periods where wind generation is sufficient to shut down all gas-fired generation, and one where hydro and imports are reduced to zero and coal generation is turned down. In reality, though not explicitly modelled here, the interconnector could probably cope with this surge in wind power through exports to the European continent. Figure 43 shows a similar, slightly more extreme episode for Days 245 to 261 (in September). As will be discussed later, this case arguably verges on an 'upper limit of comfort' of wind capacity in the UK from the viewpoint of practical system operability without invoking interventions to turn down wind generation.

Figure 42. Wind Power Surge in 2020, Days 337 to 343 


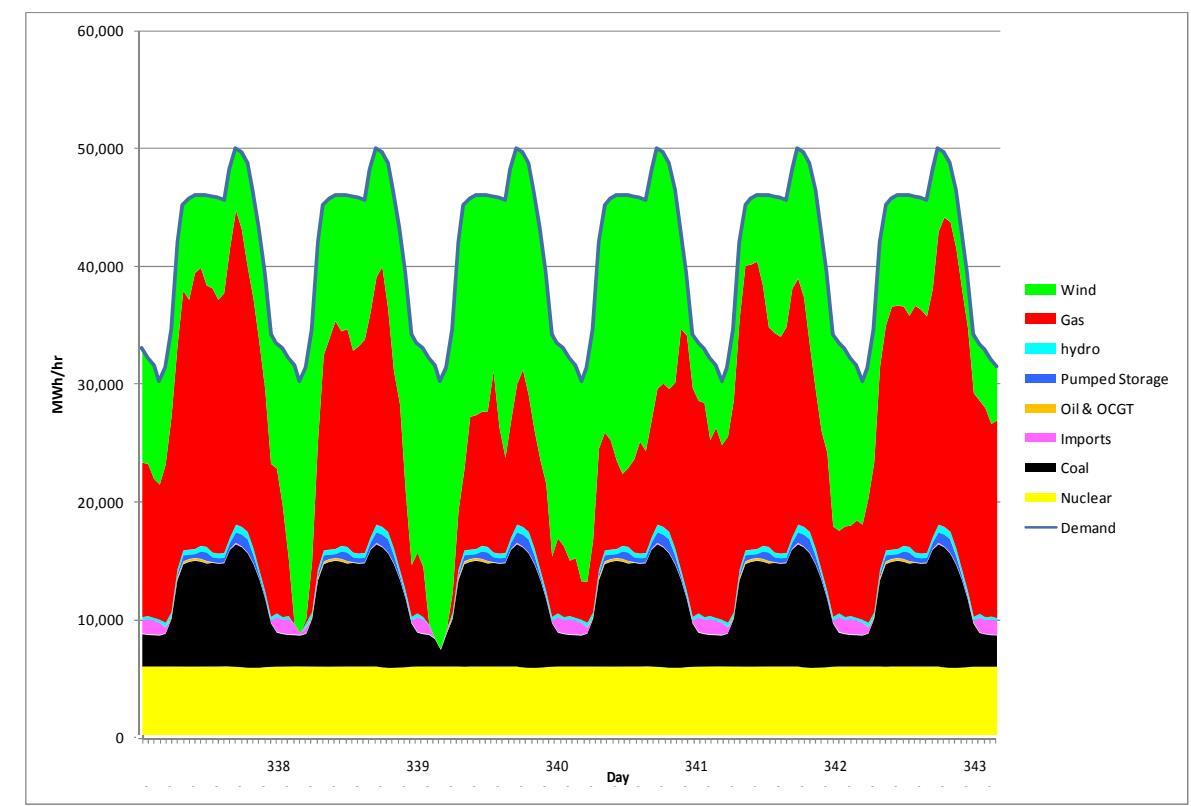

Sources: National Grid data and Own Analysis

Figure 43. Wind Power Surge in 2020, Days 245 to 261

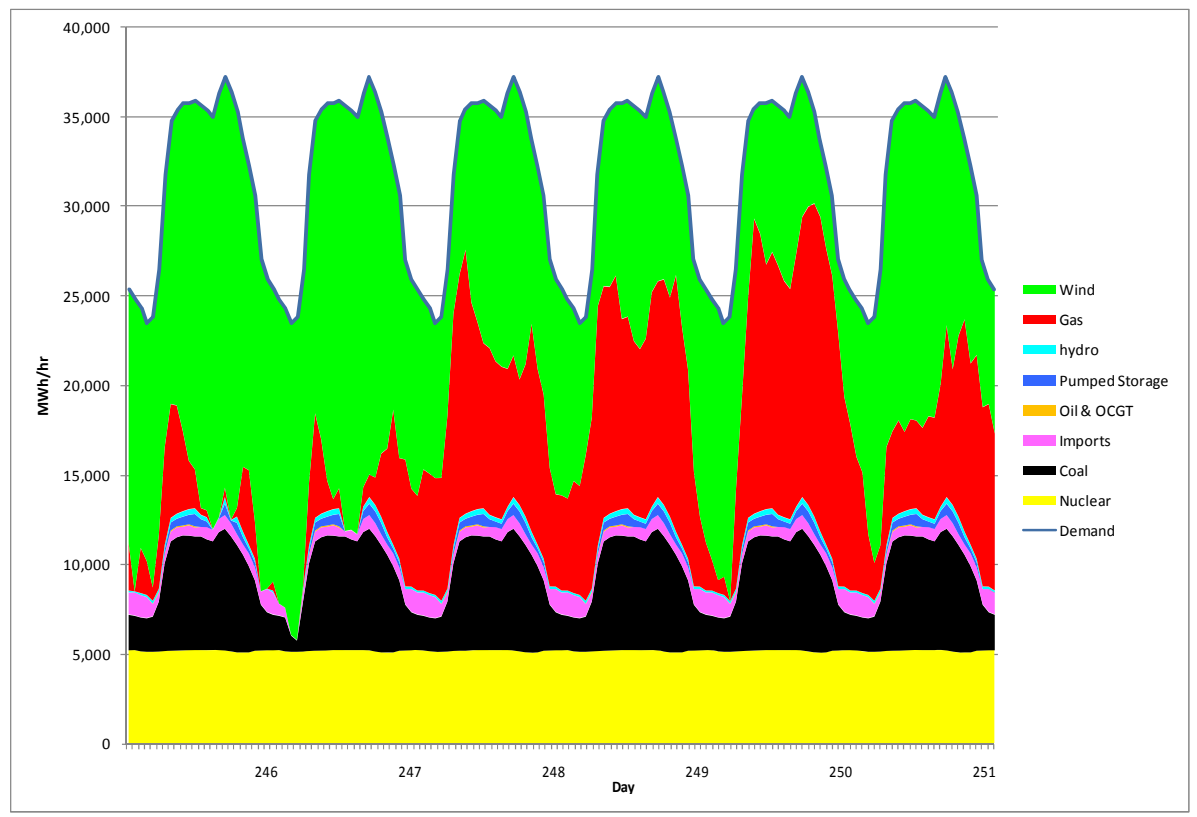

Sources: National Grid data and Own Analysis

2025 Wind and Full Generation Stack (43.2 GW Wind Capacity) 
The position by 2025 is shown in Figure 44. It is assumed that nuclear capacity is unchanged from 2020 and that coal-fired generation has reduced by a further 50\%compared with 2020 levels. Hydro, pumped storage and imports have been left the same as in the 2009 case.

Figure 44. 2025UK Modelled Daily Wind Power Generation in Generation Stack

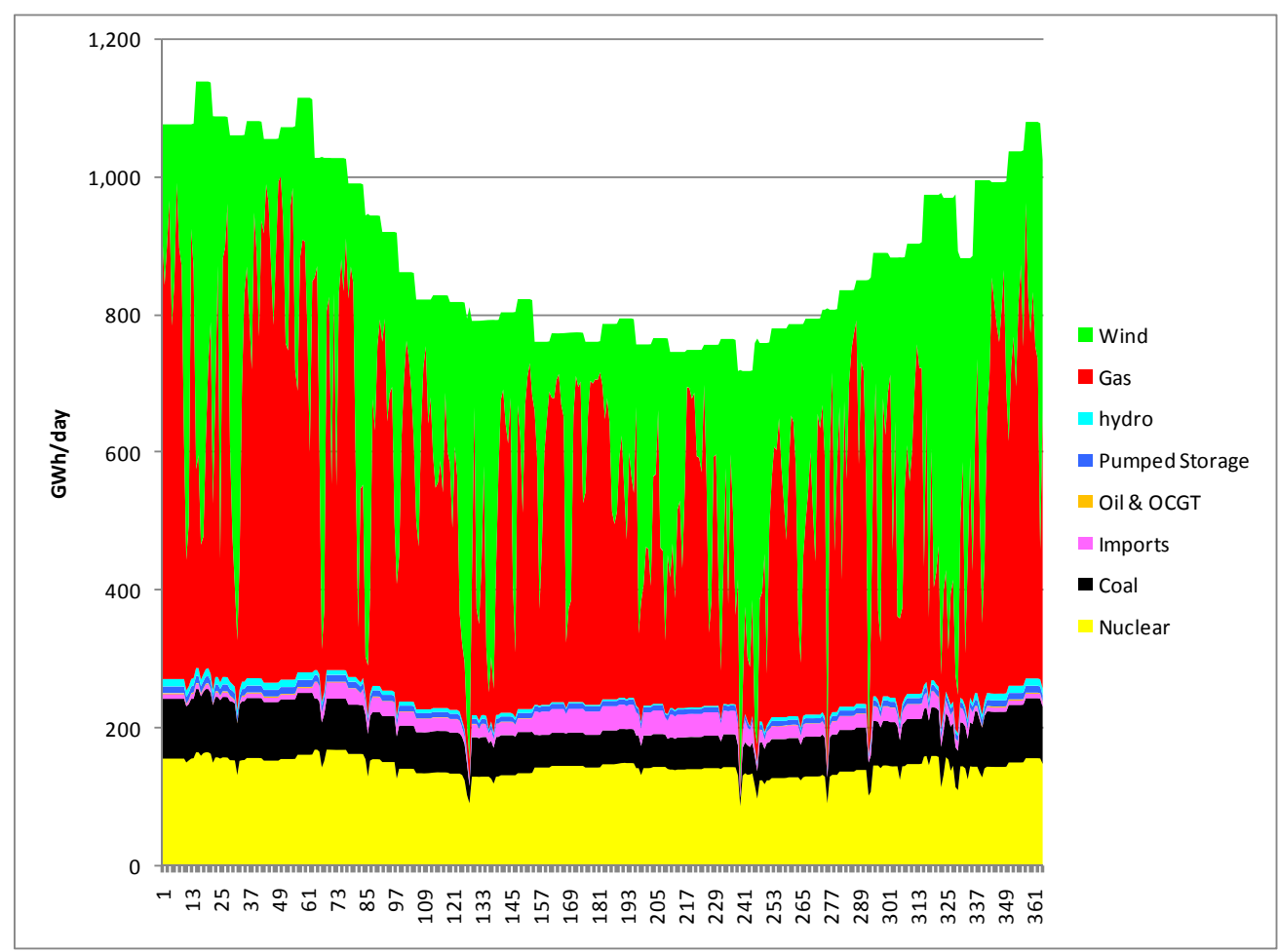

Sources: National Grid data and Own Analysis

Figure 44 clearly shows a number of incidences where wind generation requires the turndown of all other forms of generation. The situation is even starker at an hourly level as shown in Figures 45 and 46. In both these episodes all other forms of generation, including nuclear are reduced to zero and export of surplus power is required (the green areas above the demand line). Clearly this is not a situation consistent with a stable and manageable power system. 
Figure 45. Wind Power Surge in 2025, Days 121 to 127

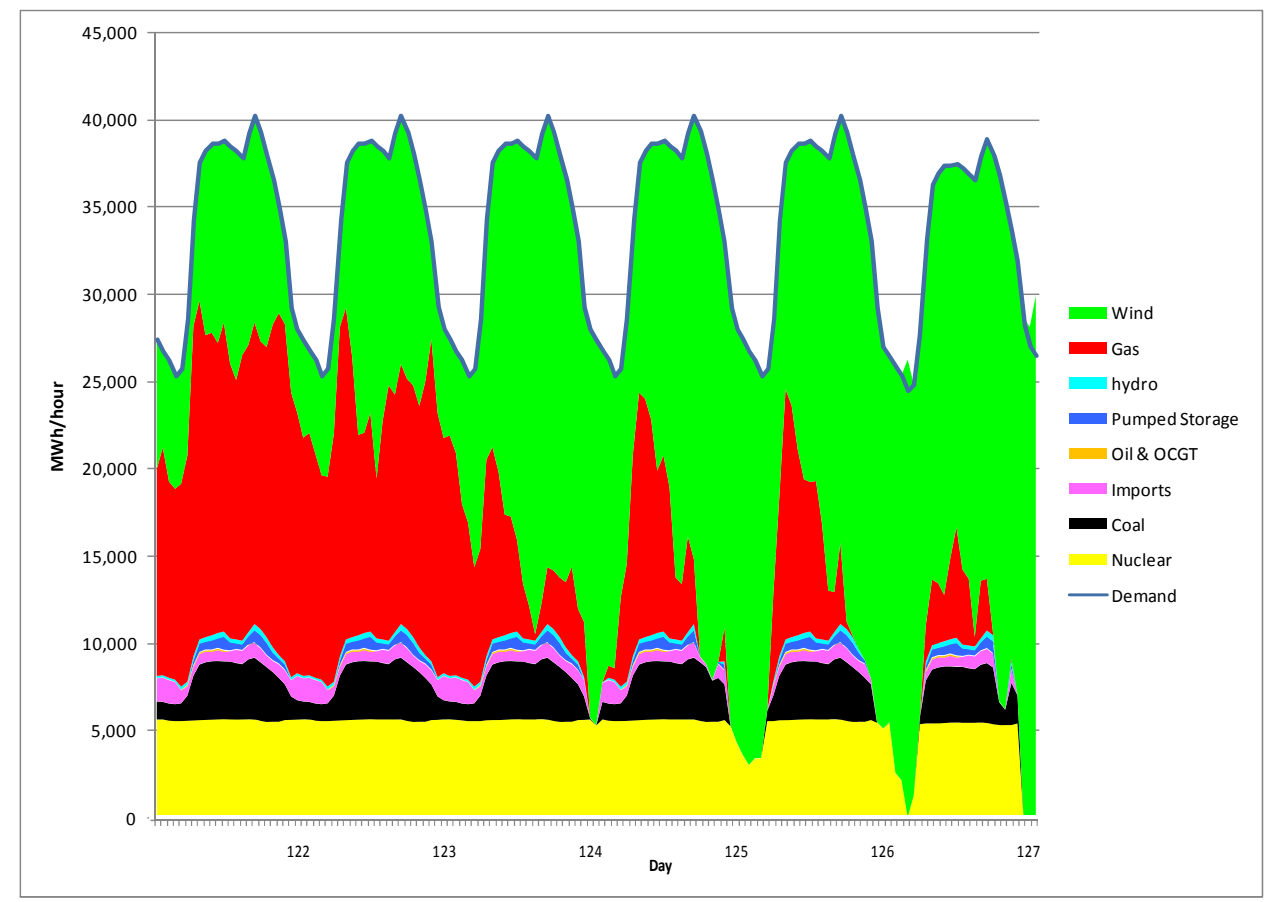

Sources: National Grid data and Own Analysis

Figure 46. Wind Power Surge in 2025, Days 241 to 247

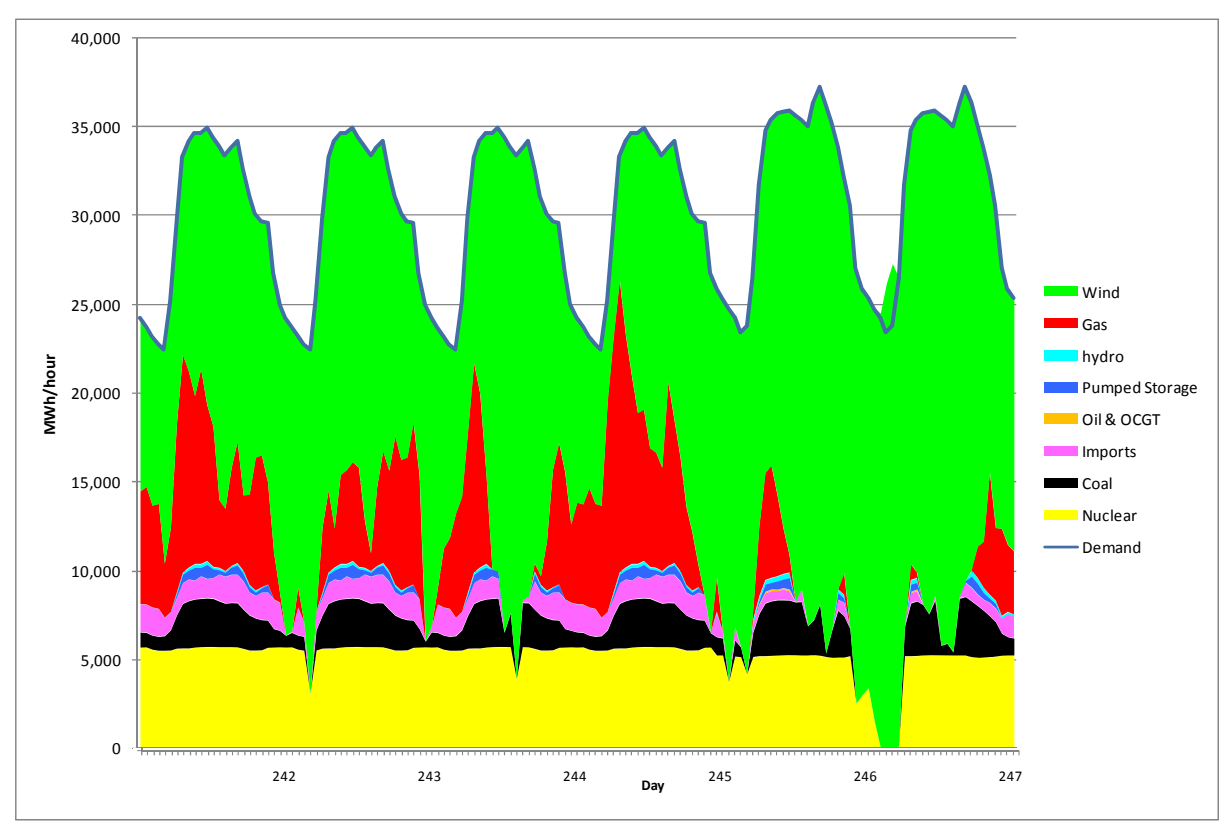

Sources: National Grid data and Own Analysis 


\subsection{Discussion of Results}

The foregoing analysis reaches some rather alarming conclusions as to the manageability of UK wind generation and the practical upper limit of capacity in the context of maintaining a workable transmission system. Prior to testing the possible objections to such findings an obvious question is whether other researchers have reached similar conclusions.

\section{Figure 47. Poyry Analysis of UK Hourly Power Balance with 43 GW of Wind Capacity}

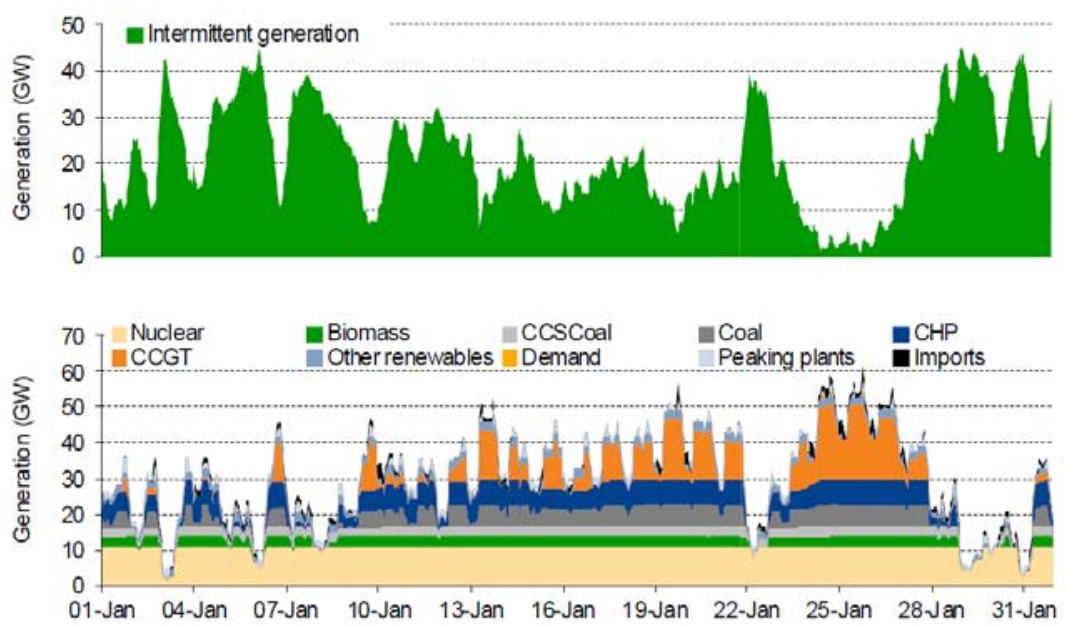

Source: Poyry 2010

Poyry ${ }^{93}$ modelled the UK power market assuming $43 \mathrm{GW}$ of wind capacity in 2030. Figure 47 is taken from their report and presents a hypothetical but very similar picture to the analysis in this paper. The report stressed the need for flexible generation to provide the buffering required to offset wind intermittency and suggested that in the UK context, gas is most suited to perform this role. The similarity of Poyry's conclusions to those reached in this paper provide firm support for the thesis that wind power variability/intermittency presents serious challenges at installed capacities above $28 \mathrm{GW}$.

The next question which arises is whether there are other means of managing the surges and lulls in wind power generation other than gas buffering, bearing in mind that the surges can build up (and fall away) very rapidly (as evidenced in the hourly graphics in Figs 42,43,45,46 and 47).

\footnotetext{
${ }^{93}$ Poyry 2010, P. 32, Figure 16
} 
While coal and nuclear are generally described as having 'limited' and 'little' ability to turn down output significantly at short notice, it has not proved possible to find any specific data for coal and nuclear plant of the vintage of those in the UK. In the UK the capacity of peaking plants (oil and OCGT), pumped storage and hydro are limited. As an alternative to intermittency buffering using flexible gas-fired generation, two other possibilities present themselves:

- export of surplus power to the continent; and,

- interventions to turn down wind generators' output.

Export of surplus power faces two constraints: the physical size of the interconnectors and the assumption that the receiving market will want to purchase this power. Table 8 shows future interconnector capacity at $3.8 \mathrm{GW}$. Usage of this export capacity would have certainly improved the situation as depicted in Figures 42 and 43 (2020), preventing the need, as shown hypothetically, to reduce coal fired generation. But for 2025, in Figures 45 and 46, the scale of the challenge to buffer the surge without encroaching significantly into nuclear generation is too great. An export capacity of around $6 \mathrm{GW}$ would be required for this (more if nuclear capacity is expanded in future), with additional export capacity needed to cover less flexible coal-fired generation. If coal or gas-fired generation capacity with carbon capture and sequestration is built beyond 2020, its degree of inflexibility, specifically the ability to turn down at short notice, will also need to be taken into account in terms of the requirement to balance the system. This consideration also applies to new nuclear generation capacity.

The role of interconnectors as a 'quick fix' is somewhat challenged by Poyry 2011which describes findings from detailed modelling of North West Europe and Scandinavia. Figure 48 shows their derivation of solar (yellow), onshore wind (dark green) and offshore wind (light green) generation over four selected months in 2010 and by contrast 2035.

Their main conclusions ${ }^{94}$ are:

- For 2035, the analysis highlights the high but unpredictable wind generation in winter, and the greater solar output in the summer months. A key and strong conclusion of the study is that in Northern Europe the overall output of the renewable generation will be highly variable, and will not average out because of weather and geography.

- Over time the operational position of all thermal plant in the market will be fundamentally altered: it will become increasingly marginal to the system and its operation far more uncertain, with starts being driven by the underlying weather, instead of responding to simple demand patterns. Inevitably the large amount of thermal capacity that essentially operates as a backup to the wind becomes more valuable for its capacity than its energy output.

- Greatly expanded interconnection over an even wider geographic area has been vaunted by several commentators and NGOs as a key to decarbonisation. However, a key finding was that the market price impact of increasing interconnection substantially (by almost 60GW in 2035) was very little in nearly all countries with the

\footnotetext{
${ }^{94}$ Poyry 2011, pp. 4, 8-11.
} 
exception of Nordpool where prices rise due to the interaction of hydropower exports to other countries.

- The heavy reinforcement of interconnection assumed in the analysis did not appear to significantly offset the need for backup plant. This surprising observation is due to the fact that weather systems - in particular high pressure 'cold and calm' periods in winter - can extend for 1,000 miles, so that periods of low wind generation are often correlated across Europe.

- While demand-side response at the moment is largely the domain of large industrial customers, future technological developments could enable this to include a far greater range of residential electrical uses, as well as in the future including electrification of heat and transport systems (for example the use of more heat pumps for heating, and extensive use of electric vehicles). Having modelled many of these in great detail Poyry found that in many ways 'demand-side' solutions are most suited to matching the needs of intermittency. Overall they found that, while 'demand-side' involvement may be attractive, the wide range of likely deployment patterns and technological developments will further complicate investment decisions - and quite possibly slow deployment.

\section{Figure 48.Aggregate Hourly Generation Output across North Europe for Four Months}

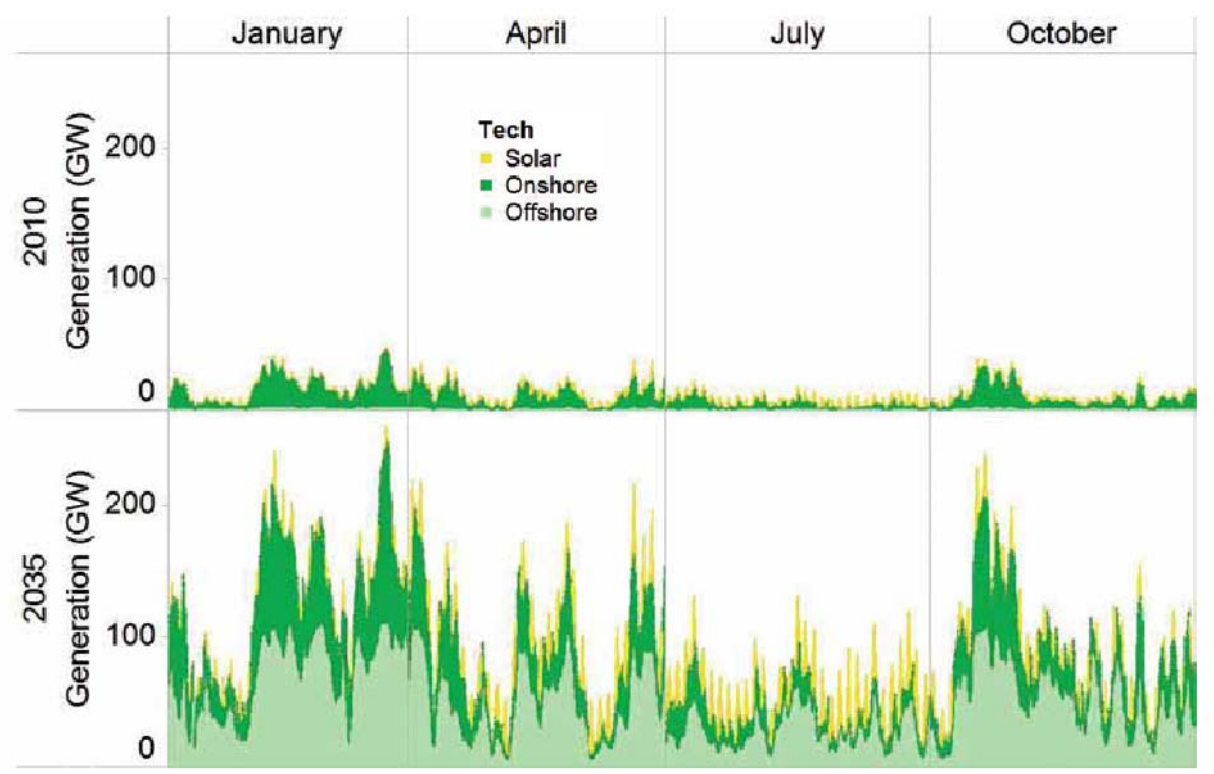

Source: Poyry 2011, P.4.

If, as Poyry concludes, interconnectors have a limited ability to cope with wind generation surges (for example in January and October in the 2025 plot in Figure 48 where Northern Europe is experiencing widespread high wind speeds), the obvious solution is to 'turndown' 
generators when their output is either not required or indeed when it jeopardises system stability. A foretaste of this issue is provided by a recent event:

In May 2011, six Scottish wind farms were asked to stop generating power on a particularly windy day in April 2011 as the transmission system between Scotland and England lacked sufficient capacity, resulting in a potential overload of the grid. ${ }^{95}$ The payments, so the article reported, were worth 'up to 20 times the value of the power they would have produced'.

The Renewable Energy Foundation ${ }^{96}$ provided further insight and background.

'National Grid is required to balance the supply and demand of electricity at all times, whatever fluctuations occur in each. The electricity Balancing Market exists to facilitate this and allows electricity generators to submit offers to sell and bids to buy energy from the system by increasing or decreasing generation. As necessary, the most cost-effective offers and bids are accepted by the electricity grid operator to balance the system, taking into consideration physical system constraints such as grid bottlenecks and the ability of generators to deliver within the timescales required.

The National Grid report demonstrates that there was a limited range of power stations capable of reducing output on request in early April, and that the costs of paying these generators to reduce their output covered a substantial range. The most economical plant was coal-fired, which offered to pay ${ }^{97} £ 28$ per MWh not to run. Some coal fired, gas fired and hydro generators were willing to reduce output at no cost, but some of these relatively economical offers could not be taken up by NG because the electricity system must always have access (to) sufficient controllable and flexible electricity generation sources to ramp up and down in order to maintain system frequency. Due to these limited options National Grid was obliged to pay wind farms to reduce output. The offer prices which the various Scottish wind farms set for such a reduction ranged from £150/MWh to £1,000/MWh. Fossil-fuelled power stations routinely pay into the system when asked to reduce output because they still receive their contracted payments, but also make savings on the fuel they have not had to burn.

Conversely, wind farms, when asked to reduce output, forego subsidies worth approximately $£ 50$ - £55/MWh from the Renewables Obligation Certificates and Levy Exemption Certificates, so require payment so as not to be out of pocket'

In the same Information Note the following is apposite:

The Renewable Energy Foundation has consistently argued that the scale and pace of wind power development has exceeded the ability of the system to integrate this uncontrollable energy source, and that high costs to the consumer would result as a consequence. Writing in

\footnotetext{
95 'Wind farms paid $£ 900,000$ to switch off for one night, Daily Telegraph, $1^{\text {st }}$ May 2011, http://www.telegraph.co.uk/earth/energy/windpower/8486449/Wind-farms-paid-900000-to-switch-offfor-one-night.html 
the preface to Paul-Frederik Bach's 2010 study for the Renewable Energy Foundation, Professor Michael Laughton observed:

The outstanding major concern in the work reported here, and one with very serious implications - especially for the United Kingdom with its predominantly island system with inadequate international interconnection capacity - is the extent to which subsidised wind power can, in practice, be used within the system without needing to be constrained off; in other words wasted, or exported at whatever market prices, perhaps disadvantageous ones, prevail elsewhere ${ }^{98}$.

Clearly for installed wind capacity above around $28 \mathrm{GW}$, an economically acceptable means by which wind power is 'turned down' needs to be implemented. This is particularly the case given that wind (and hence wind power generation) forecasting accuracy begins to fall off significantly between 6 and 12 hours ahead ${ }^{99}$ as shown in Figure 49.

Figure 49.Wind Forecasting Accuracy at 3, 6 and 12 Hours Ahead.

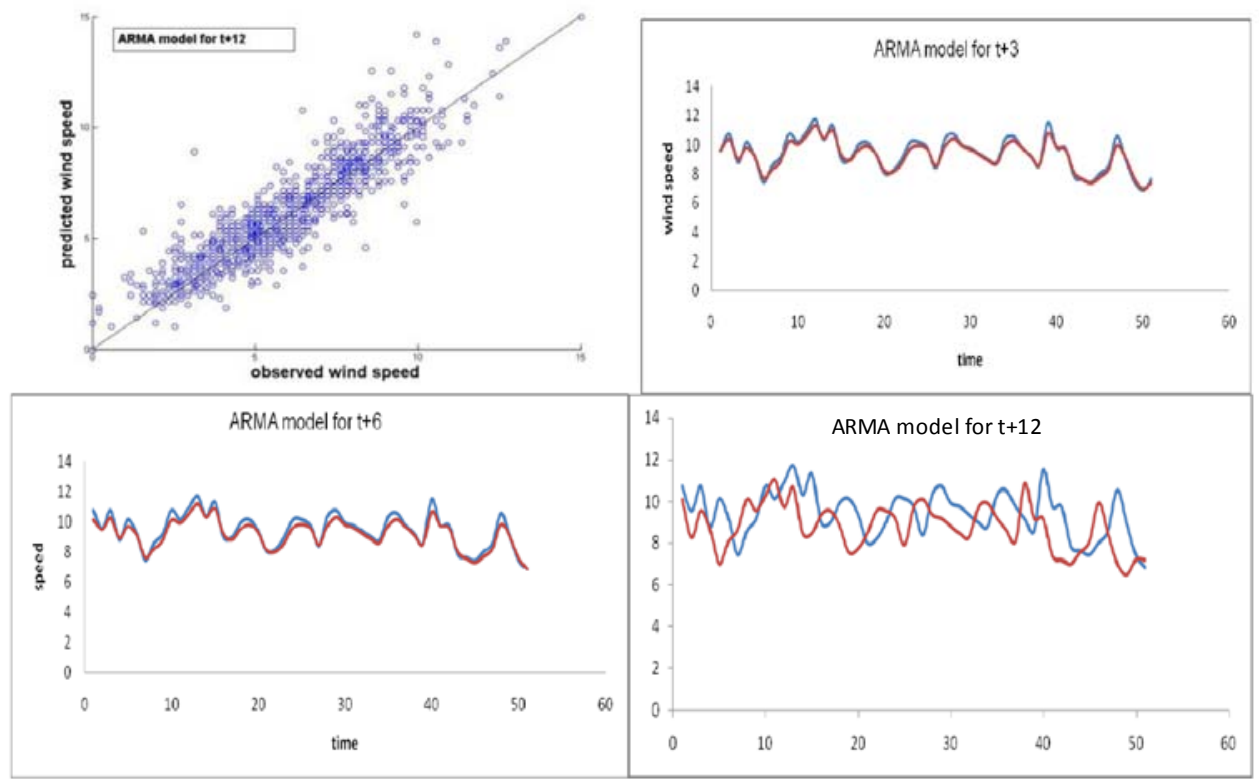

Source: Nyak \& Deo 2010

Notwithstanding the other important findings and future implications for the UK of a growth in installed wind generation capacity, the important conclusion for gas is that until technological breakthroughs are made on demand side management, gas' central role in providing buffering for variability in wind power generation is assured. In fact as installed wind capacity grows there is the danger that this 'crowds out' scope for less flexible

${ }^{98}$ REF 2011, pp. 1-2.

${ }^{99}$ Nyak \& Deo 2010, pp. 4, 7, 12. 
generation technologies such as nuclear and possibly fossil fuels with carbon capture and sequestration, unless this is facilitated by 'turn-down' of wind generation as an accepted means of maintaining system stability.

\subsection{Power Sector Gas Consumption and Flexibility Requirements}

From the modelling work described in section 6.4 and the concluding statements of Section 6.5 , the comparative gas consumption levels in the cases presented are summarised in

Table 9.

\section{Table 9. Gas Demand in UK Power Sector}

\begin{tabular}{|c|c|c|c|c|c|}
\hline & \multicolumn{2}{|c|}{ Power Generated from Gas } & \multicolumn{2}{|c|}{ Power Generated from Wind } & \multirow{2}{*}{$\begin{array}{c}\begin{array}{c}\text { Gas Demand in } \\
\text { Power* }\end{array} \\
\text { bcma }\end{array}$} \\
\hline & TWh & $\%$ of Total & TWh & $\%$ of Total & \\
\hline 2009 & 147.7 & $45 \%$ & 9.3 & $3 \%$ & 27.7 \\
\hline 2015 & 125.5 & $39 \%$ & 37.0 & $11 \%$ & 23.5 \\
\hline 2020 & 140.5 & $43 \%$ & 70.5 & $22 \%$ & 26.3 \\
\hline 2025 & 130.7 & $40 \%$ & 106.9 & $33 \%$ & 24.5 \\
\hline
\end{tabular}

* $50 \%$ efficiency assumed

Source: Own Analysis

Given the significant rise in wind generation as modelled, the demand for gas is remarkably robust. The two primary reasons for this are:

- The inherent need for gas to provide flexible balancing for wind and the significant variability of wind generation and,

- The gap left by the assumed retirement of coal-fired generation is assumed to filled by gas-fired capacity.

Finally we turn to the issue of flexibility requirements for gas supply in relation to its role in the power sector. The assessment of storage or flexibility needs in the power sector is described below:

- The hourly power sector gas consumption was determined from the modelling work described in Section 6.4. The mean hourly rate was determined. The difference between the mean hourly consumption rate (i.e. a constant, flat supply) and the actual hourly consumption was viewed as the flexibility requirement for gas in the power sector.

- The 2009 power sector gas flexibility requirements were matched by modelling a combination of a depleted field (to provide the general seasonal shape) and a salt cavern facility(to provide the shorter term flexibility). Using Table 10 as a guide, the depleted field was assumed to have a working gas capacity to withdrawal rate ratio of 95 days and an injection ratio of 125 days. The depleted field working gas capacity was calculated to be 1.5 bcm for 2009. The residual flexibility was provided by a salt cavern storage facility which was assumed to have a working gas capacity to 
withdrawal rate ratio of 20 days and an injection ratio of 20 days. The working gas capacity of salt cavern storage required was calculated to be $0.33 \mathrm{bcm}$.

Table 10. Storage Facility Characteristics

\begin{tabular}{|c|c|c|c|c|c|}
\hline Facility & Description & Injection & Withdrawal & $\begin{array}{c}\text { Operating } \\
\text { Costs }\end{array}$ & $\begin{array}{c}\text { Major } \\
\text { Use }\end{array}$ \\
\hline $\begin{array}{c}\text { Depleted } \\
\text { Fields }\end{array}$ & $\begin{array}{c}\text { Low deliverability, } \\
\text { low cycling, high } \\
\text { capacity }\end{array}$ & $\begin{array}{c}120-200 \\
\text { Days }\end{array}$ & 60-120 Days & $\begin{array}{c}\text { High with } \\
\text { some fuel } \\
\text { losses }\end{array}$ & $\begin{array}{c}\text { Seasonal } \\
\text { Cycling }\end{array}$ \\
\hline $\begin{array}{c}\text { Salt } \\
\text { Caverns }\end{array}$ & $\begin{array}{c}\text { Heligh } \\
\text { cycling, low } \\
\text { capacity }\end{array}$ & 20 Days & 5-20 Days & $\begin{array}{c}\text { Low with } \\
\text { minimal fuel } \\
\text { losses }\end{array}$ & $\begin{array}{c}\text { Peaking } \\
\text { Services }\end{array}$ \\
\hline Aquifers & $\begin{array}{c}\text { Low deliverability, } \\
\text { low cycling, high } \\
\text { capacity }\end{array}$ & $\begin{array}{c}120-200 \\
\text { Days }\end{array}$ & $60-120$ Days & $\begin{array}{c}\text { High with } \\
\text { some fuel } \\
\text { losses }\end{array}$ & $\begin{array}{c}\text { Seasonal } \\
\text { Cycling }\end{array}$ \\
\hline
\end{tabular}

Source: Schoppe 2010, Table 2, P. 20

- Equivalent storage volume requirements were evaluated for 2015, 2020 and 2025 whilst keeping the same level of depleted field capacity. As an alternative to salt cavern storage, 2015, 2020 and 2025 short term flexibility was assumed to be available from variable LNG regas output and the scale of this was determined compared with the UK's existing LNG regas capacity.

Table 11. Working Gas Volume for Power Sector Flexibility

\begin{tabular}{|r|c|c|c|}
\hline & \multicolumn{3}{|c|}{ Working Gas volume bcm } \\
\hline & Depleted Field & \multicolumn{2}{|c|}{ Salt Caven Storage } \\
\hline 2009 & 1.50 & Absolute & Incremental to 2009 \\
\hline 2015 & 1.50 & 0.33 & - \\
\hline 2020 & 1.50 & 0.68 & 0.35 \\
\hline 2025 & 1.50 & 1.50 & 1.17 \\
\hline & & 1.44 & 1.11 \\
\hline
\end{tabular}

Source: Own Analysis

As shown in Table 11, the analysis suggests that to provide the flexibility for gas in the power sector as wind capacity grows in line with the assumptions in Figure 34, an additional 1.17 bcm of salt cavern storage is required by 2020 . While this may appear a relatively low figure it is important to appreciate that the issue here is the magnitude of short term variability, 
rather than the change in storage inventory. This accords qualitatively with Poyry's ${ }^{100}$ conclusion that ...'that the gas market was able to deliver in an intermittent world with only relatively minor perturbations - although the work did highlight potential need for more storage facilities that could respond in much shorter timescales, so-called 'fast storage'. This additional storage capacity is, however, relatively small and not needed until the end of the decade'.

Alternatively such flexibility could be provided by varying re-gasification output, albeit with the added requirement to increase LNG storage tank capacity by the volume equivalent to the additional salt cavern storage working gas volume shown in Table 10.

Figure 50. Illustration of Scale of Short Term Flexibility via Regasification Terminals

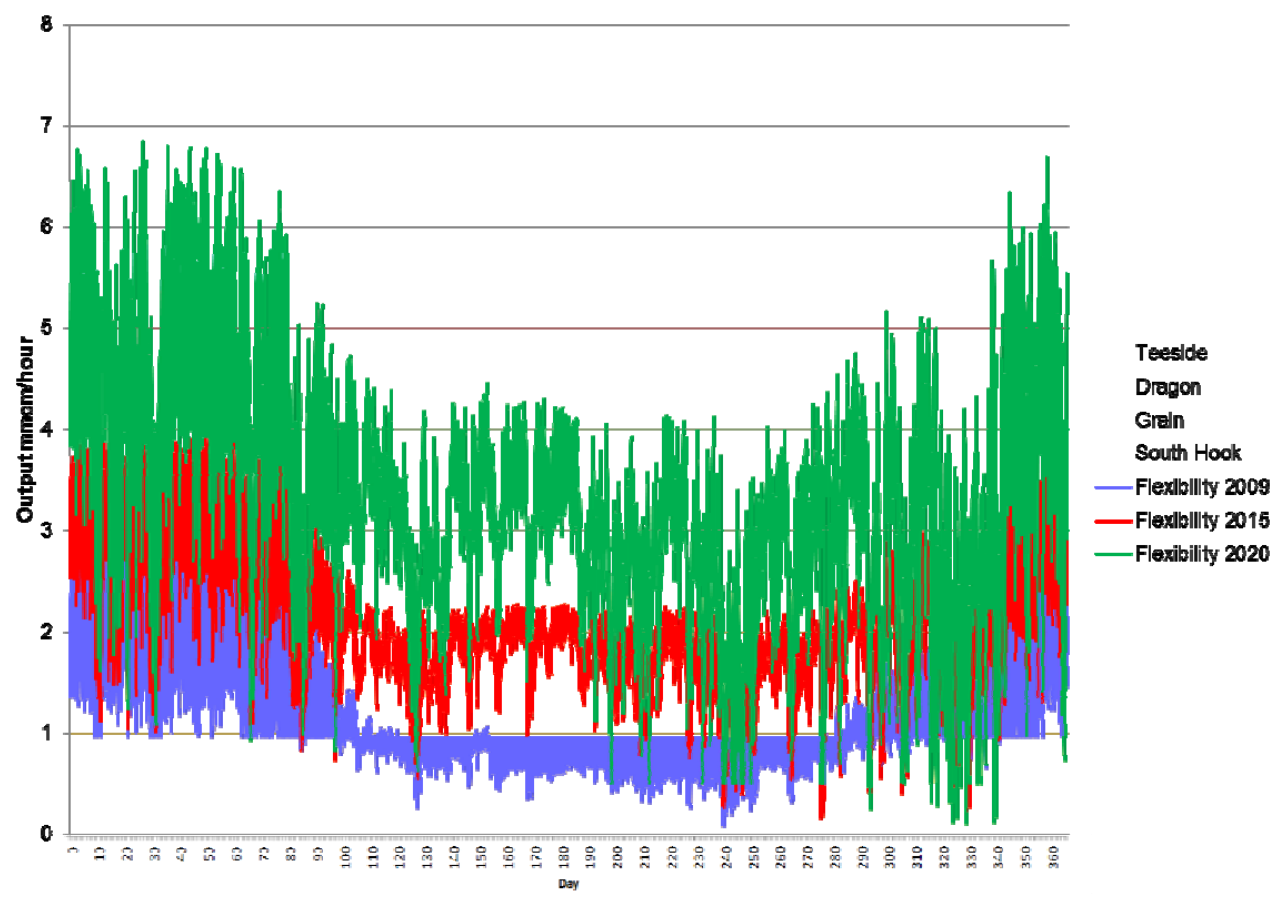

Sources: National Grid 2010a, Table 4.7 A, P.61, Own Analysis.

Clearly the addition of a further $1.17 \mathrm{bcm}$ of salt cavern storage by 2020 is feasible. At present the UK has $0.5 \mathrm{bcm}$ of salt cavern storage with a further $0.67 \mathrm{bcm}$ reported as under construction. ${ }^{101}$ It is likely however that capacity owners in the UK's LNG regas terminals might see a business opportunity to participate in the provision of short term flexibility. From Figure 50 however, it seems unlikely that the required flexibility by 2020 will be provided from regas terminals alone. This would require regas capacity $20 \%$ above that which exists in 2010 operating at times purely to provide balancing for wind generation. A further consideration relates to the distance between the primary wind generation areas

\footnotetext{
${ }^{100}$ Poyry 2010, P. 49

${ }^{101}$ GSE 2010a, UK data on storage investment database.
} 
(offshore north and east UK), gas-fired generation sites (more generally distributed) and regas terminals (primarily South Wales and Thames estuary). Modelling the dynamics of the gas and power transmission networks and their ability to respond to inputs and withdrawals is beyond the scope of this paper, however such considerations may require the installation of fast acting salt cavern or LNG peaking storage in addition to those calculated in Table 11. 


\section{Chapter 7.Conclusions}

The UK market has made a rapid transition from a self-sufficient exporter (with significant seasonal flexibility from indigenous gas fields) to significant net importer status. Almost unnoticed in this transition, much of the UK's seasonal flexibility is now supplied by Norway and the Netherlands which have chosen to size their linking pipeline infrastructure to be able to flow substantially more gas in the winter season than in the summer.

As the most liberalised gas market in Europe, the UK is able to offer 'direct line of sight' to customers via a liquid traded market. Without recourse to offering oil-indexed long term contracts, which (until recently) were the norm in Europe, the UK has successfully attracted investment in import infrastructure which in 2010 totals 150 bcma compared with typical annual consumption of 90 to $100 \mathrm{bcma}$.

Where the UK market has been unsuccessful to date is in investing in significant gas storage capacity, such that as a percentage of annual consumption it is far lower than other major European gas markets.

There is considerable uncertainty as to the composition of the UK's gas supply mix towards the end of the current decade. With European domestic production in decline and uncertainties as to the viability, scale and timing of shale gas development in Europe, incremental imports for north west Europe during the 2010s are likely to be supplied by Russia, the global LNG supply pool and, at the end of the decade, the Caspian region. Even in a post oil-indexed contract world, Russia is unlikely to wish to engage in a battle for market share to the extent that it reduces hub prices. The more likely dynamic is that Russia will seek to 'balance' the European market, at a 'reasonable' hub price level, fitting in with an uncertain level of future available LNG supply.

Two supply scenarios were constructed for the global LNG-connected world - LNG Rules the Waves and Russia Fills the Gap - to define two reasonable points on a supply mix spectrum for a UK market at 'the end of the pipeline' from Russia, and as an open market for available flexible LNG supply. This highlighted the real possibility of uncertain but significant changes in the UK's supply mix, and the critical role played by infrastructure linking the UK to the European Continent - namely the IUK and the BBL lines. Given the scale of the UK's already existing import infrastructure, there is adequate import capacity at least until the early 2020s, provided that supply is forthcoming.

A key dilemma for the UK is to ascertain the means by which seasonal flexibility will continue to be provided as indigenous production declines and progressively loses its 'seasonal bounce'. Absent assumptions of high future price volatility, new storage projects cannot be justified based on the summer - winter price differentials displayed by the forward curves of mid-2011. If no additional storage is built in addition to those projects already under construction, the UK will effectively need to 'outsource' its flexibility needs to storage facilities on the North West European Continent where some $14.8 \mathrm{bcm}$ of new onshore facilities are currently under construction. As a consequence flows through the IUK and BBL 
lines will exhibit highly seasonal flowrates with the magnitude of seasonality growing through time.

The issue for the UK, particularly in the 'Russia Fills the Gap' scenario, is what would be the consequence of a low probability, high impact event: for example, the IUK shutting down, as it did in 2002 for a period of 34 days - which would prevent the UK accessing continental European supplies and storage. Although diversion of supply by Norway from the Continent to the UK and re-direction of LNG in response to higher price signals would serve to mitigate this situation, the UK could still suffer supply shortages for a relatively short (but politically acute period), with wholesale prices rising to choke off industrial demand, causing fuel switching in the power sector and possibly also rationing supply to residential and commercial end users.

The cost of providing an additional $4 \mathrm{bcm}$ of storage is of the order of $£ 2$ - 3billion. If such additional capacity is not provided by commercial investors, it should be funded through some form of government - imposed customer service obligation. When compared to the cost of renewables support and the associated cost of grid reinforcement (£190 billion - $£ 200$ billion) for the Ofgem Green Transition and Green Stimulus scenarios, this is a relatively modest premium to pay to mitigate the risk of the type of infrastructure failure event which has already occurred twice in the 2000's ${ }^{102}$, but when domestic production was higher and more flexible than it is now.

The gas industry has to date failed to make its case at a policy level for inclusion in the energy mix as part of the carbon reduction drive to meet $\mathrm{CO}_{2}$ and renewables targets by 2020 . The Green Lobby regards gas as 'just another fossil fuel' and the strapline from the industry that 'gas is $50 \%$ cleaner than coal' (in terms of $\mathrm{CO}_{2}$ emissions in power generation), has not proved so far to be one that has convinced the carbon community. The European Gas Advocacy Forum ${ }^{103}$ commissioned a report ${ }^{104}$ which demonstrated that European $2050 \mathrm{CO}_{2}$ abatement targets can be met at considerably lower cost by a higher utilisation of existing gas-fired capacity, an increase in nuclear generation, an earlier phase-out of conventional coal-fired generation and less emphasis on offshore wind generation. As CCS technology matures (it is assumed), by 2030 it will be deployed in gas-fired generation. While the report describes its 'optimised pathways' in great detail, it is not a particularly accessible read for a non-energy sector audience. The report does provide a credible basis from which to launch a lobbying campaign, however such a campaign will require more than painstaking analysis. While the task of defining a more convincing de-carbonisation strategy for gas continues ${ }^{105}$, what is clear from this paper is that a truism (though not a particularly elegant headline) for gas in the present decade is 'want wind, need gas'.

It would appear that the more ambitious targets for wind generation in the UK have been formulated without a full appreciation of the costs and complexities caused by intermittency

\footnotetext{
${ }^{102}$ Rough Fire and IUK outage - see page 42.

${ }^{103}$ An industry group including Centrica, Eni, E.ON Ruhrgas, Gazprom, GDF SUEZ, Qatar Petroleum, Shell and Statoil.

${ }^{104}$ EGAF 2011

${ }^{105}$ see Van Foreest 2011
} 
of very substantial levels wind generation. The analysis in Section 6 concludes that the maximum feasible limit of 'unconstrained' wind generating capacity for the UK is around 28 GW. At higher levels than this, the country faces the prospect of short notice intervention to reduce turbine output with the added complication that forecasts of wind speed (and hence generation output) beyond six hours into the future are inherently uncertain. National Grid, in its 'Operating the Electricity Transmission Networks in 2020', June 2011 Update, estimated the cost of managing wind variability by 2020 at $£ 286$ million $^{106}$.

Gas will have to play a key role in providing the flexible buffer generation which will allow the power system to cope with varying wind speed and consequently varying power output. With coal (including coal with carbon capture and sequestration) and nuclear likely to have much lower short term turndown flexibility, gas has a key role to play. Electricity interconnectors are not a solution to this issue since high and low wind events are likely to be correlated across much of North West Europe. The conclusion of this analysis is that, depending on the assumptions made on the pace of unabated coal generation retirement and future nuclear capacity build, the scale of gas consumption in the power sector by 2020 will need to be little changed from 2009 levels, even with 28 GW of wind capacity.

The additional short term gas supply flexibility, in the form of salt cavern storage, required to allow gas to support wind generation was found to be reasonable - a little over $1 \mathrm{bcm}$ of additional salt cavern storage capacity by $2020^{107}$ (or less if varying regas terminal output provided some of this flexibility). This would be capacity required over and above that required for seasonal space heating flexibility, or to provide short term supply/demand balancing due to factors other than wind-related perturbations.

One key aspect which is mentioned in passing but is beyond the scope of this paper is the issue of how investment in new gas-fired generation (needed to buffer wind as coal, and perhaps older gas-fired, generation capacity is retired) is to be encouraged given the uncertainties in load factors caused by an unpredictable future growth trajectory in wind capacity.

The aim of this study has been to explain and 'de-mystify' the uncertainties of the UK's future gas supply mix in an increasingly LNG-connected world, and to confirm and quantify the extent to which a substantial increase in the share of wind generation will affect gas-fired generation. The conclusion is that gas will retain a central and undiminished role in the UK's power generation mix up to 2025 - however ensuring that additional storage capacity will be constructed is unfinished business which requires near term action.

\footnotetext{
${ }^{106}$ National Grid 2011b, para 2.22, P. 10

${ }^{107}$ However this may need to be higher to provide system-wide balancing given the differing locations of wind and gas fired generation.
} 


\section{Appendix A: Critical Assumptions made in the analysis.}

This Appendix describes in some detail the key assumptions about future supply, demand and storage build for key elements of the modelled system. Where there is a range of uncertainty as to the future trend of the variable in question this is openly discussed.

\section{UK Gas Demand}

Figure A1.UK Gas Demand 2001 to 2025

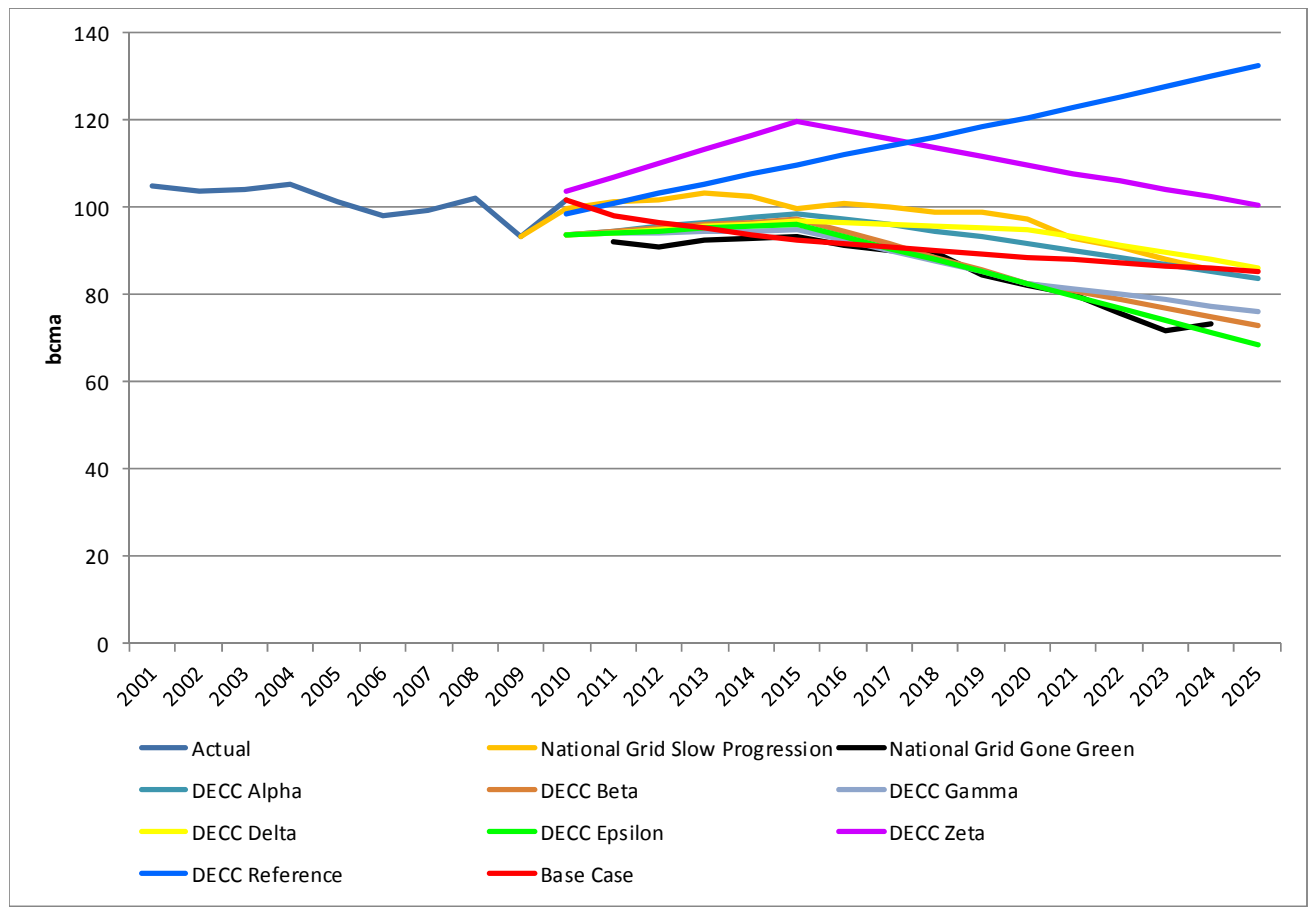

Sources: IEA Monthly Data, National Grid 2010a, Figs 3.5A ${ }^{108}$

In the context of the drive to achieve 2020 environmental targets, there is unsurprisingly a wide range of views on future gas demand trajectories. Figure A1 shows the Base Case (red line) used in this forecast (assuming 'normal' temperature years for 2011 onwards), the National Grid's Slow Progression case (orange line) and the Gone Green case (black line). For comparison the seven DECC cases from their Pathway Analysis are shown. ${ }^{109}$ The Base Case is similar to DECC's low gas cases until 2018 after which it is higher but still no higher than DECC's Beta, Gamma and Delta cases. In deriving the Base Case view of UK gas demand for the analysis, the British Gas Home Energy Report $2011^{110}$ was reviewed. Energy efficiency savings were identified in the domestic sector arising from the installation of energy efficient boilers, wall cavity and loft insulation and energy advice. Some of the

\footnotetext{
${ }^{108}$ Note that the National Grid demand data has been scaled to match IEA actual data for 2009.

${ }^{109} 2050$ Pathways Analysis as presented in Poyry 2010, Figure 7, P. 17

${ }^{110}$ British Gas 2011
} 
report's findings were incorporated in the demand forecast shown above as 'Base Case' although it was judged that such savings were subject to a 'creaming effect', i.e. that the savings would be subject to diminishing returns as the population of households able to afford such savings was exhausted.

In order to derive a typical, sectoral monthly demand profile for future years, a combination of IEA and Eurostat monthly data from January 2000 for the power and non-power sectors was used. Figure A12 illustrates this effect in the context of total European demand. Short term intermittency effects due to variable wind turbine output were not included in this analysis as these are addressed specifically in Chapter 6.

\section{UK GasProduction}

As with UK demand there is a range of views of the future trend of UK domestic production. Figure A2 shows actual annual production data for 2005 to 2010. From 2010 onwards Wood Mackenzie and National Grid have widely differing views, mainly due to the assumed timing of gas in the 'Technical' category; i.e. improved recovery from existing fields. For this analysis, an assumed future trend is more closely aligned with the National Grid projection. ${ }^{111}$ No upside has been specifically assumed for a future in which shale gas is successfully developed at scale in the UK. If shale is successful its impact would likely slow the decline in post 2020 conventional UK production.

Figure A2. UK Annual Production 2005 - 2025

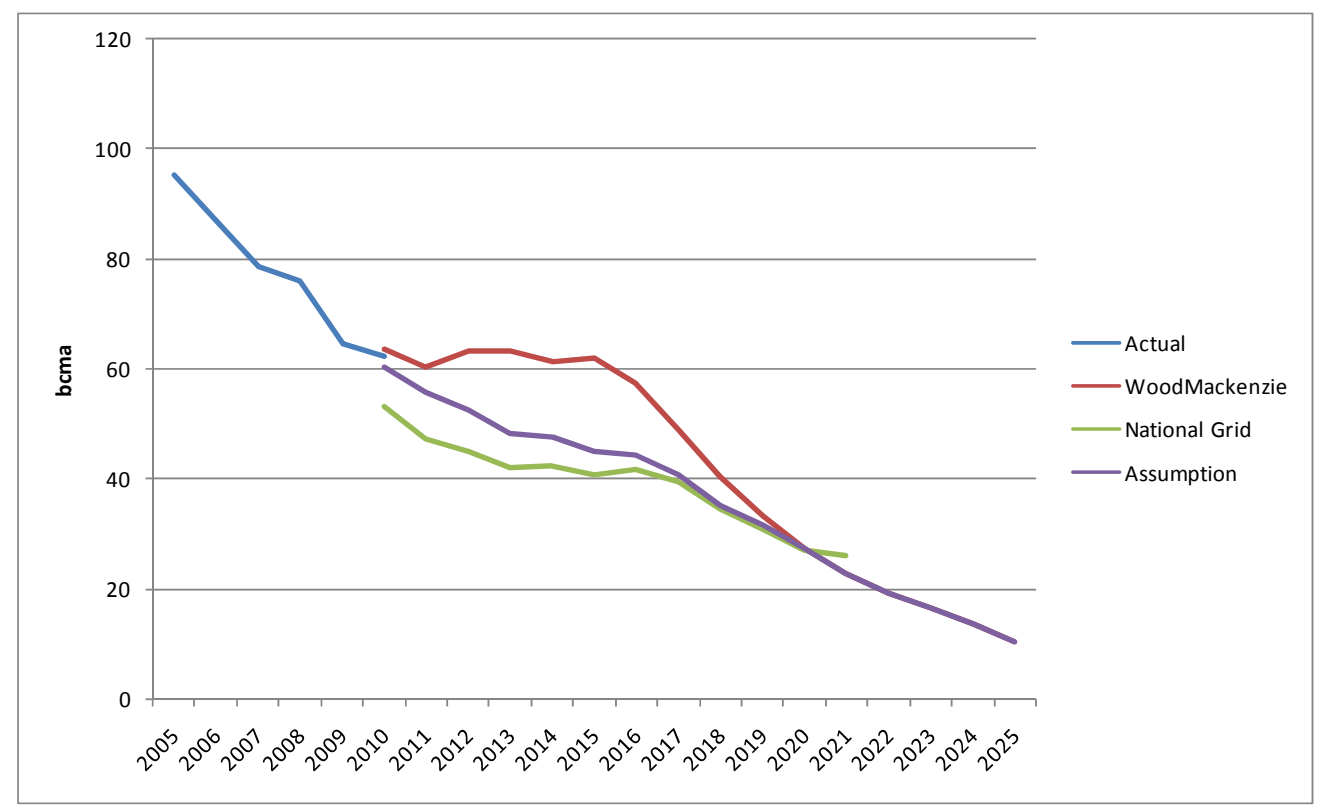

\footnotetext{
${ }^{111}$ National Grid provides projections on the basis of 'gas contract years' i.e. from October through September of the following year. This introduces some uncertainty in the representation of an equivalent calendar year data set.
} 
Sources: IEA Monthly Data, Wood Mackenzie North Sea Service 2010), National Grid 2010a, Figure 4.8G,P. 74.

In order to create a monthly projection for this paper, five years of DECC individual field data was combined with Wood Mackenzie data on future annual production at field level. The resulting projection was then scaled to fit the 'Assumption' curve on Figure A2 at an annualised level. FigureA3 shows actual historical UK monthly production data (blue) and the derived future projection (green).

Figure A3. UK Gas Production - 2005 - 2025.

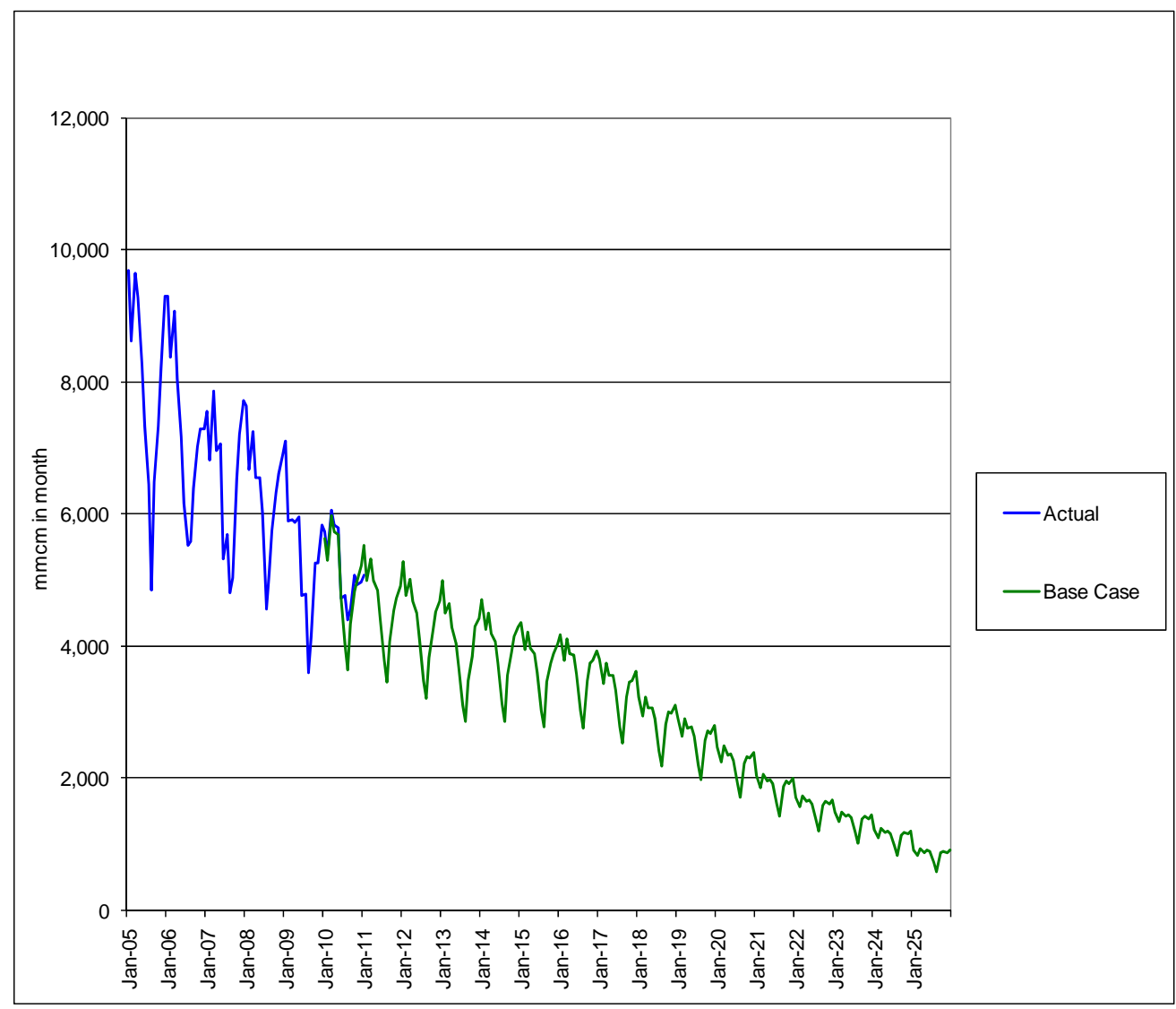

Sources: IEA Monthly Data, DECChttps://www.og.decc.gov.uk/pprs/full_production.htm, Own Analysis.

The projection shows a continuation of the annual production decline seen since the beginning of the 2000s and the progressive loss of seasonal swing as older fields with buyernominated contracts and the seasonally produced Morecambe Bay field decline.

Norwegian Production WoodMackenzie (orange line) and National Grid (blue line) again have differing views of future Norwegian production as shown in Figure A4. Also shown are the high (green) and low(red) boundaries of the range shown in a presentation by the 
Norwegian Ministry of Petroleum and Energy at the 2011 FLAME Conference. ${ }^{112}$ The current Norwegian export capacity of 120 bcma is shown as a black hashed line.

Figure A4. Future Annual Norwegian Production.

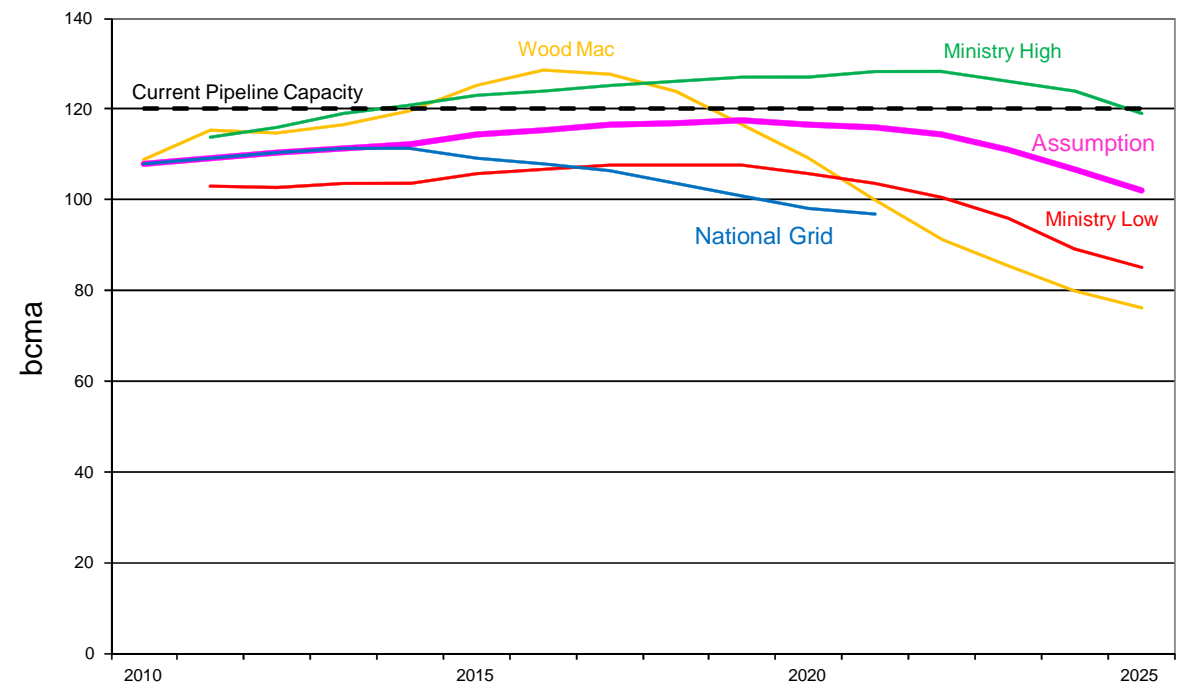

Sources: Wood Mackenzie North Seas Service 2010, National Grid 2010a, Figure 4.5A, P.56, Norwegian Ministry of Petroleum, FLAME 2011 Presentation

From the Norwegian Petroleum Directorate website, five years of monthly field level production data was assembled ${ }^{113}$. When combined with WoodMackenzie's view of the future annual production for the same fields an aggregate monthly Norwegian gas production profile was derived. This was scaled to correspond to the 'Assumption' profile in Figure A4. This is the future level of Norwegian production used in the analysis. The resulting future monthly trend is shown in Figure A5.

\footnotetext{
${ }^{112}$ Presentation by Erik Johnsen, Deputy Director General Norwegian Ministry of Petroleum and Energy, FLAME Conference, May $12^{\text {th }} 2011$, Slide 5.

${ }^{113}$ NPD 2010
} 
Figure A5. Future Norwegian Gas Production

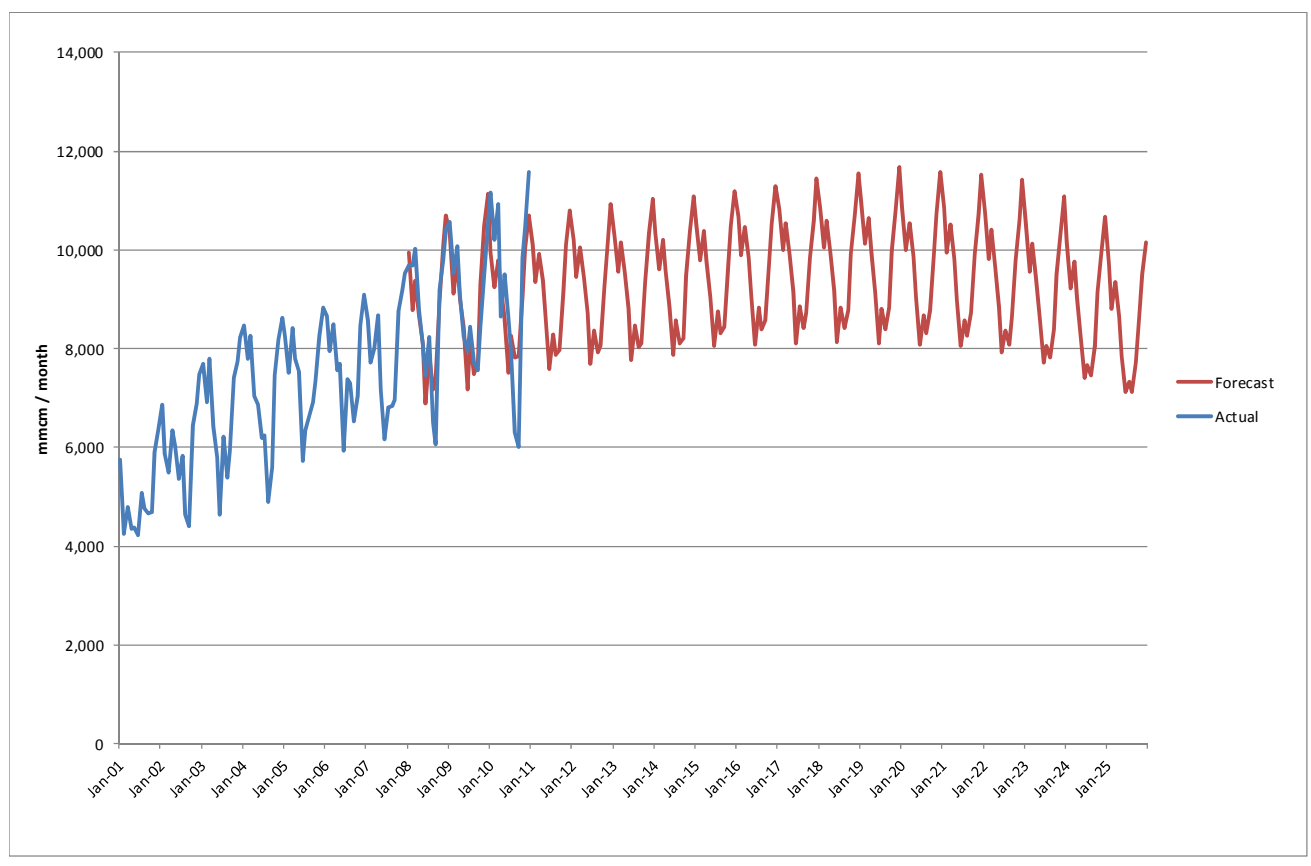

Sources: IEA Monthly Data, own analysis based on NPD, Wood Mackenzie North Sea Service 2010, Norwegian Ministry of Petroleum

Unlike the future UK monthly profile, the longevity of the Troll field in Norway ensures that production is capable of a high level of seasonal swing into the future.

\section{Netherlands Production}

A view of past and future annual Netherlands production was obtained from the Dutch Ministry of Economic Affairs Oil and Gas Portal ${ }^{114}$, and is shown in Figure A6.

${ }^{114}$ NL 2010 
Figure A6. Netherlands Annual Gas Production 2000 - 2034

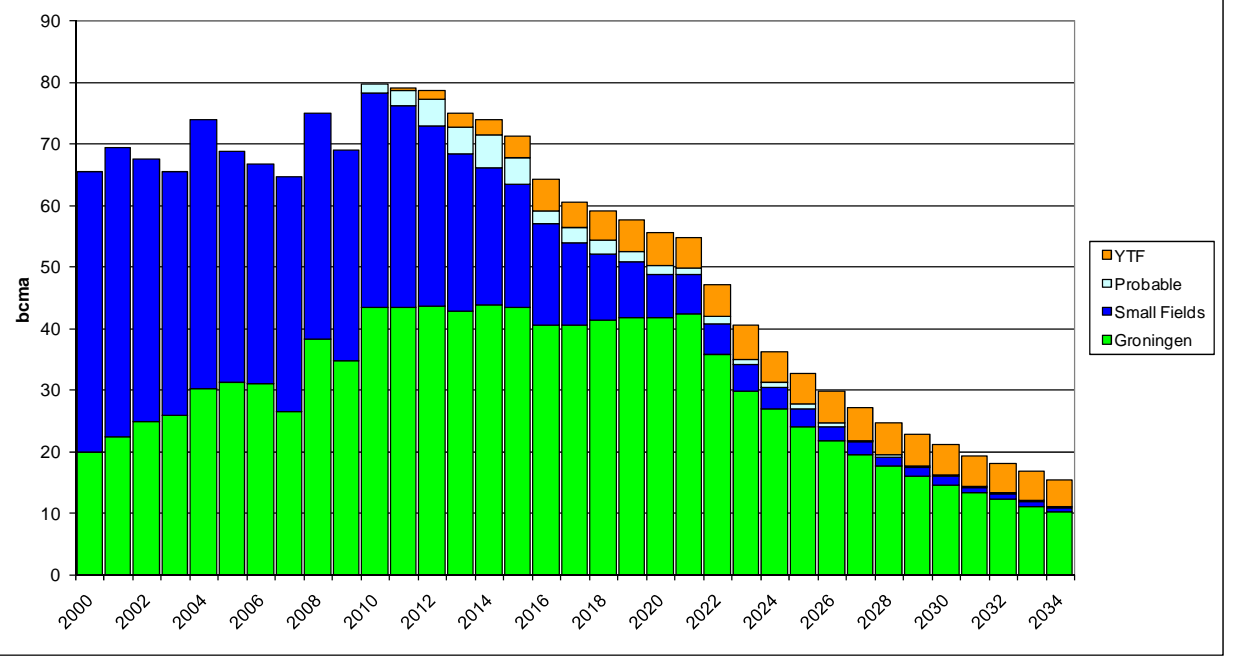

Source: Dutch Ministry of Economic Affairs (normalised to $38.43 \mathrm{Mj} / \mathrm{m3}$ )(because of presence of hi-cal and lo-cal fields)

The same source also provides a year of recent monthly field level production data, which combined with the above annual series allows us to construct a future monthly gas production view, shown in Figure A7.

\section{Figure A7. Future and Recent Actual Netherlands Monthly Gas Production}

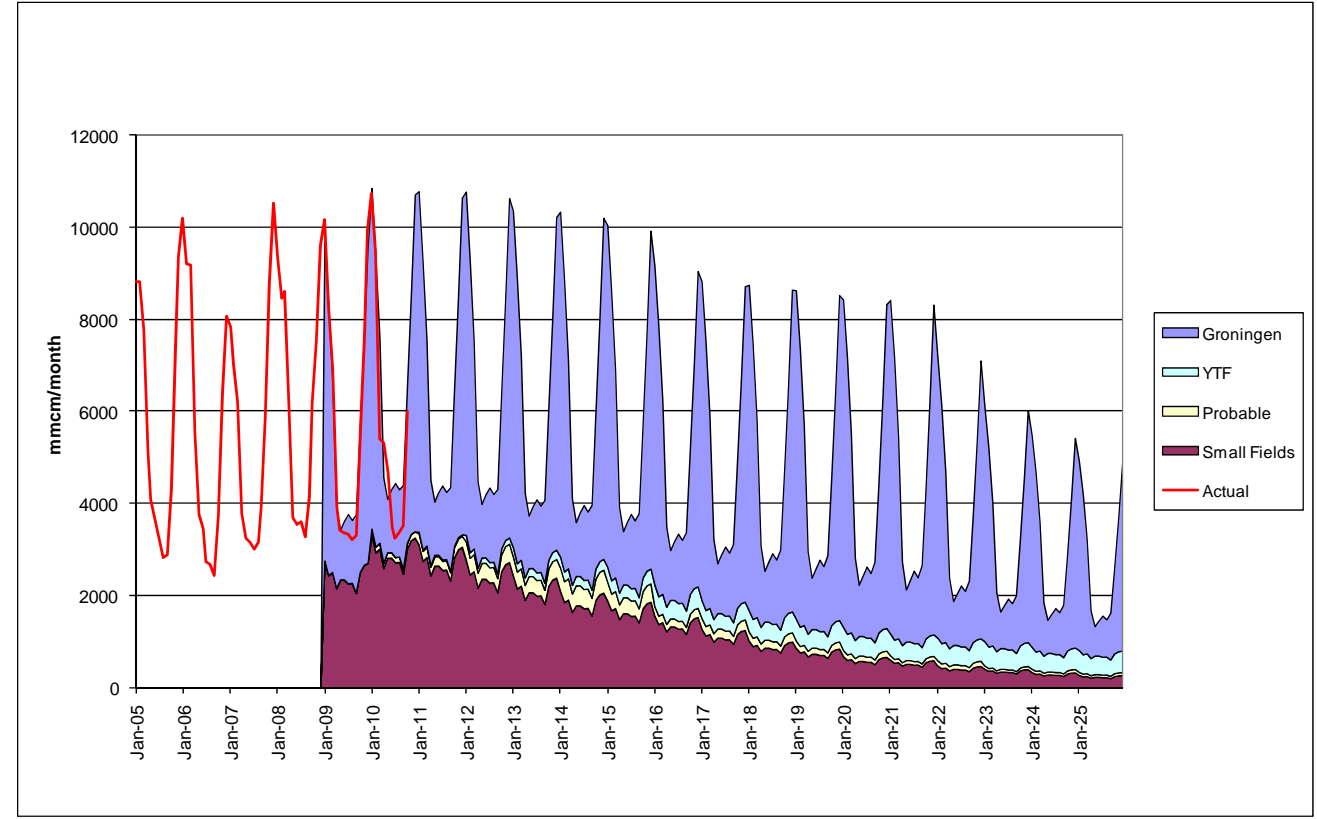

Source: IEA Monthly Data, Dutch Ministry of Economic Affairs 


\section{Denmark and Other European Production}

Figure A8 shows historic actual Danish production and future projections from EnergieStyrelsen ${ }^{115}$

\section{Figure A8. Past and Future Danish Gas Production}

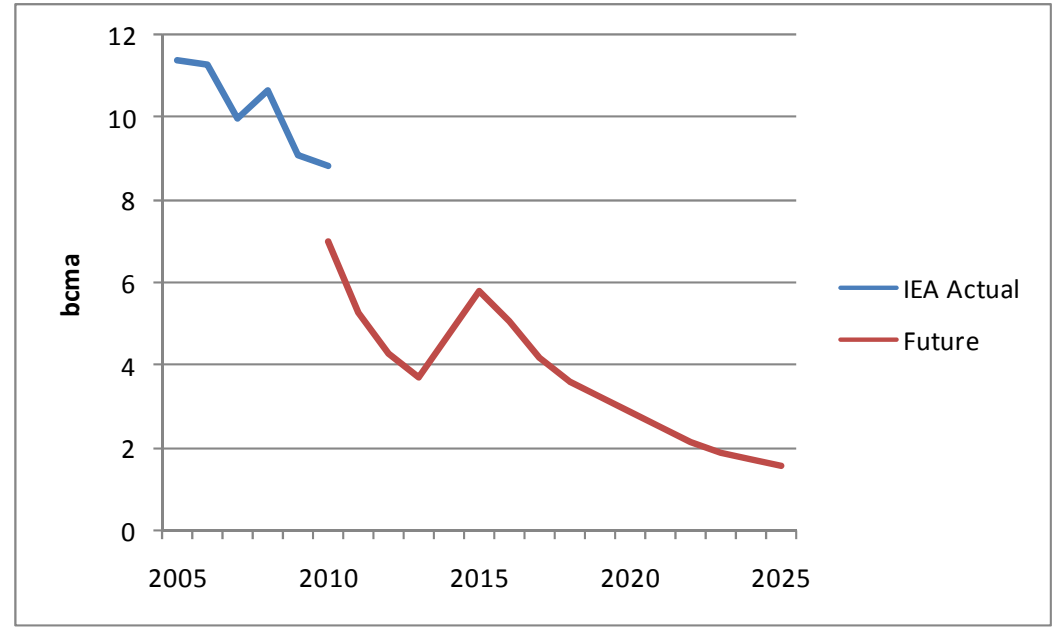

Source: EnergieStyrelsen 2010.

\section{Figure A9. Other European Gas Production}

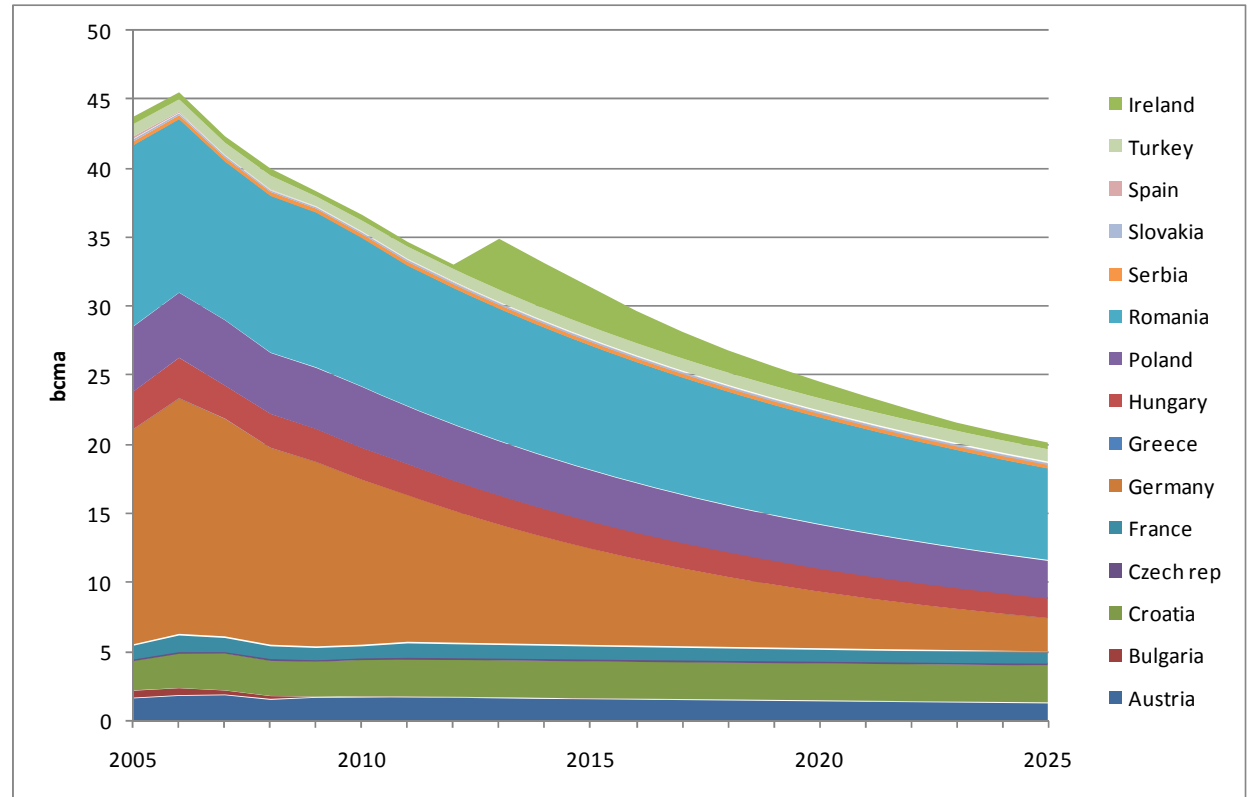

Source: IEA Monthly Data, own analysis.

${ }^{115}$ EnergieStyrelsen 2010: Figure 6.7, P. 83. 
Other European future gas production was estimated at an annual level by assuming a future decline profile. Figure A9 illustrates this, with 2005 to 2010 as actuals from the IEA and post 2010 levels as projections. The sharp increase in Irish production is due to the Corrib field which is assumed to commence production in 2013.

Applying average monthly profiles for producing countries to this future annual projection enables a monthly projection to 2025 to be derived. For the countries shown in Figure A9 as well as Denmark, Figure A10 shows the future monthly profile for 'Other European Producers'

\section{Figure A10. Historic and Projected 'Other European' Production}

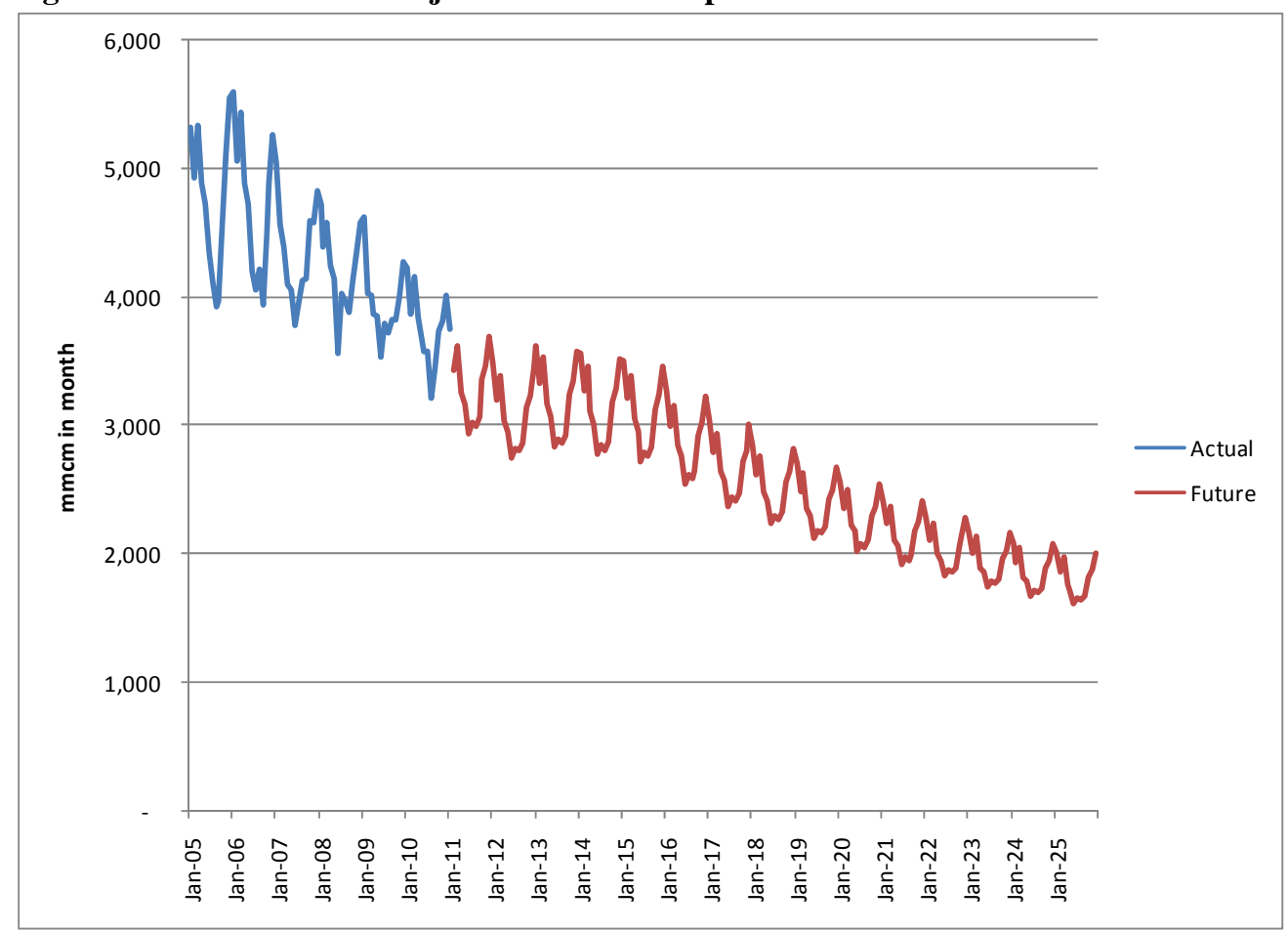

Source: IEA Monthly Data, Own analysis

Finally Figure A11 shows a plot of total monthly European gas production from 2001 to 2025; Actual and Projected. The period of overlap between January 2008 and December 2010 (where the forecast is based on historic average monthly profiles applied to actual annual demand data) suggests that this approach is reasonably robust. 
Figure A11. Total European Monthly Gas Production 2001 - 2025

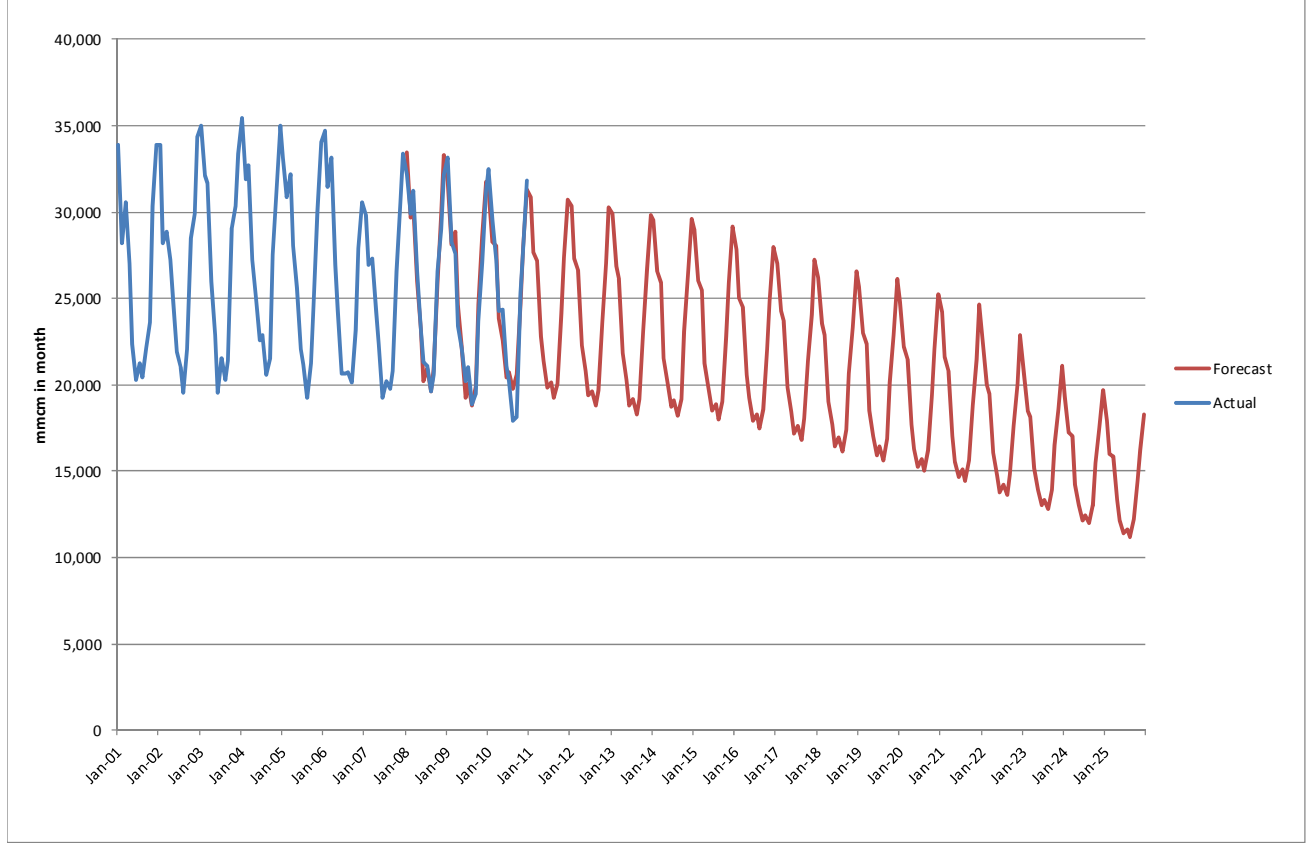

Source: IEA Monthly Data, Own Analysis

\section{Shale Gas}

As extensively discussed in Gény 2010, if current exploratory drilling of shale plays, notably in Poland, Germany and the UK are successful technically, if the cost base of European shale allows development to be viable at prevailing natural gas prices and if the regulatory framework and public acceptance issues are overcome, one might expect to see shale make a contribution to European domestic production in the post-2020 period. Given the low intensity of shale gas activity however, it is not expected to reverse the decline of European domestic production in the period to 2025.

\section{European Gas Demand ${ }^{116}$}

A view of future European gas demand was developed at a country level by assembling annual data by sector for the period 2000 to 2008 (the most current year for which sectoral data is available), and aggregate IEA or Eurostat ${ }^{117}$ annual demand data to 2009. A judgement was made for the likely long term demand trend, post-recession, based on previous sector trends but adopting a conservative approach. The assumption thus generated (in which the UK is represented as the 'Base Case' view described above) is compared with other recent

\footnotetext{
${ }^{116}$ As defined for the purpose of modelling in this paper Europe includes: Austria, Belgium, Bulgaria, Croatia, Czech Republic, Denmark, Estonia, Finland, France, Germany, Greece, Hungary, Ireland, Italy, Latvia, Lithuania Luxembourg, Netherlands, Norway, Poland, Portugal, Romania, Serbia, Slovakia, Slovenia, Spain, Sweden, Switzerland, Turkey, UK

${ }^{117}$ IEA data used for all countries except Bulgaria, Croatia, Estonia, Latvia, Lithuania, Romania, Slovenia, for which Eurostat data used.
} 
third party views in Figure A12. Due to the differing geographic definitions of 'Europe' covered by each source, these have been normalised to 2009 IEA and Eurostat actuals. Note that in the 'Assumption' trend the data for 2010 includes actual data. The National Grid view was compiled in 2009 and does not anticipate this.

Figure A12. European Demand Comparisons

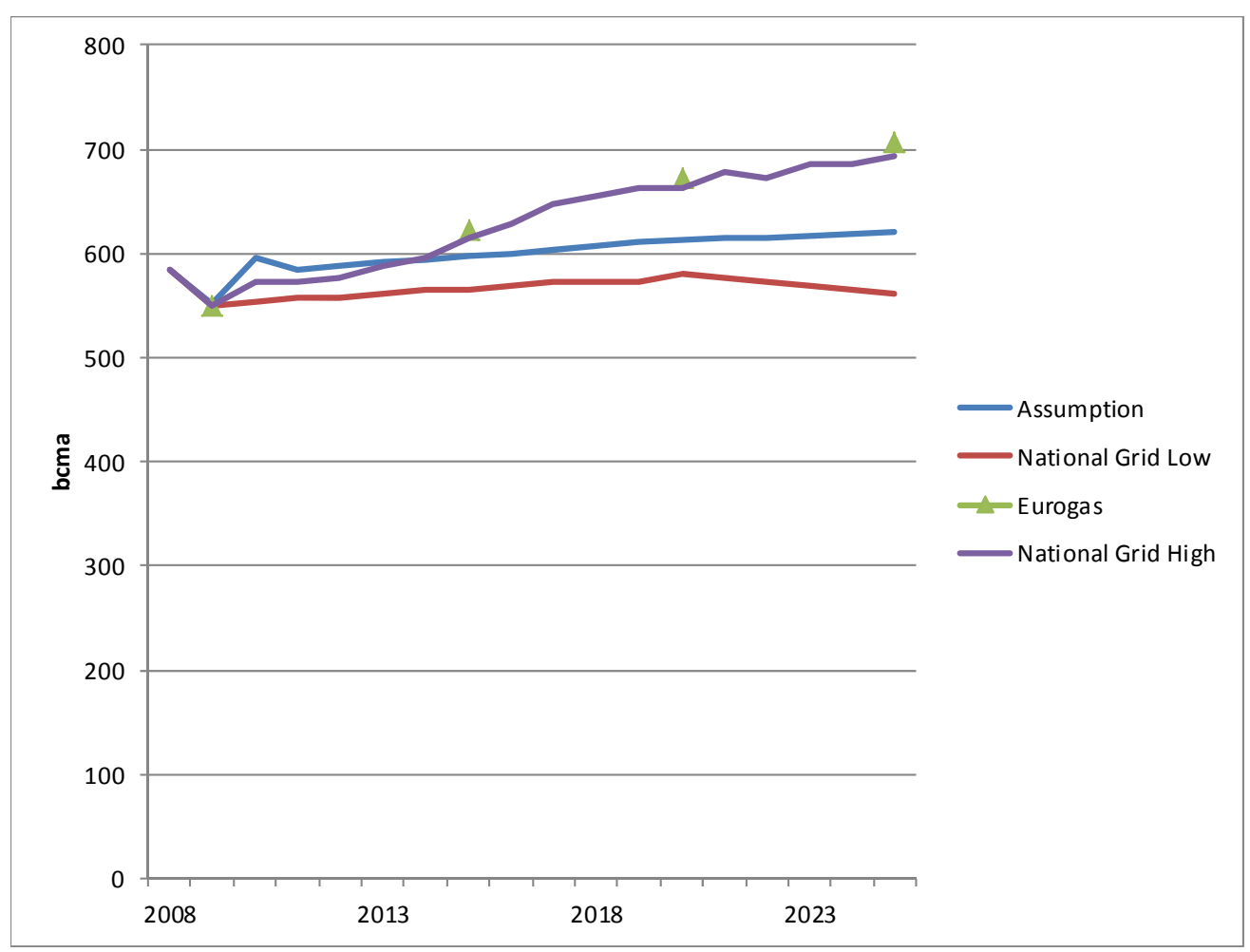

Sources: Eurogas 2010, National Grid 2010a, Figure 4.4A, P. 50. \{National Grid misspelt in blue line\}

In order to derive a monthly forecast of demand the following approach was adopted. At a country level monthly demand data was assembled from 2000 for power and non-power sectors using Eurostat and IEA data. Figure A13 shows the past and future power, nonpower and total monthly demand for Europe.

Figure A13 shows the variation in monthly demand for Europe, particularly during the winter months in the period 2005 to 2010. It also shows the projected monthly power and non-power demand assuming average weather patterns. As the future growth assumed is overwhelmingly in the power generation sector (which has relatively limited seasonal variation), the 'average weather year' summer-winter demand differential is not expected to grow significantly. This has implications for the level of seasonal storage usage Europe requires in the future. 
Figure A13. Monthly European Demand 2005 to 2025

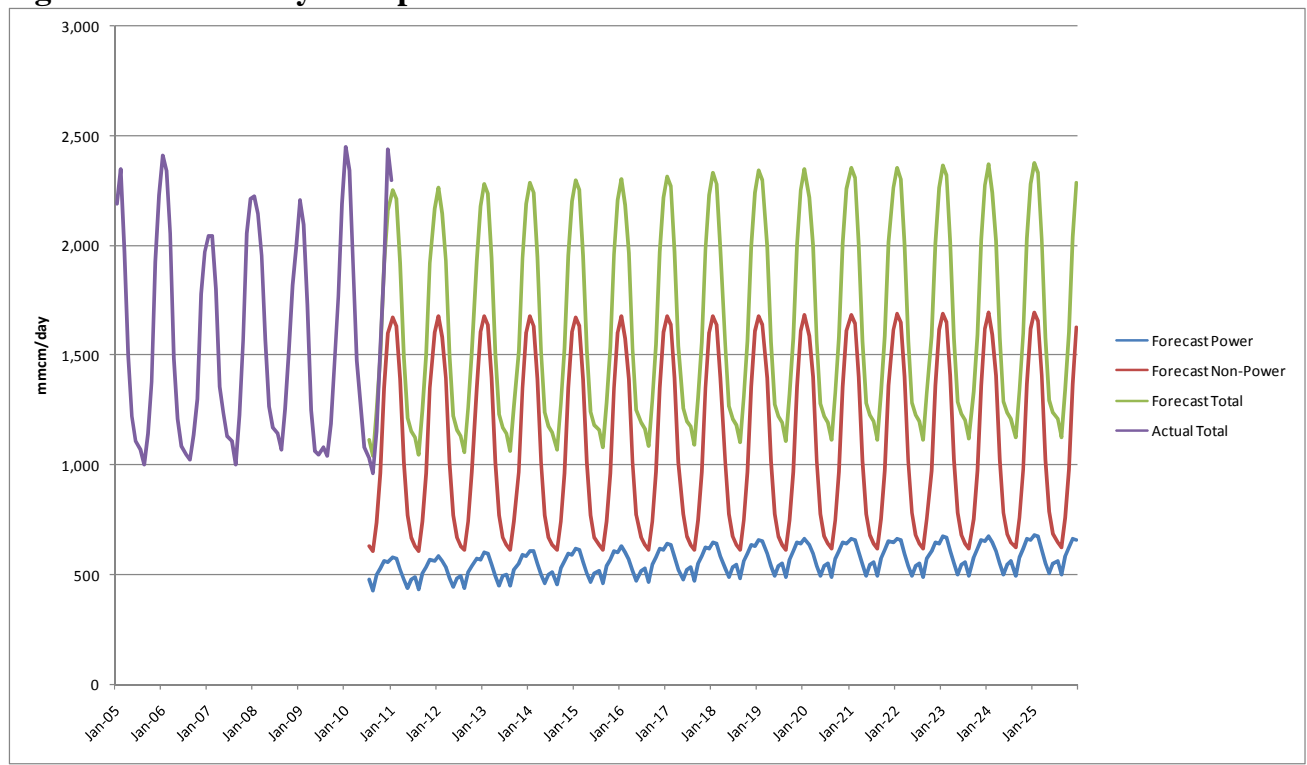

Sources: IEA Monthly Data, Eurostat Monthly Data, Own Analysis

\section{European Storage Capacity}

European Gas Storage capacity has received much attention in the media and gas conferences in recent years. The rationale has been that as European domestic production and its seasonal flexibility declines, to be replaced by less flexible pipeline imports and LNG (whose seasonal supply flexibility for Europe in a global context is less clear) the need for storage in Europe will grow.

Since 2008, Gas Storage Europe (GSE, part of Gas Infrastructure Europe) ${ }^{118}$ has made great improvements to the general data transparency on the subject of European Storage. On a daily basis it provides working gas inventory data on $84 \%$ of the total estimate of $85 \mathrm{bcm}$ of European storage capacity.

GSE also keeps a database of European storage facilities from 2008, both existing and future projects. Prior to 2008 data on aggregated European storage working gas inventory was presented in graphical form in a report by the Clingendael Institute ${ }^{119}$

Figure A14 combines the Clingendael graph data with more recent data from GSE. It shows the annual growth rate of working gas volume slowing from 2 to $3 \mathrm{bcm}$ per year in the 1990s to $1 \mathrm{bcm}$ per year during the early to mid-2000s with a recent acceleration to some $5 \mathrm{bcm}$ per year post 2007.

\footnotetext{
${ }^{118}$ GIE Website: http://www.gie.eu/index.htm

${ }^{119}$ Clingendael 2006.
} 
Figure A14. European Storage Working Gas Capacity

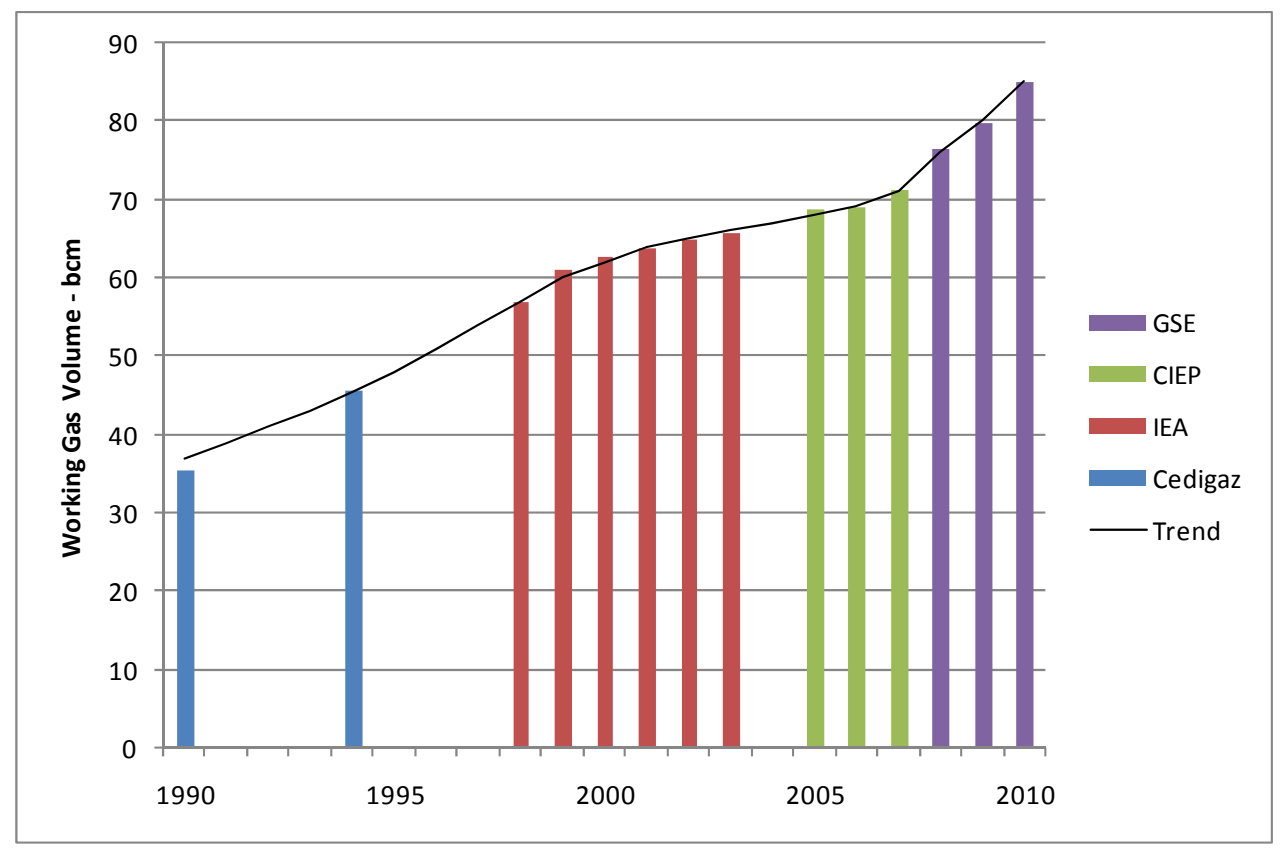

Sources: Clingendael2006, GSE 2010.CIEP = Clingendael International Energy Programme

Table A1. European Gas Storage Working gas Capacity - 2008 - 2010.

\begin{tabular}{|l|cccc|}
\hline \multicolumn{5}{|c|}{ BCM Working Gas Volume } \\
\hline & 2008 & 2009 & 2010 & $2010-2008$ \\
\hline Austria & 4.0 & 4.2 & 4.7 & 0.7 \\
Belgium & 0.7 & 0.7 & 0.7 & 0.0 \\
Bulgaria & 0.4 & 0.4 & 0.4 & 0.0 \\
Czech Republic & 2.3 & 3.1 & 3.1 & 0.8 \\
Denmark & 1.0 & 1.0 & 1.0 & 0.0 \\
France & 11.9 & 12.3 & 12.6 & 0.8 \\
Germany & 18.4 & 19.6 & 20.4 & 2.0 \\
Hungary & 3.7 & 3.7 & 6.1 & 2.4 \\
Ireland & 0.0 & 0.0 & 0.2 & 0.2 \\
Italy & 14.0 & 14.3 & 14.9 & 1.0 \\
The Netherlands & 5.1 & 5.1 & 5.1 & 0.0 \\
Poland & 1.6 & 1.6 & 1.6 & 0.1 \\
Portugal & 0.2 & 0.2 & 0.2 & 0.0 \\
Romania & 2.7 & 2.7 & 2.7 & 0.0 \\
Serbia & 0.0 & 0.0 & 0.0 & 0.0 \\
Slovakia & 2.6 & 2.8 & 2.8 & 0.2 \\
Sweden & 0.0 & 0.0 & 0.0 & 0.0 \\
Spain & 3.8 & 4.1 & 4.1 & 0.3 \\
UK & 4.3 & 4.3 & 4.4 & 0.1 \\
\hline Total & $\mathbf{7 6 . 5}$ & $\mathbf{8 0 . 0}$ & $\mathbf{8 5 . 1}$ & $\mathbf{8 . 6}$ \\
\hline
\end{tabular}

Source: GSE 2010. 
From Table A1 it is apparent that Hungary and Germany have shown the highest growth in this three year period, with France, The Czech Republic and Austria also adding significant new capacity.

Of the 8.6 bcm increase in storage working gas volume over the period $2008-2010$ it is worth noting that Depleted Fields accounted for 5.7 bcm, Salt Caverns for 2.1 bcm, Aquifers $0.7 \mathrm{bcm}$ and LNG Peak Shavers $0.2 \mathrm{bcm}$.

Gas Storage Europe's Project Data Base provides the following breakdown of future projects which it claims to be under construction, with a view on timing as shown in Table A2. In total these amount to $27.3 \mathrm{bcm}$ of new storage capacity; (for context this represents $32 \%$ of current capacity).

\section{Table A2. European Gas Storage Projects Under Construction}

\begin{tabular}{|l|c|c|c|}
\hline & by 2012 & by 2015 & $\begin{array}{c}\text { Beyond } \\
2015\end{array}$ \\
\hline Austria & 2.7 & 0.6 & 0.0 \\
\hline Belgium & 0.1 & 0.0 & 0.0 \\
\hline Denmark & 0.0 & 0.0 & 0.0 \\
\hline France & 0.2 & 0.3 & 0.4 \\
\hline Germany & 2.0 & 1.6 & 2.5 \\
\hline Hungary & 0.7 & 0.0 & 0.0 \\
\hline Italy & 1.8 & 2.5 & 0.0 \\
\hline Netherlands & 0.5 & 4.1 & 0.0 \\
\hline Poland & 1.0 & 0.0 & 0.7 \\
\hline Portugal & 0.1 & 0.0 & 0.0 \\
\hline Serbia & 0.5 & 0.0 & 0.0 \\
\hline Spain & 4.1 & 0.5 & 0.0 \\
\hline UK & 0.0 & 0.2 & 0.5 \\
\hline Total & 13.5 & 9.8 & 4.0 \\
\hline
\end{tabular}

Source GSE 2010.

The 13.5 bcm of projects due to come onstream in the 2011 - 2012 timescale is slightly higher than the recent growth rate. Beyond 2012, the rate of growth slows, however this could be augmented by new projects maturing from the speculative category.

By apportioning the 'by 2012' category equally between 2011 and 2012; the 'by 2015' equally between 2013,14 and 15; and the 'Beyond 2015' category equally between 2016 and 2017, the profile for European storage capacity for 2008 to 2017 is derived and is shown in Table A3.

Comparing 2017 with 2008, of the 36bcm of additional storage capacity, 8 is in Germany, 5.3 in Italy, 4.9 in Spain, 4.6 in the Netherlands, 4 in Austria, 3.1 in Hungary and 1.7 in Poland. With the exception of Spain, these are all national gas markets which import gas from Russia. 
Table A3. Existing Storage Capacity 2008 - 2010 and Phased Projects Currently Under Construction.

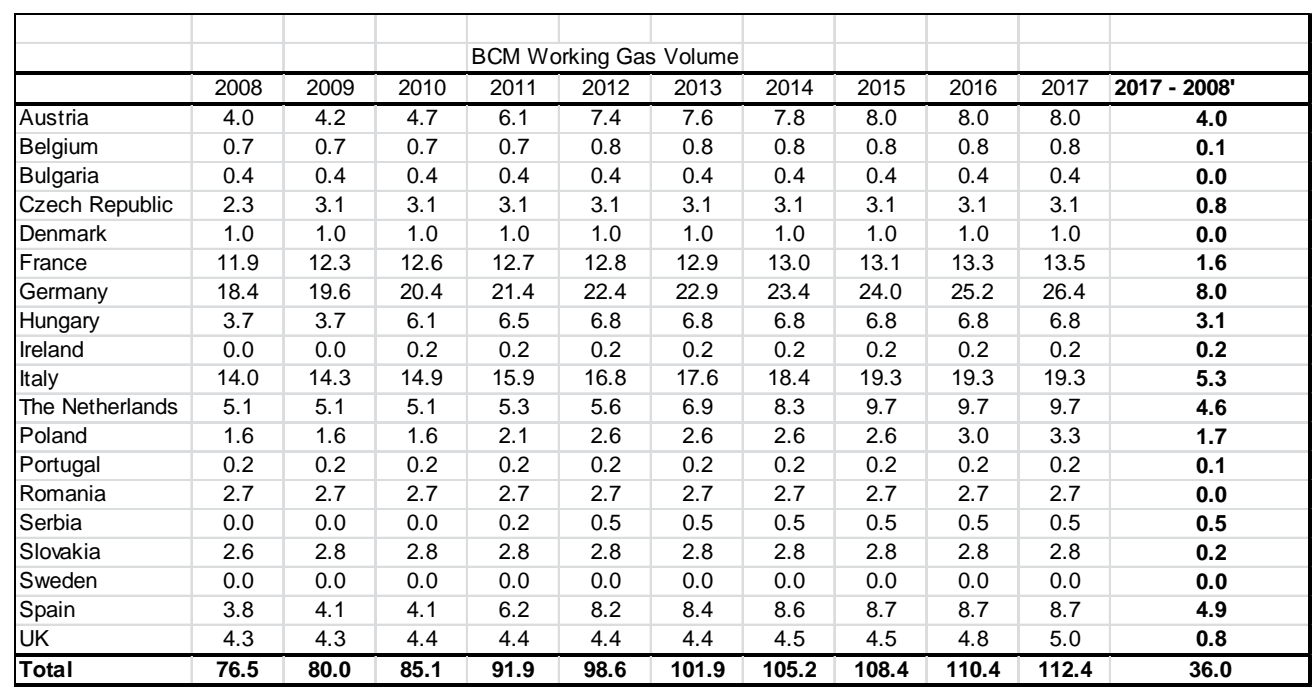

Source: GSE 2010.

Figure A15. Comparison of Europe Storage Working Gas Volume and Utilisation 2005 2010

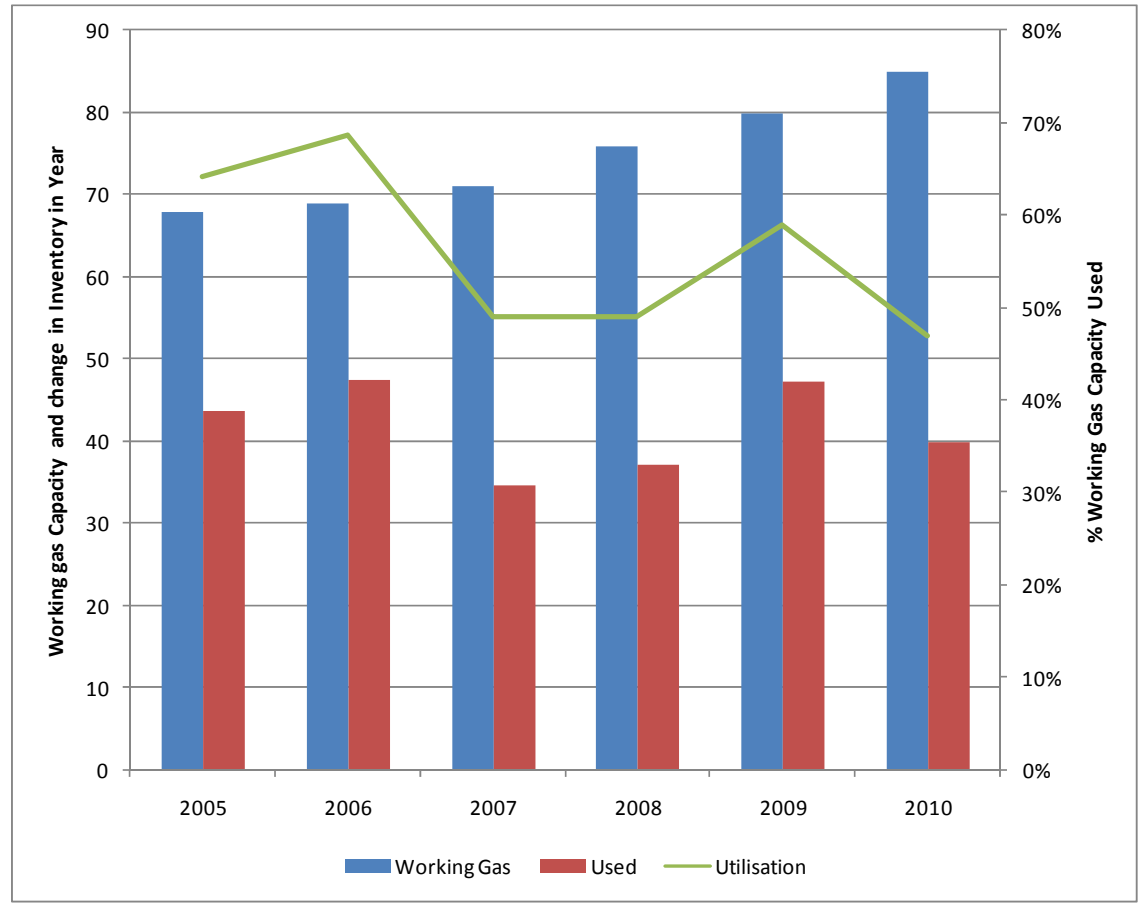

Sources: GSE 2010, IEA Monthly Data, Own Analysis. 
What is somewhat perplexing about the recent and likely future growth rates in storage capacity at least to 2012, is the low average utilisation of storage by Europe in recent years, even in the very cold year 2010.

Figure A15 shows in blue the European Working Gas Volume and in red the change in storage inventory during the year in question. This is expressed as a \% utilisation line in green. The picture is one of utilisation rates falling from $60 / 70 \%$ in 2005 and 2006 to 50/60\% in $2007-2010$.

For the purposes of this analysis we will treat Continental Europe as separate from the UK for storage purposes.

For Continental Europe the Assumptions used in this analysis are shown in Figure A16.

Figure A16. Continental Europe Storage Capacity and Utilisation Assumptions

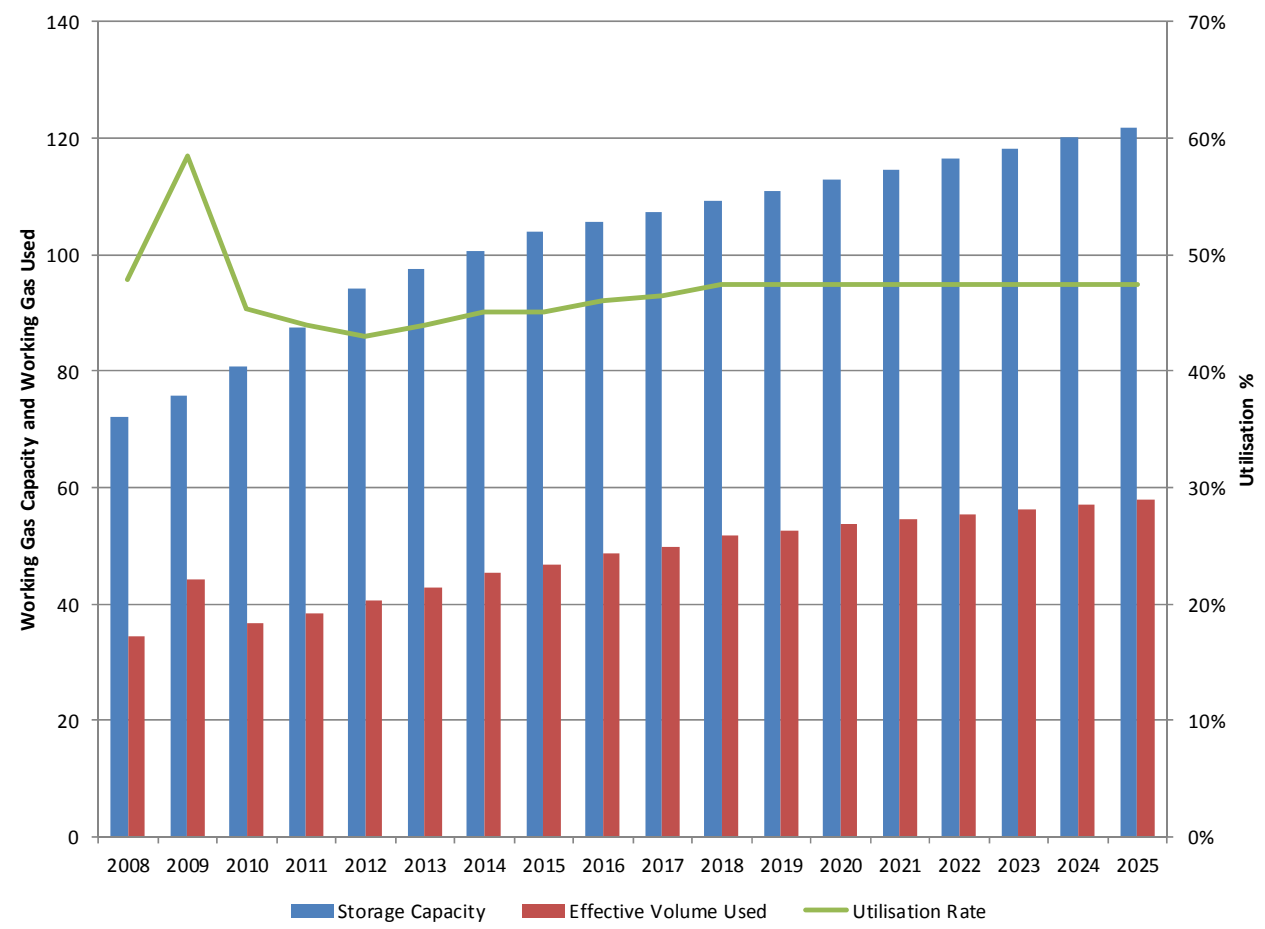

Sources: GSE 2010, Own Analysis

\section{European Pipeline Imports}

Figure A17 shows estimated imports of pipeline gas from Russia, Algeria, Libya, Azerbaijan (and post 2020 other possible Caspian region suppliers) and Iran for the 'LNG Rules the Waves Scenario and the additional increment (orange) in the 'Russia Fills the Gap' scenario. 
Figure A17. Pipeline Supplies to Europe

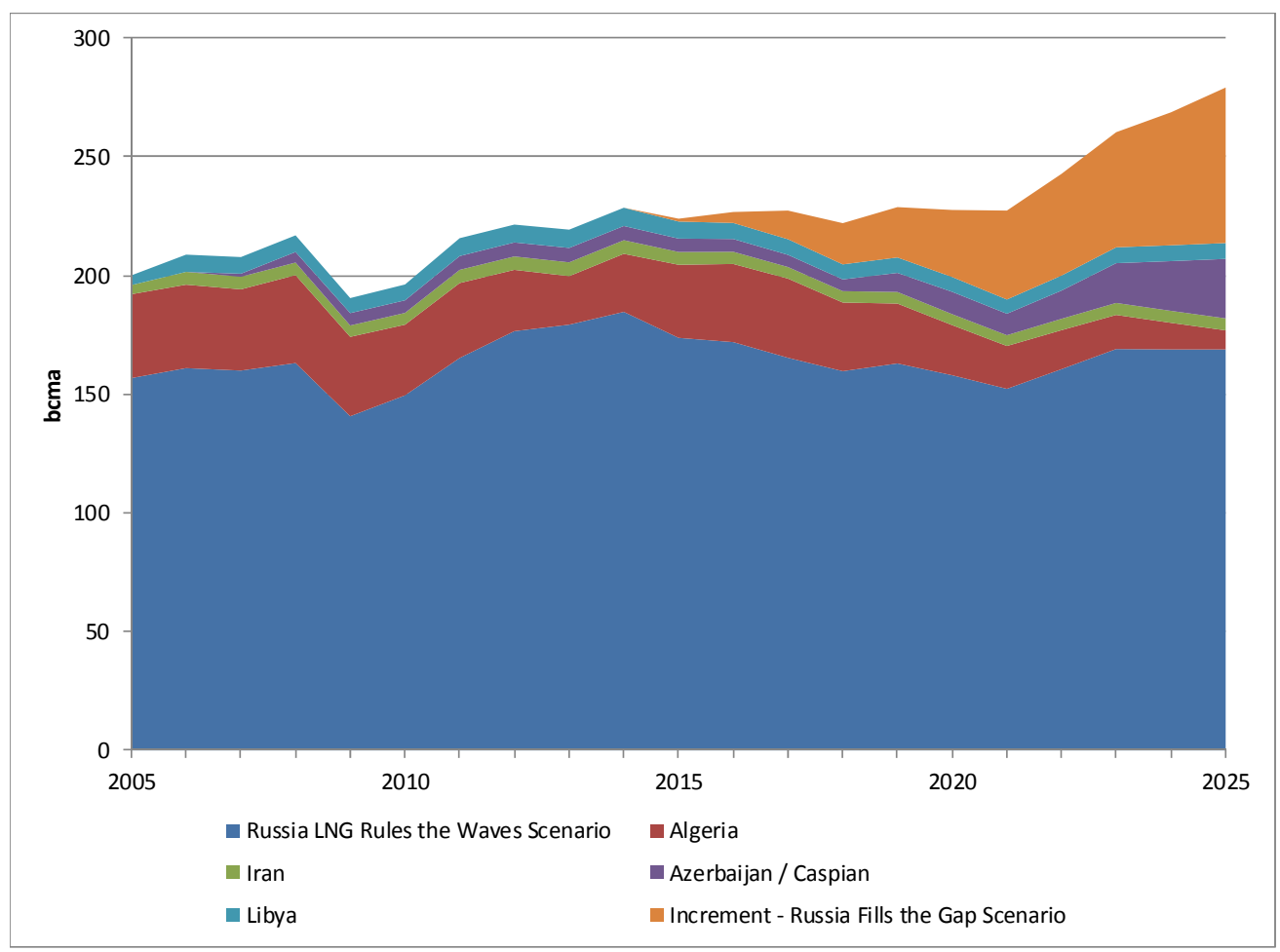

Sources: IEA Monthly Data, Own Analysis.

Note the decline in pipeline gas available from Algeria post $2017^{120}$ which broadly corresponds to and is offset by the assumed growth in supplies from Azerbaijan/Caspian based on Shah Deniz Phase 2 and from Turkmenistan and/or Iraq.

\section{Asian LNG Demand}

Figure A18 shows the LNG import demand assumptions for Asia. Data to 2010 is actual and beyond 2010 is derived from a graphic originating from Wood Mackenzie. The 2011 and 2012 rise in Japan's LNG requirements is an assumed 12 bcma to offset the nuclear capacity lost as a result of the Fukushima disaster. Asian demand growth is subject to significant uncertainty and has a primary call on global LNG supplies, and a direct impact on LNG available for Europe.

\footnotetext{
${ }^{120}$ Source: Darbouche, P.40, Figure 1.12
} 


\section{Figure A18. Asian LNG Demand}

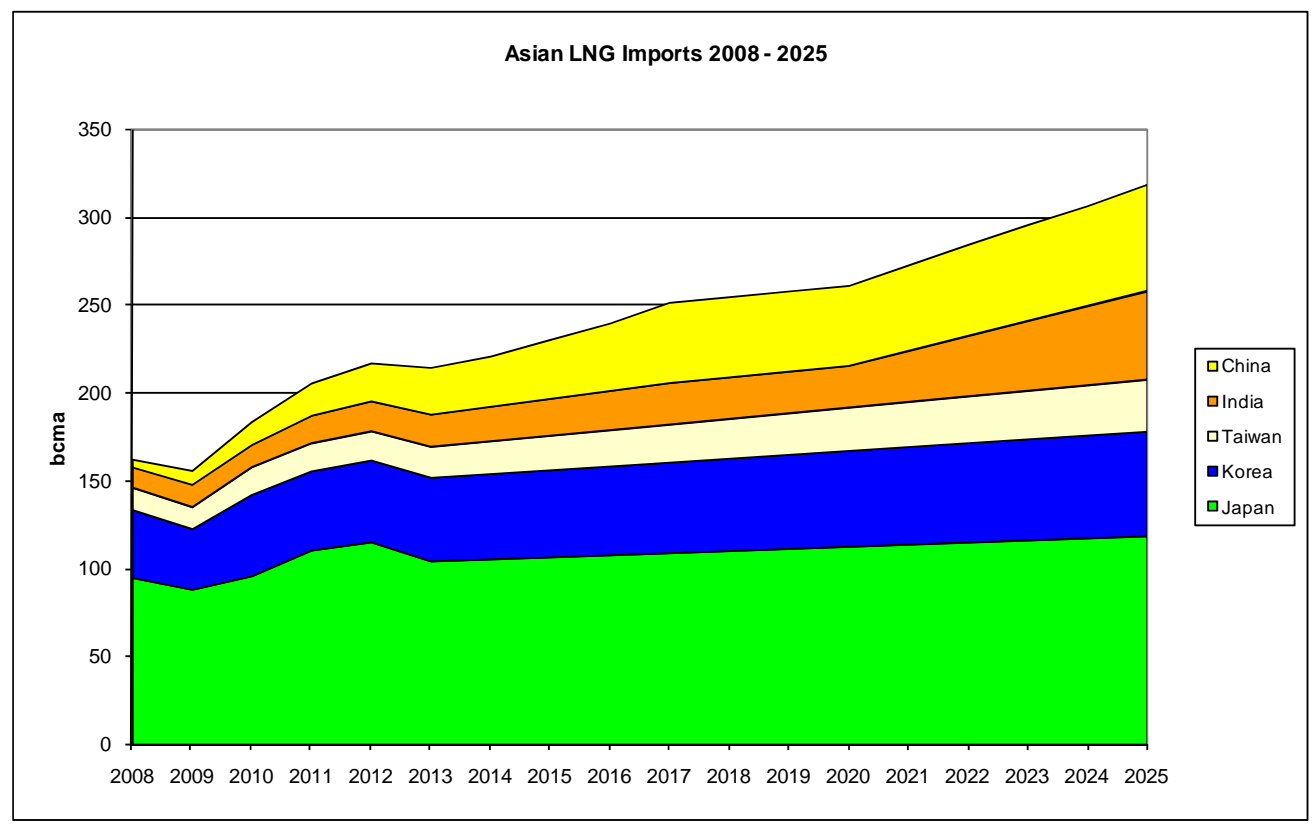

Sources: Waterborne LNG, Wood Mackenzie

\section{North American LNG Import Requirements.}

North America represents a key area of uncertainty in terms of the balance of the LNGconnected world of the future. The growth in shale gas production has more than offset an underlying decline in conventional gas production, resulting in a net growth in aggregate production. In the past US production has proved difficult to predict and in 2011 there are optimists and pessimists on the sustainability of the shale revolution.

While shale plays are extensive, economically viable production is centred on 'sweet spots' characterised by higher well flowrates. Even here well flowrates can vary significantly. The production from a single well declines more rapidly than from conventional gas wells and so production from shale plays requires continuous intensive drilling in order to maintain production levels. While shale gas production is still growing rapidly, in $1^{\text {st }}$ quarter 2011 , production from the Barnett shale play, the first to be exploited, has reached a plateau. The uncertainties about US production can be summarised as follows:

- Will shale gas production continue to grow at current low prices?

- How significantly will shale gas production respond to higher prices?

- Can future shale gas production grow sufficiently to offset declines in conventional gas and keep up with demand net of imports from Canada and Mexico? 
In a future where shale gas disappoints, the US could become a significant importer of LNG (as was originally expected to be the case). This would increase competition for global LNG supply and require an increase in European pipeline imports as LNG was redirected to the US.

In a future where shale gas growth continues to be strong, the US could become an LNG exporter, with one project already approved for this eventuality.

For the purpose of this analysis a 'neutral' case has been assumed where the US, Canada and Mexico in aggregate continue to import only some 20 bcma of LNG. This is shown in Figure 19.

\section{Figure A19. North America Balance}

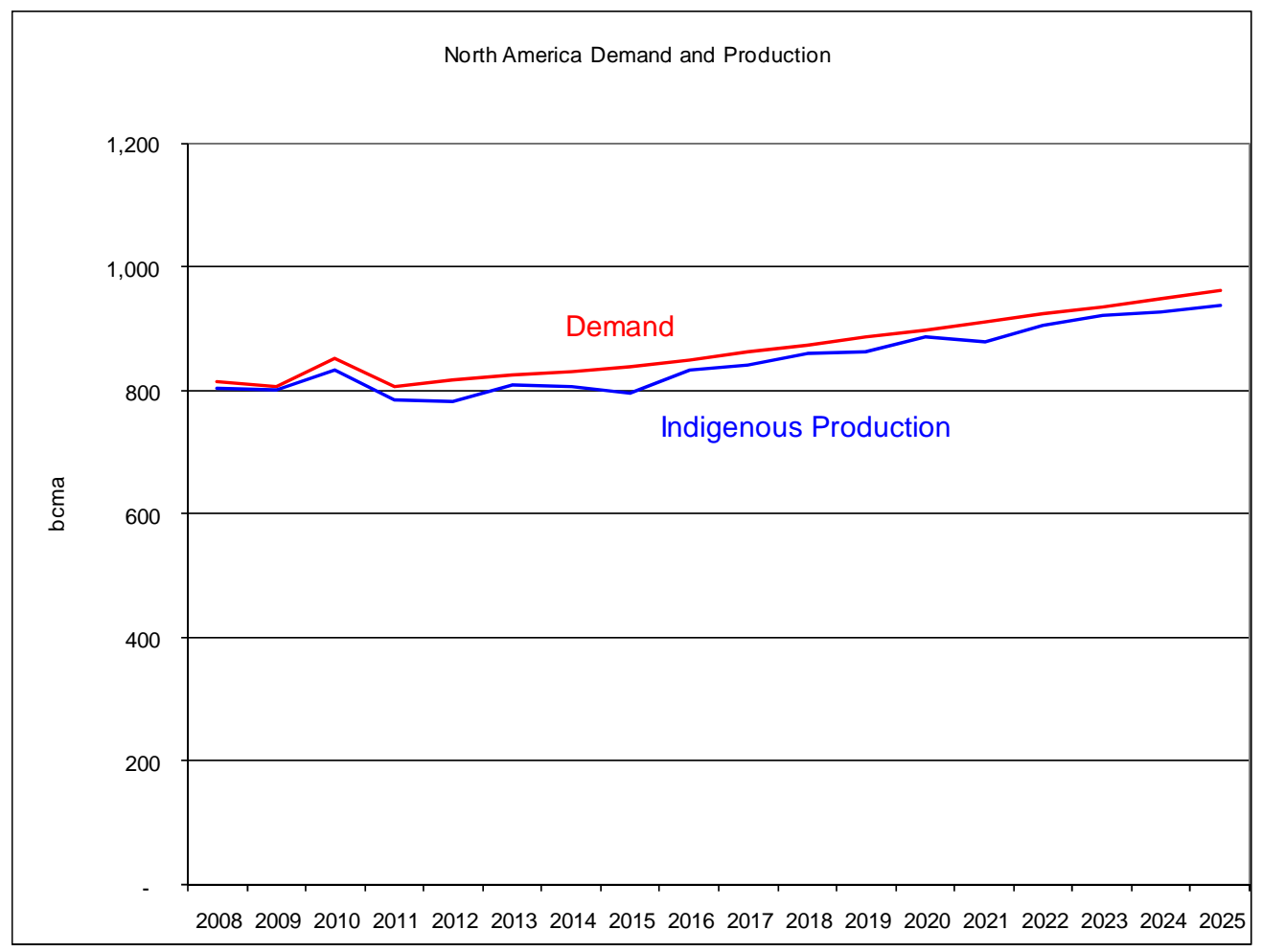

Sources: IEA, EIA, Own Analysis

\section{New LNG Markets}

Since 2008 Argentina, Brazil ${ }^{121}$, Chile, Kuwait and Dubai have become LNG importers. Other countries may follow including Singapore, Pakistan and Thailand. Since the discovery of significant gas resources offshore Israel the likelihood of Cyprus becoming an LNG

\footnotetext{
${ }^{121}$ Brazil's offshore pre-salt play has given rise to significant hydrocarbon discoveries (mainly oil but also gas). This has the potential to reduce Brazil's need for gas imports within the period to 2025 .
} 
importer may have reduced, depending on whether it is selected as the location for the liquefaction plant associated with these discoveries.

Past and future import levels for these countries are shown in Figure A20. As many are seasonal importers, there is significant uncertainty around future projections of imports.

\section{Figure A20. New LNG Markets}

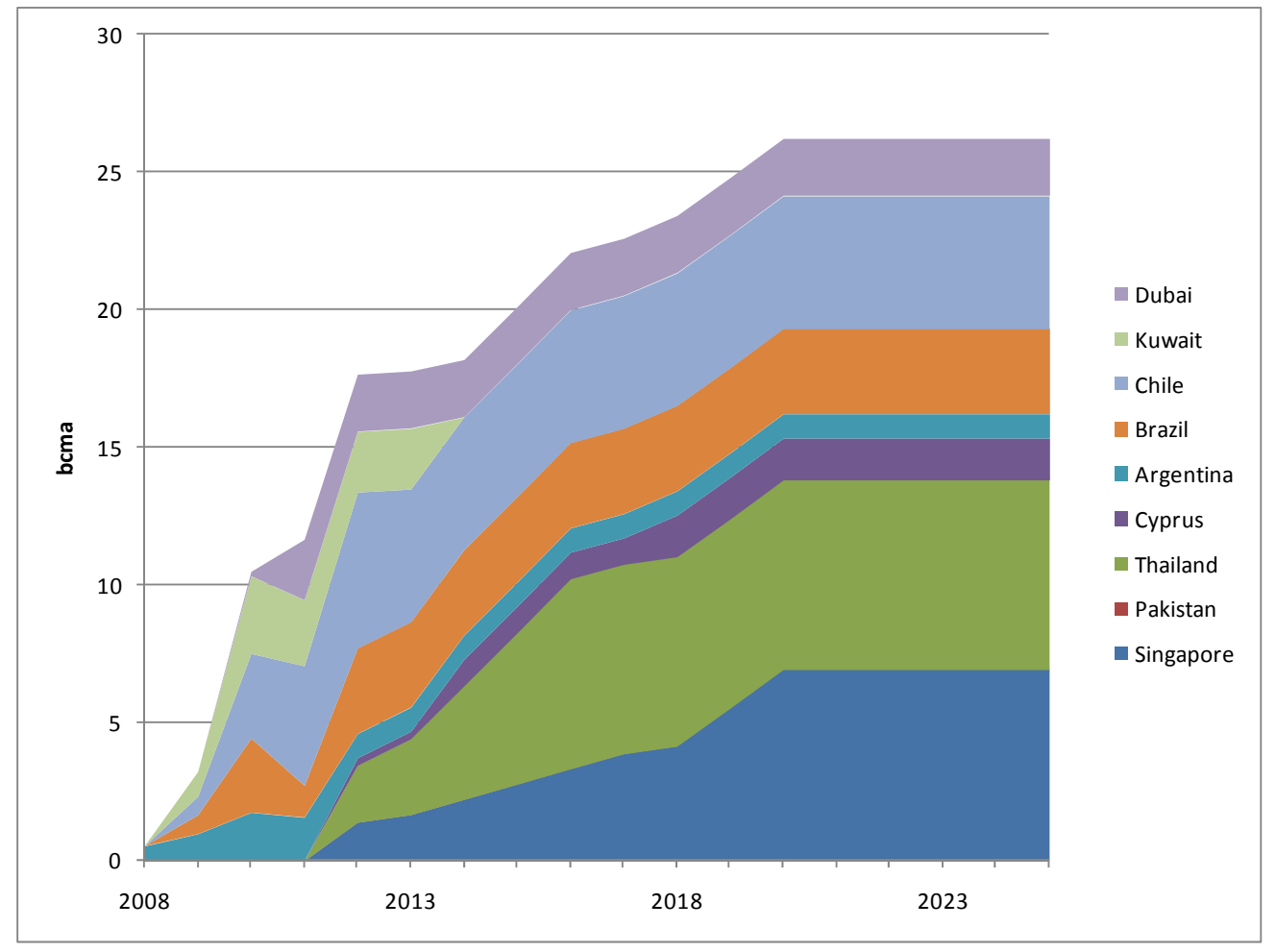

Sources: Waterborne LNG, Own Analysis. 


\section{Appendix B: Methodology of Wind Generation Analysis}

The methodology for this analysis is as follows:

\section{Data Assembly}

- The UK onshore and offshore geography was divided into 20 sub-areas. Representative weather stations for each area were selected and hourly wind speed data for the whole of 2009 was acquired.

- A current and future wind generation capacity profile was 'mapped' onto the $20 \mathrm{UK}$ sub-areas referred to above, from data on current wind farm capacity, and assumptions about future capacity, location and timing.

- A standard turbine generation output versus wind speed curve was defined from which wind power generation can be calculated hourly for each UK sub-area and aggregated to a UK level, using assumed hub-height/land surface shear factors.

\section{Wind Generation History Match and Future Wind Generation Modelling}

- For 2009 the shear factor assumptions were tuned to match the aggregate 2009 onshore and offshore DECC reported actual wind generation statistics.

- The same hourly wind date, turbine curve and tuned shear fact assumptions were applied to future years to simulate the impact of higher wind generation capacities with a shifting geographic focus, using the same wind data from 2009.

- The derived wind generation results were consolidated at a UK level on an hourly and daily basis for 2015, 2020 and 2025.

\section{Future Year Generation Stack Interactions and Flexibility Requirements}

- Based on National Grid ‘Typical Summer' and ‘Typical Winter' daily generation profiles by fuel/technology type and weekly electricity demand data, the interaction between wind, gas and other sources of generation was analysed.

- The hourly and daily gas consumption in the power sector on an hourly and daily basis for 2015, 2020 and 2025 was derived.

- The implications of rapidly changing power sector gas supply requirements and possible means of providing the flexibility needed were analysed. 


\section{Glossary}

Annual Contract Quantity (ACQ): The quantity that, under a gas contract, a buyer has the right to nominate and the seller the obligation to deliver.

Bacton-Zeebrugge Interconnector: see IUK

BBL: shorthand for the Balgzand (Holland) to Bacton (UK) pipeline, capacity $19.9 \mathrm{bcma}$.

Bcm: one billion cubic metres.

Bcma: one billion cubic metres per annum.

Carbon Sequestration and Storage: The process involving the removal of Carbon Dioxide gas from a gaseous mixture (most often in a power generation context), transporting the $\mathrm{CO}_{2}$ and storing it in an underground structure such as a depleted oil or gas field or aquifer.

CATS: The UK offshore sub-sea Central Area Transmission System, a 223 mile pipeline from the Central North Sea to the CATS processing terminal in Teesside on the North East coast of England.

\section{CCS: see Carbon Sequestration and Storage}

Coal Bed Methane: methane which is held within the structure of the coal matrix by adsorption. This may be produced in commercial quantities when the coal is de-pressurised and de-watered in situ through drilling and the application of suitable well technology.

Conventional Gas: Natural gas produced from an underground reservoir other than shale gas, tight gas or coal bed methane.

CSO (Customer Service Obligations): See PSO.

Destination Clause: a provision in a long-term gas supply contract which has the effect of forbidding wholesalers from re-selling the commodity outside the countries where they are established thereby guaranteeing the seller a form of protection. This practice helps to maintain price differentials across different national markets.

EU Emissions Trading System: A cap and trade system under which participating EU Member States allow qualifying $\mathrm{CO}_{2}$ emitting installations to trade $\mathrm{CO}_{2}$ permits. The number of $\mathrm{CO}_{2}$ permits are limited by agreed caps on $\mathrm{CO}_{2}$ emissions at the Member State level.

FID: Final Investment Decision: usually in the context of a gas project, this is the joint decision on the part of the investment companies and any state entities to proceed with the full development of a project through to commercial operation.

Gas Storage: The storage of natural gas in either underground structures such as depleted oil or gas reservoirs, salt caverns or aquifers, or alternatively as LNG either in storage tanks at regasification terminals or LNG Peak Shaving facilities.

GW: Gigawatt, i.e. 1 billion watts 
IGTI: The Interconnection Turkey-Greece-Italy pipeline project for transmitting natural gas to Italy and Turkey comprises three segments: expansion of the Turkish national grid;, building a pipeline between Turkey and Greece; and building a further pipeline between Greece and Italy. The project will also include a bypass line between Greece and Bulgaria. The ITGI project is scheduled to be operational by 2015. The 296 kilometer-long and 32indiameter Turkey-Greece pipeline was inaugurated in November 2007. It can transmit 11.5 bcma of natural gas, to be shared between Italy and Greece.

IUK: the shorthand name for the Bacton (UK) to Zeebrugge (Belgium) bi-directional gas pipeline. Import capacity 25.5 bcma, export capacity 20 bcma.

Langeled: The 725 mile pipeline from the Nyhamna terminal in Norway via the Sleipner Riser platform in the North Sea to Easington Gas Terminal in England. Its capacity is 25.8 bcma.

Large Combustion Plant Directive: the LCPD aims to reduce acidification, ground level ozone and particles throughout Europe by controlling emissions of sulphur dioxide and nitrogen oxides and dust from large combustion plants. Member States can choose to meet the obligations by either complying with emission limits or limiting the remaining operating life of plant whose emissions exceed these limits.

LNG Peak Shaver: a gas storage facility which provides high output of natural gas albeit for a short duration. The facility extracts natural gas from the transmission grid, liquefies the gas by cooling it to minus 162 degrees Centigrade and storing it in an insulated vessel. When gas is required to meet peak loads the LNG is regasified and injected into the transmission system.

Oil Indexed Gas Prices: gas prices within long term contracts which are determined by formula containing rolling averages of crude oil or defined oil product prices.

Pigging: Pigging in the maintenance of pipelines refers to the practice of using pipeline inspection gauges or 'pigs' to perform various operations on a pipeline. These include cleaning and inspecting of the pipeline.

PSO (Public Service Obligations): Directive 2003/55/EC of the European Parliament and of the Council of 26 June 2003 concerning common rules for the internal market in natural gas provides for the possibility for Member States to impose public service obligations to guarantee security of supply, economic and social cohesion objectives, regularity, quality and price of the gas supply and protection of the environment.

MWh: A unit of energy equivalent to a Megawatt of power over the duration of one hour.

Mmcm/day: Million cubic metres per day.

Mmbtu: Million British thermal units

Mmcm; million cubic metres 
Nabucco: A pipeline project (in 2011, yet to achieve Final Investment Decision) which would transport gas from the Caspian region through Turkey and the Balkans to Austria. The envisaged capacity is 30 bcma.

NBP: the UK's National Balancing Point: a virtual point (hub) in the National Transmission System where gas trades are deemed to occur. It is also used as shorthand for the UK spot gas price.

OCGT: Open Cycle Gas Turbine. The open cycle gas turbine is the most basic gas turbine unit. The working fluid does not circulate through the system, therefore it is not a true cycle. It consists of a compressor, a combustion chamber and a gas turbine. The compressor and the gas turbine are mounted on the same shaft.

Pre-Salt Play: This refers to the prospective trend offshore Brazil. The hydrocarbon reservoirs are buried below as much as 6,500 feet of salt. Reservoirs in this domain are complex heterogeneous layered carbonates, which makes accurate reservoir characterization very challenging. The pre-salt environment is very corrosive with significant amounts of carbon dioxide $\left(\mathrm{CO}_{2}\right)$ and hydrogen sulphide $\left(\mathrm{H}_{2} \mathrm{~S}\right)$ present.

Shale Gas: natural gas formed in fine-grained shale rock (called gas shales) with low permeability in which gas has been adsorbed by clay particles or is held within minute pores and micro fractures.

Storage Inventory: the quantity of working gas volume in storage. Working gas is distinct from 'cushion gas' which is only withdrawn from storage when a storage site is decommissioned.

Take or Pay (TOP): sometimes called the 'minimum bill', this is the quantity of gas which, during a gas contract year, customers are obliged to pay for regardless of whether they physically take it for resale or not.

TAP: the Trans Adriatic Pipeline is a proposed project to transport natural gas from the Caspian and Middle East regions via a new gas transportation route starting in Greece via Albania and the Adriatic Sea to Italy and further to Western Europe.

Tight Gas: natural gas formed in sandstone or carbonate (called tight gas sands) with low permeability which prevents the gas from flowing naturally.

TWh: A unit of energy equivalent to a Terawatt of power over the duration of one hour.

UKCS: The UK Continental Shelf

Working Gas: see Storage Inventory 


\section{Bibliography}

BADC: British Atmospheric Data Centre website: http://badc.nerc.ac.uk/home/index.html

BAFA: The German Federal Office of Economics and Export Control website which reports natural gas production, imports, exports and storage inventory changes: http://www.bafa.de/bafa/en/index.html

BP 2011: BP Statistical Review of World Energy

2011, http://www.bp.com/sectionbodycopy.do?categoryId=7500\&contentId=7068481

British Gas 2011: British Gas Home Energy Report 2011, An assessment of the drivers of domestic natural gas consumption, http://www.cebr.com/wp-content/uploads/British-GasHome-Energy-Report-2011.pdf

BWEA: Information on the location, start-up date and capacity of existing UK wind farms is contained in a comprehensive form in tables available on the British Wind Energy Association website (http://www.bwea.com/ukwed/operational.asp). Information on future wind farm projects is also available from links on the following page on the website:http://www.bwea.com/ukwed/index.asp.

CCC 2008: Committee on Climate Change: 'Building a low-carbon economy - the UK's contribution to tackling climate change', $1^{\text {st }}$ December 2008,http://www.theccc.org.uk/reports/building-a-low-carbon-economy

Cedigaz 2004: ‘LNG Trade and Infrastructures’, Cedigaz February 2004.

Cedigaz 2008: Pipeline Long Term Gas Contracts by Exporter, Cedigaz, Armelle Lecarpentier, August 2008

Cedigaz \& BP : Cedigaz Historic Pipeline Trade Data as published in the annual BP Statistical Review of World Energy

Clingendael 2006: The European Market for Seasonal Storage', Clingendael International Energy Programme, Discussion Paper, February 2006.

http://www.clingendael.nl/publications/2005/20050800_ciep_misc_gas_storage.pdf

Committee on Climate Change 2008: 'Building a low-carbon economy - the UK's contribution to tackling climate change', 1st December 2008, http://www.theccc.org.uk/reports/building-a-low-carbon-economy

Darbouche: 'Natural Gas Markets in the Middle East and North Africa', Edited by B. Fattouh and J Stern, Chapter 1 Algeria’s Natural Gas Market’ Hakim Darbouche, OIES 2011, pp. 12 -47 .

DECC: The UK Department of Energy and Climate Change, website: http://www.decc.gov.uk/en/content/cms/statistics/statistics.aspx 
DECC 2010a: Gas Security of Supply: a policy statement from DECC, Department of Energy and Climate Change, HM Government, London, April

2010, http://www.decc.gov.uk/publications/AdvancedSearch.aspx?term=gas\%20security\%20 of\%20supply\&tags $=21 \&$ urn $=\&$ fromDate $=\&$ toDate $=\&$ alpha $=$

DECC 2010b: 2050 Pathway Analysis, DECC, June 2010, http://www.decc.gov.uk/assets/decc/What\%20we\%20do/A\%20low\%20carbon\%20UK/ 2050/216-2050-pathways-analysis-report.pdf

DECC Wind Speed: 'Average wind speed and deviations from the long term mean (ET 6.2)' from DECC

Website: http://www.decc.gov.uk/en/content/cms/statistics/source/temperatures/temperatures. $\underline{\text { aspx }}$

DECC Wind Power Statistics:, DUKES table

7.4, http://www.decc.gov.uk/en/content/cms/statistics/source/renewables/renewables.aspx

DTI 2006: The Energy Challenge - Energy Review Report, Department of Trade and Industry, Cm 6887, HM Government, London, July 2006, Para 4.42. Available at:

http:// www.berr.gov.uk/files/file31890.pdf

DUKES (Digest of UK Energy

Statistics) http://www.decc.gov.uk/en/content/cms/statistics/publications/ecuk/ecuk.aspx

Dutch Ministry of Economic Affairs (see NL 2010)

EGAF 2011: Making the Green Journey Work, Optimised pathways to reach 2050 abatement targets with lower costs and improved feasibility, European Gas Advocacy Forum, February 2011, http://www.centrica.com/files/pdf/making the_green_journey_work.pdf

EIA 2009: Locations of U. S. Natural Gas Import \& Export Points, 2009, http://www.eia.gov/pub/oil_gas/natural_gas/analysis_publications/ngpipeline/impex_li st.html

EIA Monthly Data: EIA Website: US gas production, storage and demand data downloads at http://tonto.eia.doe.gov/dnav/ng/ng_prod_sum_dcu_NUS_m.htm

EnergieStyrelsen 2010: Denmark’s Oil and Gas Production and sub-soil use, 2009, http://www.ens.dk/Documents/Netboghandel\%20-

\%20publikationer/2010/Denmarks_oil_and_gas_production.pdf

Escobar and Artega 2011: Underground Natural Gas Storage in the UK: Business Feasibility Case Study, SPE 143019, May 2011.

Eurogas 2010: Eurogas Long Term Outlook for Gas Demand and Supply 2007 - 2030, Eurogas, 2010, http://www.eurogas.org/publications_environment.aspx 
Eurostat Monthly Data: Gas demand, production, imports, exports and national stock movements for European countries. Eurostat provides data for Bulgaria, Croatia, Estonia, Latvia, Lithuania, Romania and Slovenia which the IEA does not cover.

Gény 2010: 'Can Unconventional Gas be a Game Changer in European Gas Markets’ , Florence Gény, NG46, December 2010, OIES. http://www.oxfordenergy.org/wpcms/wpcontent/uploads/2011/01/NG46-

CanUnconventionalGasbeaGameChangerinEuropeanGasMarkets-FlorenceGeny-2010.pdf

Fattouh and Stern 2011: Natural Gas Markets in the Middle East and North Africa, eds. B. Fattouh and J Stern, OIES/OUP, 2011.

GSE 2010 : The Storage Database on Gas Storage Europe’s website athttp://www.gie.eu/maps_data/storage.html

GSE 2009: Historic UK storage inventory data

at http://transparency.gie.eu.com/chart_storage.php?r=22

Heather OIES (forthcoming 2011): 'Continental European Gas Hubs: are they fit for purpose?'

Henderson 2010: Non-Gazprom Gas Producers in Russia, James Henderson, OIES NG45, 2010.

ICIS-Heren, ICIS-Heren, European Gas Hub Report, Full Report Winter 2010

IEA Annual Data Series: This is a subscription service for annual data on European natural gas demand by sector. http://data.iea.org/ieastore/statslisting.asp

IEA Monthly Data: This is a subscription service for monthly data on European natural gas demand, production, imports, exports and national stock levels. When released, data is usually three months old. http://data.iea.org/ieastore/statslisting.asp

ILEX 2006: Strategic Storage and Other Options to Ensure Long-Term Gas Security, ILEX Energy Consulting, a report to DTI, April 2006.

IUK, Interconnector UK website: This is the website of the operating company of the Bacton Zeebrugge interconnector pipeline. The site contains information on daily pipeline flows and archived news

releases.http://www.interconnector.com/onlineservices/historicflows.htm

National Grid 2009: National Grid, Transportation Ten Year Statement 2010; http://www.nationalgrid.com/NR/rdonlyres/9F20D3A2-4331-4F7A-A5A0943B66E29FE8/47352/TenYearStatement20091.pdf

National Grid 2010a: National Grid, Transportation Ten Year Statement 2010, http://www.nationalgrid.com/NR/rdonlyres/E60C7955-5495-4A8A-8E808BB4002F602F/44779/TenYearStatement2010.pdf 
National Grid 2010b: National Electricity Transmission System Seven Year Statement, National Grid, May 2010, http://www.nationalgrid.com/NR/rdonlyres/A2095E9F-A0B84FCB-8E66-6F698D429DC5/41470/NETSSYS2010allChapters.pdf

National Grid 2011a: National Electricity Transmission System Seven Year Statement May 2011,http://www.nationalgrid.com/NR/rdonlyres/D4D6B84C-7A9D-4E05-ACF6D25BC8961915/47015/NETSSYS2011Chapter2.pdf

National Grid 2011b: 'Operating the Electricity Transmission Networks in 2020, June 2011 Update, National Grid, June 2011,http://www.nationalgrid.com/NR/rdonlyres/DF928C199210-4629-AB78-BBAA7AD8B89D/47178/Operatingin2020_finalversion0806_final.pdf

NL 2010: Dutch Ministry of Economic Affairs Oil and Gas Portal, containing monthly field production data and future annual projections. http://www.nlog.nl/en/production/production.html

Norwegian Ministry of Petroleum, FLAME 2011 Presentation

NPD 2010: Norwegian Petroleum Directorate website containing monthly production data by field,

http://www.npd.no/engelsk/cwi/pbl/en/index.htm

Nyak \& Deo 2010: Munir Ahmad Nayak and M. C. Deo "Wind Speed Prediction by Different Computing Techniques”, BALWOIS 2010 - Ohrid, Republic of Macedonia -25, 29 May 2010: http://balwois.com/balwois/administration/full_paper/ffp-1384.pdf

Ofgem 2009: Project Discovery: Energy Market Scenarios, Consultation Document 122/09, London, October 2009.

Oxera 2010: Strong nerves needed? The economics of gas storage investments, Oxera, June 2010, http://www.oxera.com/cmsDocuments/Agenda_June $\% 2010 / T h e \% 20$ economics\%20of $\% 20$ gas\%20storage\%20investment.pdf. Associated presentation: http://www.eprg.group.cam.ac.uk/wp-content/uploads/2010/05/2-Kristensen$\underline{\text { v2.pdf }}$

Pirani: 'Elusive Potential: Natural Gas Consumption in the CIS and the Quest for Efficiency', Simon Pirani, NG53, OIES, July 2011, http://www.oxfordenergy.org/wpcms/wp-

content/uploads/2011/07/NG-531.pdf

Platts: a subscription energy markets service.

Poten2008 :Poten\& Partners Presentation: 'The Outlook for Atlantic Basin LNG Supply and Transportation', 14th Annual NECA Conference on Fuels Issues , Boston, MA, September 24, 2008,http://www.necanews.org/dev/documents/080924mikhaiel_nelly.pdf

Poyry 2009: Timeline for Wind Generation to 2020 and a set of progress Indicators, a report to the Committee on Climate Change, Poyry July

2009, http://downloads.theccc.org.uk/docs/503_WindTimelinesProgressIndicators_v7_0.pdf 
Poyry 2010: Gas: At the Centre of a Low Carbon Future, Poyry, September

2010, http://www.oilandgasuk.co.uk/cmsfiles/modules/publications/pdfs/EC022.pdf

Poyry 2011: The Challenges of Intermittency in North West European Power markets, Poyry, March 2011, http://www.poyry.com/linked/en/press/NEWSIS.pdf

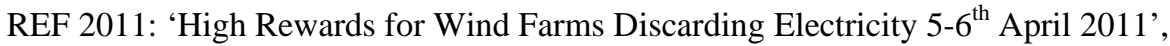
Information Note, Renewable Energy Foundation, $1^{\text {st }}$ May 2011, http://www.ref.org.uk/publications/231-high-rewards-for-wind-farms-discardingelectricity-5th-6th-april-2011

Rogers 2010: LNG Trade-flows in the Atlantic Basin: Trends and Discontinuities, Howard V Rogers, March 2010, NG 41, OIES

Schoppe 2010: 'The Valuation of Natural Gas Storage: A Knowledge Gradient Approach with Non-Parametric Estimation', Jennifer Schoppe, June 2010, Princeton University.

Stern 2008: Natural Gas in Asia, Jonathan Stern, OIES 2008.

Stern 2010: "UK Gas Storage: a case of market failure”, in Rutledge I, and Wright p, eds, UK Energy Policy and the End of Market Fundamentalism, OUP/OIES 2010, pp.129 - 164.

Stern \& Rogers 2011: 'The Transition to Hub-Based Gas Pricing in Continental Europe', Jonathan Stern and Howard Rogers, NG49, March 2011,

OIES. http://www.oxfordenergy.org/wpcms/wp-content/uploads/2011/03/NG49.pdf

Tradewind 2008a, WP2.6 Equivalent Wind Power Curves, J R McLean, Tradewind $15^{\text {th }}$ July 2008,http://www.tradewind.eu/fileadmin/documents/publications/D2.4_Equivalent_Wind_Po wer_Curves_11914bt02c.pdf

Tradewind 2008b: Tradewind Project, WP 2.4 - Characteristic Wind Speed Time Series, J McLean, Tradewind, $15^{\text {th }}$ July, 2008, http://www.tradewind.eu/fileadmin/documents/publications/D2.3_Characteristic_Win d_Speed Time_Series_11914bt01c.pdf

Van Foreest 2011: 'Does natural gas need a decarbonisation strategy?

The cases of the Netherlands and the UK', Floris van Foreest, NG 51, OIES, May 2011, http://www.oxfordenergy.org/wpcms/wp-content/uploads/2011/05/NG-51.pdf

Waterborne LNG: Waterborne LNG is a subscription service providing US, European and Asian reports data and commentary on LNG cargo movements. Data is reported at an individual tanker level and summarised by month. In this way the complete global supplierimporter matrix can be assembled at a monthly level. Data is available back to January 2004.

Wicks 2009: Energy Security: a national challenge in a changing world, Malcolm Wicks MP, August 2009, Available at: www.decc.gov.uk

Wood Mackenzie North Sea Service 2000: This is a subscription service which provides analysis and commentary on individual UK oil and gas fields and infrastructure. Aggregated data and projections provide a view of future production levels. 
Wood Mackenzie North Sea Service 2010: Data was kindly provided by Wood Mackenzie from their 2010 North Sea Service, otherwise available by subscription.

Figures

Figure 1. UK Primary Energy Consumption by Fuel and $\mathrm{CO}_{2}$ Emissions.

Figure 2. UK Gas Production: WoodMackenzie's 2000 forecast vs. Actual Data 5

Figure 3. UK Storage Working Gas Volume (Existing and Under Construction) plus Potential Projects

Figure 4. UK Gas Demand by Sector 2000 - 2008 (Actual)

Figure 5. Global Gas Consumption by Region 1990 - 2010

Figure 6. Global Gas Supply Channels 1995 - 2010

Figure 7. UK Supply, Demand, Imports and Exports

January 2000 - December 2010

Figure 8. Seasonal Flexibility Sources expressed in

Storage Working Volume Equivalent

Figure 9. UK Market Events 2001 - 2010

Figure 10. Schematic Representation of Global LNG System Modelled 21

Figure 11. Slippage in LNG Supply Expectations 2004 - 2009

Figure 12. Global LNG Supply Sources $\quad 26$

Figure 13. European Pipeline Imports $\quad 27$

Figure 14. Future UK Storage Cases Assumed 29

Figure 15. UK Annual Supply and Demand in the 'LNG Rules the Waves'

Scenario, Low Storage Case

Figure 16. Continental Europe Annual Supply and Demand in the

'LNG Rules the Waves' Scenario, Low Storage Case

Figure 17. UK Monthly Supply and Demand Balance in the

'LNG Rules the Waves' Scenario, Low Storage Case

Figure 18. IUK Flows for Three Storage Cases in the

'LNG Rules the Waves' Scenario 
Figure 19. UK Annual Supply and Demand in the 'Russia Fills the Gap'

$$
\text { Scenario, Low Storage Case }
$$

Figure 20. Continental Europe Annual Supply and Demand in the 'Russia Fills the Gap’ Scenario, Low Storage Case

Figure 21. UK Monthly Supply and Demand Balance in the

'Russia Fills the Gap' Scenario, Low Storage Case.

Figure 22. IUK Flows for Three Storage Cases in the

'LNG Rules the Waves' Scenario

Figure 23. Historic and Future UK Monthly Imports of

Pipeline Gas from Norway

Figure 24. IUK Flows for Both Scenarios by Storage Case

Figure 25. Month Ahead Prices for NBP, NCG, TTF and Zeebrugge, January 2010 - January 2011 (Euros/MWh)

Figure 26. Existing and Under Construction Storage Capacity in Continental Europe

Figure 27. UK Gas Price Forward Curve on $6^{\text {th }}$ July 2011

Figure 28. Storage Volume in 2010 as \% of 2010 Consumption for European Markets

Figure 29. Cumulative installed wind capacity in UK and Germany

1996 - 2007 and projected UK 2008 - 2020 in the

Committee on Climate Change 2008 Report

Figure 30. UK Area Sub-division with Representative Weather Stations

Figure 31. Hourly Wind Speed for 2009 at Three Selected Locations

Figure 32. Annual UK Mean Wind Speed Compared with 9 Year Average.

Figure 33. Future Wind Generation Capacity Assumptions

Figure 34. Regional Distribution of 2009 Wind Capacity and 
Assumed Distribution for 2015, 2020 and 2025

Figure 35. Present Day Regional Normalised Wind Turbine Power Curves 61

Figure 36. UK Hourly Wind Power Generation 2009, 2015, 2020 and 2025

Figure 37. Typical Winter Demand, Thursday Dec $3^{\text {rd }}, 2009$

Figure 38. Typical Summer Demand, Thursday June $11^{\text {th }}, 2009$

Figure 39. 2009 UK Modelled Daily Wind Power Generation in Generation Stack 67 Figure 40. 2015 UK Modelled Daily Wind Power Generation in Generation Stack 68

Figure 41. 2020 UK Modelled Daily Wind Power Generation in Generation Stack 69

Figure 42. Wind Power Surge in 2020, Days 337 to 343

Figure 43. Wind Power Surge in 2020, Days 245 to 261

Figure 44. 2025 UK Modelled Daily Wind Power Generation in Generation Stack 71

Figure 45. Wind Power Surge in 2025, Days 121 to 127

Figure 46. Wind Power Surge in 2025, Days 241 to 247

Figure 47. Poyry Analysis of UK Hourly Power Balance with 43 GW of Wind Capacity $\quad 73$

Figure 48. Aggregate Hourly Generation Output across North Europe for Four Months

Figure 49. Wind Forecasting Accuracy at 3, 6 and 12 Hours Ahead.

Figure 50. Illustration of Scale of Short Term Flexibility via

Regasification Terminals

\section{Appendix Figures}

Figure A1. UK Gas Demand 2001 to 2025

Figure A2. UK Annual Production 2005 - 2025

Figure A3. UK Gas Production - 2005 - 2025

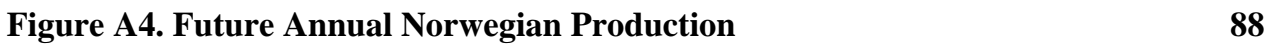

Figure A5. Future Norwegian Gas Production $\quad 89$ 
Figure A6. Netherlands Annual Gas Production 2000 - $2034 \quad 90$

Figure A7. Future and Recent Actual Netherlands Monthly Gas Production 90

Figure A8. Past and Future Danish Gas Production 91

Figure A9. Other European Gas Production $\quad 91$

Figure A10. Historic and Projected ‘Other European’ Production 92

Figure A11. Total European Monthly Gas Production 2001 - 2025

Figure A12. European Demand Comparisons $\quad 94$

Figure A13. Monthly European Demand 2005 to 2025

Figure A14. European Storage Working Gas Capacity 96

Figure A15. Comparison of Europe Storage Working Gas Volume and $\begin{array}{ll}\text { Utilisation } 2005-2010 & 98\end{array}$

Figure A16. Continental Europe Storage Capacity and Utilisation Assumptions 99

$\begin{array}{ll}\text { Figure A17. Pipeline Supplies to Europe } & 100\end{array}$

Figure A18. Asian LNG Demand 101

Figure A19. North America Balance $\quad 102$

$\begin{array}{ll}\text { Figure A20. New LNG Markets } & 103\end{array}$ 


\section{Tables}

Table 1. Gas Storage Under Construction by Location and Type 44

Table 2. UK Gas Storage Economics Under Different Market Scenarios 46

Table 3. Existing UK Import Infrastructure $\quad 50$

Table 4. Potential Future Wind Generation Capacity (GW) 54

Table 5. Forecast Impact on Domestic Gas Consumption Amongst British Gas Customers If All Measures Implemented, Annual Percentage Change

Table 6. Wind Power Generation Initial Model Results Compared with DECC Reported Values

Table 7. National Grid's Annual Electricity Requirement Base Forecast and Scenarios

Table 8. UK Installed Capacity - Nuclear, Coal, Hydro, Pumped Storage and Interconnector

Table 9. Gas Demand in UK Power Sector

Table 10. Storage Facility Characteristics

Table 11. Working Gas Volume for Power Sector Flexibility

Appendix Tables

Table A1. European Gas Storage Working gas Capacity - 2008 - 2010.

Table A2. European Gas Storage Projects Under Construction

Table A3. Existing Storage Capacity 2008 - 2010 and Phased Projects 